\title{
Über die Rolle der induzierbaren NO-Synthase für die Statinmyotoxizität in einem In vitro-Skelettmuskelmodell
}

\author{
INAUGURAL-DISSERTATION \\ zur Erlangung des Doktorgrades \\ der Medizinischen Fakultät der \\ Georg-August-Universität zu Göttingen
}

vorgelegt von

Sonka-Johanna Brandenburg, geb. Sanders

aus Achim

Göttingen 2016 
Dekan:

Referent:

Ko-Referent/in:

Drittreferent/in:
Prof. Dr. rer. nat. H. K. Kroemer

Prof. Dr. med. W.-H. Zimmermann Prof. Dr. Jens Schmidt

Datum der mündlichen Prüfung: 14.03.2017 


\section{Inhaltsverzeichnis}

I Inhaltsverzeichnis 1

II Abkürzungsverzeichnis 4

III Abbildungsverzeichnis 8

$\begin{array}{ll}\text { IV Tabellenverzeichnis } & 10\end{array}$

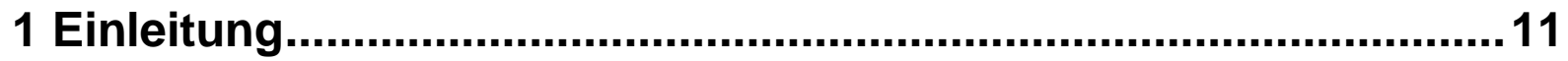

1.1 HMG-CoA-Reduktase-Inhibitoren (Statine) und NO ............................. 12

1.2 Statin-induzierte Myopathie ............................................................ 13

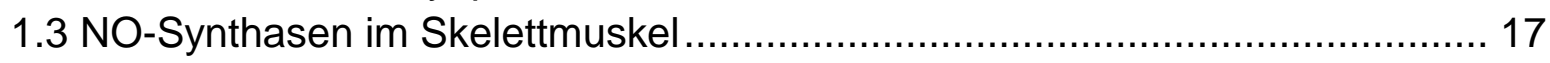

1.4 Tissue Engineering von Skelettmuskel........................................... 19

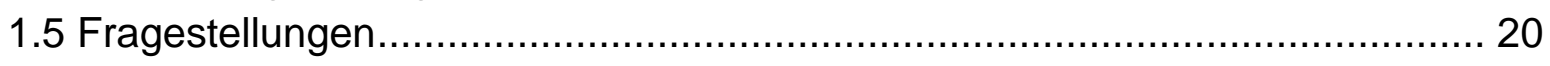

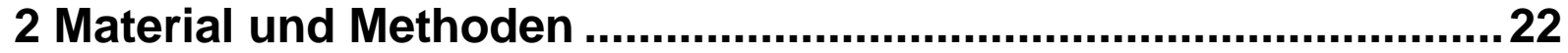

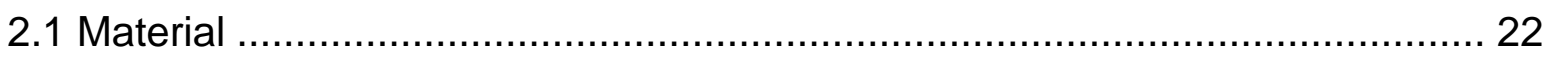

2.1.1 Geräte und Verbrauchsmaterialien .................................................. 22

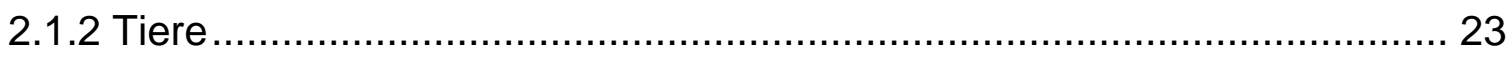

2.1.3 Chemikalien und Zellkultursubstanzen.............................................. 24

2.1.4 Zellkulturmedien und Puffer .......................................................... 26

2.1.4.1 Medien für zellbiologische Methoden........................................ 26

2.1.4.2 Substanzen zur Behandlung und ihre Lösungsmittel ....................... 28

2.1.4.3 Puffer für die Kontraktionsmessung .......................................... 29

2.1.4.4. Puffer für proteinbiochemische Methoden .................................. 30

2.1 .5 Antikörper............................................................................... 31

2.1.5.1. Primärantikörper für Western-Blot- und Immunfluoreszenz-Analysen 31

2.1.5.2 Sekundärantikörper für Western-Blot-Analysen .............................. 31

2.1.5.3 Sekundärantikörper für Immunfluoreszenz-Analysen ....................... 32

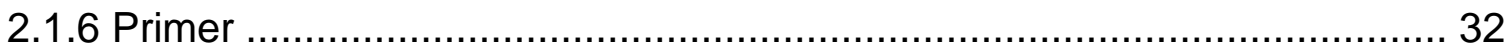

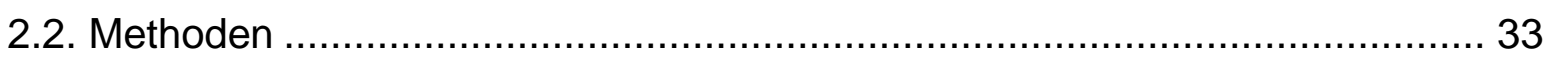

2.2.1 Zellbiologische Methoden ........................................................... 33

2.2.1.1 Myoblastenisolation ........................................................ 33

2.2.1.1.1 Myoblastenisolation aus der Ratte......................................... 33

2.2.1.1.2 Myoblastenisolation aus der Maus ........................................... 34

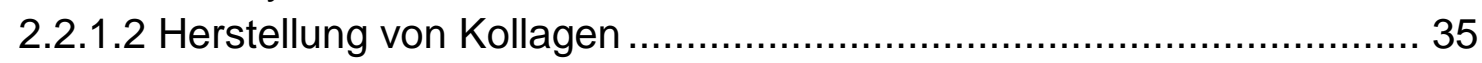

2.2.1.3 Herstellung von Hühnerembryonenextrakt.................................. 35

2.2.1.4 Herstellung der Engineered Skeletal Muscle-Schalen ..................... 35

2.2.1.5 Herstellung von Engineered Skeletal Muscle................................ 36

2.2.1.6 Herstellung von 2D-Myoblasten-Kultur ..................................... 37

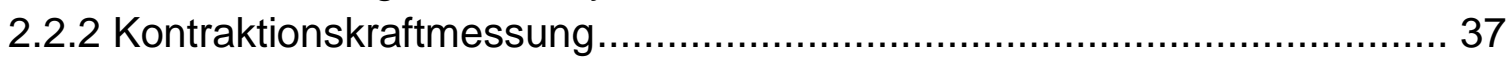

2.2.3. Molekulargenetische Methoden .................................................... 38 
2.2.3.1 RNA-Isolation aus Engineered Skeletal Muscle............................... 38

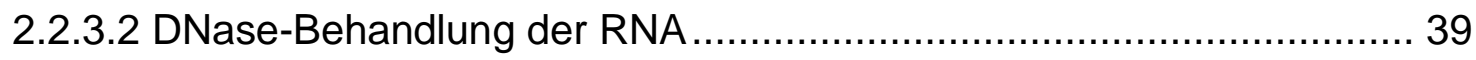

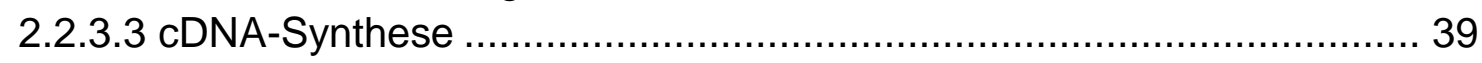

2.2.3.4 Quantitative Polymerase-Ketten-Reaktion ....................................... 39

2.2.4 Proteinbiochemische Methoden ............................................................. 40

2.2.4.1.1 Proteingewinnung aus Engineered Skeletal Muscle .................... 40

2.2.4.1.2 Proteingewinnung aus Mäusegehirn ........................................ 40

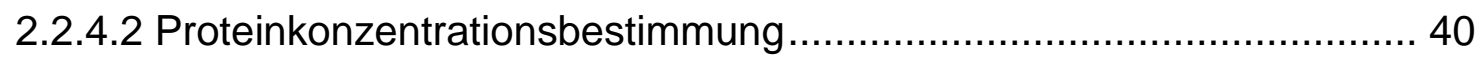

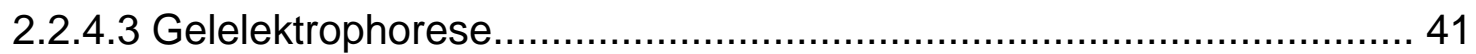

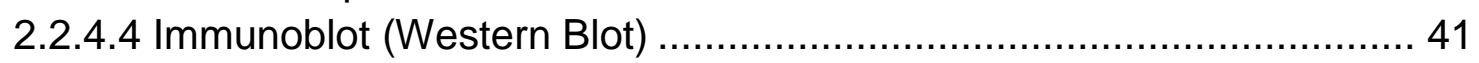

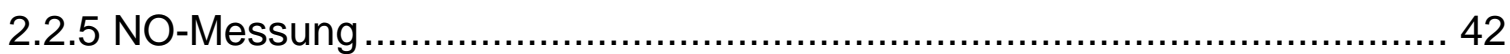

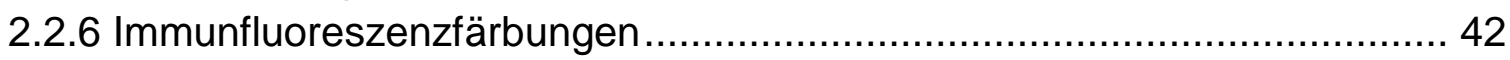

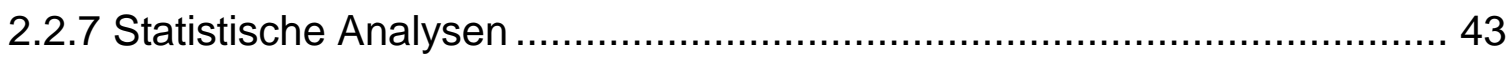

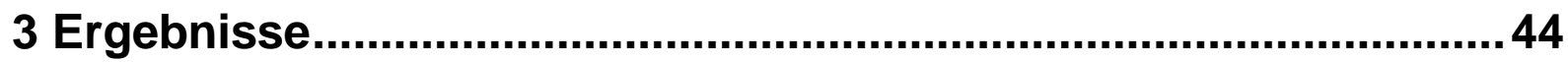

3.1 Morphologische und funktionelle Eigenschaften von Engineered Skeletal

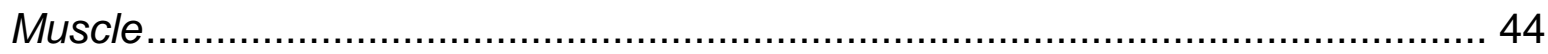

3.2. Effekt von Cerivastatin auf die Kontraktionskraft von Engineered Skeletal

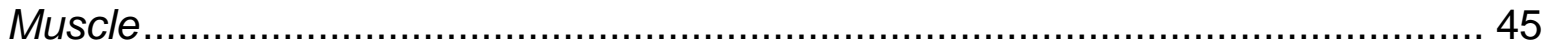

3.3 Expression der NO-Synthasen im Skelettmuskel und im Engineered Skeletal

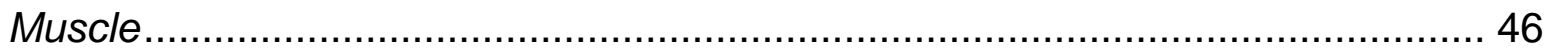

3.4 Cerivastatin-Behandlung induziert die iNOS, aber nicht die nNOS und eNOS 48 3.5 Vasodilatator-stimuliertes Phosphoprotein in Cerivastatin-geschädigtem

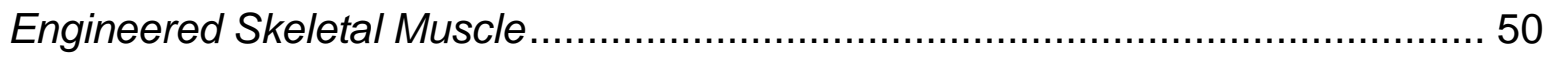

3.6 Kraftverlust und iNOS-Induktion sind HMG-CoA-Reduktase-abhängig ........... 51

3.7 Die funktionelle Rolle der iNOS für die Statin-induzierte Toxizität .................. 54

3.8 Vergleich der tetanischen Kraftentwicklung zwischen Wildtyp- und iNOS-

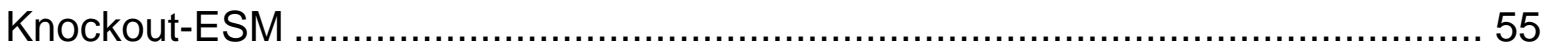

3.9 Die Statintoxizität in Engineered Skeletal Muscle bei gleichzeitiger Behandlung mit L-NAME, SNP und NOC-12 ................................................................ 56

3.10 Vergleich des Einflusses von NCX 6560 und Atorvastatin auf die Kontraktionskraft von Engineered Skeletal Muscle ......................................... 60

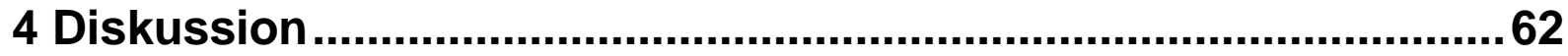

4.1 Engineered Skeletal Muscle als Modell für Statin-induzierte Myotoxizität: Rolle

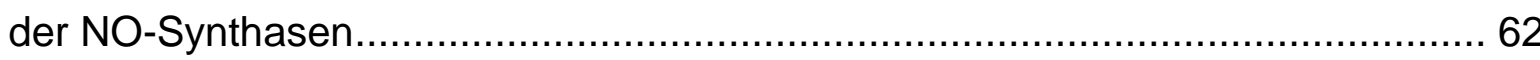
4.2 HMG-Co-A-Reduktase-Abhängigkeit der Myotoxizität und die Bedeutung der

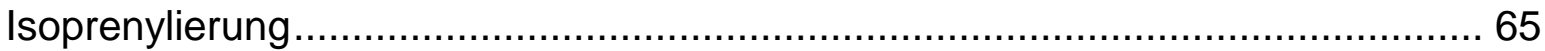

4.3 iNOS und NO-Wirkung in Engineered Skeletal Muscle ................................ 67

4.4 Stellenwert der Steigerung der iNOS-Expression für die Myotoxizität............. 68

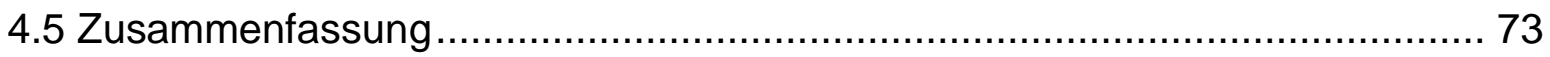

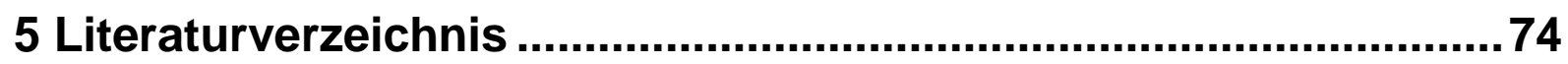

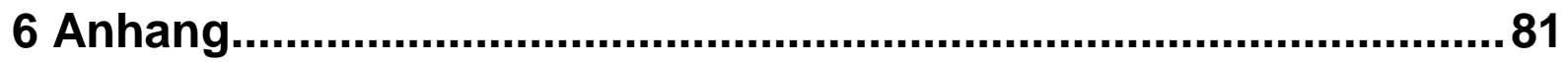

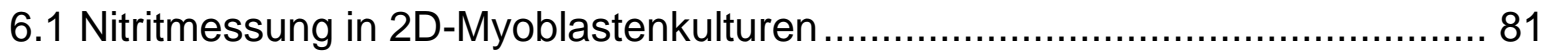


6.2 Nitrotyrosinfärbung . 


\section{Abkürzungsverzeichnis}

A

BSA

Ctr

$\mathrm{Ca}^{2+}$

$\mathrm{CBFHH}$

cDNA

cGMP

$\mathrm{CO}_{2}$

CYP

DAPI

dest.

DMEM

DMSO

DNA

dNTP

EDTA

eNOS

ESM

FAM

FCS

g
Ampere

bovine serum albumin, Rinder-Serum-Albumin

control, Kontrolle

Calciumion

calcium- and bicarbonate-free HEPES-buffered

Hanks' balanced salt solution

complementary DNA, komplementäre DNS

cyclic guanosine monophosphate, zyklisches

Guanosinmonophosphat

Kohlenstoffdioxid

Cytochrom P450

4',6-Diamidin-2-phenylindol

destilliert

Dulbeccos modifiziertes Eagle Medium

Dimethylsulfoxid

desoxyribonucleic acid, Desoxyribonukleinsäure

Desoxyribonukleotidtriphosphat

Ethylendiamintetraessigsäure

endotheliale NO-Synthase

engineered skeletal muscle,

künstlich entwickeltes Skelettmuskelgewebe

6-Carboxyfluorescein

fetal calf serum, fetales Kälberserum

Gramm, auch: Erdbeschleunigung 
GAPDH

h

$\mathrm{H}_{2} \mathrm{O}$

HEPES

HDL

HMG-CoA

HUVEC

iNOS

ITS-X

$\mathrm{KCl}$

$\mathrm{kDa}$

$\mathrm{KH}_{2} \mathrm{PO}_{4}$

$\mathrm{KO}$

LDL

L-NAME

LPS

$\mathrm{Mg}^{2+}$

$\mathrm{MgCl}_{2}$

$\mathrm{MgSO}_{4}$

mol

mRNA

n

$\mathrm{N}_{2}$

$\mathrm{Na}^{+}$
Glycerinaldehyd-3-Phosphat-Dehydrogenase

Stunde

Wasser

2-(4-(2-Hydroxyethyl)-1-piperazinyl)-

Ethansulfonsäure

high density lipoprotein, Lipoprotein hoher Dichte

Hydroxy-3-Methylglutaryl-Coenzym-A

human umbilical vein endothelial cells,

Endothelzellen aus der humanen Nabelschnurvene

induzierbare NO-Synthase

Insulin-Transferrin-Selen-Ethanolamin

Kaliumchlorid

Kilodalton

Kaliumdihydrogenphosphat

Knockout

lower density lipoprotein, Lipoprotein niederer

Dichte

Nw-Nitro-L-Arginine-Methylesterhydrochlorid

Lipopolysaccharid

Magnesiumion

Magnesiumchlorid

Magnesiumsulfat

Stoffmenge

messenger RNA, Boten-RNS

Nano $\left(10^{-9}\right)$

Stickstoff

Natriumion 


\begin{tabular}{|c|c|}
\hline $\mathrm{NaCl}$ & Natriumchlorid \\
\hline \multirow[t]{2}{*}{ NADPH } & Nicotinamidadenindinukleotidphosphat (reduzierte \\
\hline & Form) \\
\hline $\mathrm{NaHCO}_{3}$ & Natriumhydrogencarbonat \\
\hline $\mathrm{NaHPO}_{4}$ & Natriumhydrogenphosphat \\
\hline $\mathrm{NaOH}$ & Natriumhydroxid \\
\hline \multirow[t]{3}{*}{ NF-kB } & $\begin{array}{l}\text { nuclear factor 'kappa-light-chain-enhancer' of } \\
\text { activated B-cell, }\end{array}$ \\
\hline & ein für die Immunreaktion und Zellproliferation \\
\hline & relevanter Transkriptionsfaktor \\
\hline nNOS & neuronale NO-Synthase \\
\hline NO & Stickstoffmonoxid \\
\hline NO-Synthase & Stickstoffmonoxid-Synthase \\
\hline n. s. & nicht signifikant \\
\hline $\mathrm{O}_{2}$ & Sauerstoff \\
\hline \multirow[t]{2}{*}{ PBS } & phosphate-buffered saline, Phosphat-gepufferte \\
\hline & Salzlösung \\
\hline \multirow[t]{2}{*}{ PCR } & polymerase chain reaction, Polymerase- \\
\hline & Kettenreaktion \\
\hline PFA & Paraformaldehyd \\
\hline RNA & ribonucleic acid, Ribonukleinsäure \\
\hline RT & Raumtemperatur \\
\hline SD & standard deviation, Standardabweichung \\
\hline SDS & sodium dodecyl sulfate, Natrium-Dodecylsulfat \\
\hline SDS-Page & SDS-Polyacrylamidgelelektrophorese \\
\hline \multirow[t]{2}{*}{ SEM } & standard error of the mean, Standardfehler des \\
\hline & Mittelwertes \\
\hline SNP & sodium nitroprusside, Natrium-Nitroprussid \\
\hline
\end{tabular}


TAMRA

Taq

TBS

TBST

U

ü.N.

UV

V

wt
6-Carboxytetramethylrhodamin

Termophilus aquaticus

Tris-buffered saline, Tris-gepufferte Salzlösung

Tris-gepufferte Salzlösung mit Tween 20

unit, Einheit

über Nacht

ultraviolett

Volt

Wildtyp 


\section{Abbildungsverzeichnis}

Abb. 1: $\quad$ ESM-Kultur und ESM-Kontraktionsmessung 38

Abb. 2: $\quad$ Morphologie und Funktion der ESM

Abb. 3: Analyse des Kraftverlusts in ESM unter chronischer

Cerivastatinbehandlung

Abb. 4: $\quad$ Vergleich der Genexpression von nNOS, iNOS und eNOS im Skelettmuskel der neonatalen Ratte und im ESM

Abb. 5: $\quad$ Proteinexpression der nNOS und iNOS im Skelettmuskel

Abb. 6: $\quad$ Quantifizierung der Proteinexpression der drei NO-Synthase-Isoformen in 15 Tage alten ESM

Abb. 7: $\quad$ RNA-Expression der NO-Synthasen unter Cerivastatinbehandlung

Abb. 8: Proteinexpression von iNOS in ESM unter Cerivastatinbehandlung

Abb. 9: $\quad$ VASP-Phosphorylierung unter Cerivastatin

Abb. 10: Vereinfachte Darstellung der Cholesterinbiosynthese

Abb. 11: Analyse der HMG-CoA-Reduktase-Abhängigkeit des Cerivastatin-induzierten Kraftverlusts

Abb. 12: Analyse der iNOS-Proteinexpression unter Cerivastatin und Cholesterinvorläufermolekülen

Abb. 13: Kraftentwicklung und iNOS-Expression unter 1400W 55

Abb. 14: Kraftentwicklung in iNOS-KO-ESM unter Cerivastatin

Abb. 15: Vergleich des Kraftverlusts bei gleichzeitiger Behandlung mit SNP bzw. L-NAME

Abb. 16: Konzentrationswirkungskurve von SNP

Abb. 17: Vergleich der iNOS-Expression in ESM nach Behandlung mit Cerivastatin und SNP

Abb. 18: Kraftentwicklung unter Cerivastatin und NOC-12

Abb. 19: Vergleich der tetanischen Kraftentwicklung von ESM nach fünftägiger Behandlung mit Atorvastatin bzw. NO-Atorvastatin (NCX 6560)

Abb. 20: Schemadarstellung der HMG-CoA-Reduktase-Hemmung 
auf die Cholesterinbiosynthese

Abb. 21 Konzentrationsabhängige Hemmung der Nitritsynthese

durch 1400W in der 2D-Myoblastenkultur

Abb. 22 Konzentrationsabhängige Hemmung der Nitritsynthese

durch L-NAME in der 2D-Myoblastenkultur

82

Abb. 23 Nitrotyrosinfärbung in 2D-Myoblasten nach Behandlung mit Cerivastatin für fünf Tage. 


\section{Tabellenverzeichnis}

Tab. 1: $\quad$ Pharmakokinetik der Statine 14

Tab. 2: Geräte und Verbrauchsmaterialien 22

Tab. 3: Versuchstiere 23

Tab. 4: $\quad$ Feinchemikalien und Zellkultursubstanzen $\quad 24$

Tab. 5: $\quad$ Substanzen zur Behandlung der ESM 28

Tab. 6: $\quad$ Primärantikörper für Western-Blot (WB)- und Immunfluoreszenz-Analysen (IF) 31

Tab. 7: Sekundärantikörper für Western-Blot-Analysen 31

Tab. 8: $\quad$ Sekundärantikörper für Immunfluoreszenz-Analysen 32

Tab. 9: $\quad$ Genspezifische Primer 32

Tab. 10: $\quad$ PCR-Reaktionsansatz 39 


\section{Einleitung}

Cholesterin ist ein wichtiger Bestandteil von Zellmembranen und Synthesevorstufe für Gallensäuren und verschiedene lebensnotwendige Hormone. Erhöhte Cholesterinkonzentrationen im Blut sind jedoch an der Entstehung der Atherosklerose beteiligt. Serumwerte $>200 \mathrm{mg} / \mathrm{dl}$ Gesamtcholesterin werden als Hypercholesterinämie bezeichnet, die alimentär oder genetisch bedingt sein kann. Eine Hypercholesterinämie korreliert mit einem erhöhten Risiko für kardiovaskuläre Ereignisse wie z. B. die koronare Herzkrankheit oder periphere Gefäßverschlüsse (Deutsche Gesellschaft zur Bekämpfung von Fettstoffwechselstörungen und ihren Folgeerkrankungen 2011). Sie sind die häufigste Todesursache in Deutschland (Statistisches Bundesamt 2015) und kosten das Gesundheitssystem jährlich ca. 37 Milliarden Euro (Statistisches Bundesamt 2010). Daher ist die konsequente Behandlung bestehender kardiovaskulärer Risikofaktoren wie Hypercholesterinämie, Diabetes mellitus, Rauchen und Übergewicht notwendig. Zur Therapie der Hypercholesterinämie werden je nach Risikoprofil und Begleiterkrankungen der Patienten neben diätischen Maßnahmen vor allem so genannte Statine, Inhibitoren der HMG-CoA-Reduktase, eingesetzt. Nach den neuen Leitlinien der American Heart Association wird die Behandlung mit Statinen bei entsprechendem Risikoprofil bereits sogar ohne Hypercholesterinämie empfohlen (Stone et al. 2013).

Unerwünschte Wirkungen der Statine sind Kopfschmerzen, gastrointestinale Symptome, ein Anstieg der Transaminasen im Serum sowie muskuläre Beschwerden, die sich als Muskelschmerzen oder schnelle Ermüdung der Muskulatur äußern können. Diese Muskelbeschwerden treten der PRIMO-Studie (Prediction of Muscular Risk in Observational Conditions) zufolge abhängig von der Dosis bei 0,1 bis $10 \%$ der Patienten auf, vor allem innerhalb des ersten Monats nach Therapiebeginn (Bruckert et al. 2005). In der folgenden Dissertationsarbeit sollen mögliche Mechanismen für die Statin-induzierte Myotoxizität anhand eines Biomuskelgewebes untersucht werden. Besonderer Fokus soll auf die Fragestellung gelegt werden, ob NO-Synthasen an der Pathogenese der Statin-induzierten Myopathie beteiligt sind. 


\subsection{HMG-CoA-Reduktase-Inhibitoren (Statine) und NO}

Statine sind die wichtigste Substanzgruppe in der Therapie der Hypercholesterinämie und bei erhöhtem kardiovaskulärem Risiko z. B. nach stattgehabtem Myokardinfarkt oder bei peripherer arterieller Verschlusskrankheit (Baigent et al. 2005). Es ist vielfach belegt, dass Statine das Risiko an einem Myokardinfarkt oder einem Schlaganfall zu sterben sowie das Auftreten von kardiovaskulären Ereignissen, Schlaganfällen und transitorischen intrazerebralen Attacken senken können (LaRosa et al. 1999; Collins et al. 2004; Heart Protection Study Collaborative Group, 2007). Entdeckt wurde die Substanzgruppe in den 1980-er Jahren durch die Isolation von Lovastatin aus Aspergillus terreus (Bundesministerium für Bildung und Forschung 2004). Das Statinmolekül ähnelt dem Substrat HMG-CoA des für die Cholesterinsynthese notwendigen Enzyms HMG-CoA-Reduktase und erwirkt darüber seine kompetitive Hemmung. Mittlerweile sind eine Reihe von hochpotenten HMGCoA-Reduktase-Inhibitoren entwickelt worden (Cerivastatin, Atorvastatin, Rosuvastatin, Simvastatin, Pravastatin, Fluvastatin und Lovastatin). Alle führen zu einer ausgeprägten Reduktion der Cholesterinbiosynthese in der Leber mit kompensatorischer Aufnahme der cholesterinreichen LDL-Partikel (Lipoprotein niedriger Dichte) aus dem Plasma in die Leberzellen. Damit lässt sich eine Senkung des Gesamtcholesterins und LDL-Cholesterins um bis zu 30-50\% vom Ausgangswert erreichen (Deutsche Gesellschaft zur Bekämpfung von Fettstoffwechselstörungen und ihren Folgeerkrankungen 2011).

Neben der Normalisierung von LDL und Gesamtcholesterin werden auch pleiotrope Effekte, die unabhängig von der Lipidsenkung auftreten, diskutiert: Statine sollen anti-atherosklerotisch und anti-inflammatorisch wirken sowie die Endothelfunktion verbessern. Die genauen Mechanismen der endothelialen Dysfunktion, wie sie z. B. bei Patienten mit Diabetes mellitus, arterieller Hypertonie oder bei inhalativem Tabakkonsum vorkommt, sind nicht geklärt, jedoch wird als eine mögliche Ursache die reduzierte Verfügbarkeit von NO diskutiert, die z. B. durch eine geringere Bioverfügbarkeit von L-Arginin, eine reduzierte NO-Synthase-Aktivität oder eine gestörte intrazelluläre Signalkaskade verursacht sein kann (Tousoulis et al. 2012). In koronaren und systemischen Gefäßen ist die eNOS die vorherrschende NOSynthase-Isoform. Laufs et al. schildern, dass Simvastatin mit einer verstärkten 
Expression der eNOS in Endothelzellen und einer verringerten endothelialen Dysfunktion assoziiert ist (Laufs et al. 1998). Außerdem werden Statinen antithrombotische Effekte über die Reduktion der Thrombozytenreaktivität und der Thromboxan- und Thromboplastinsynthese (Liao und Laufs 2005) sowie ein Plaquestabilisierender Effekt zugesprochen (Wehling und Diener 2005).

\subsection{Statin-induzierte Myopathie}

Obwohl die Behandlung mit einem Statin von den meisten Patienten gut vertragen wird, ist zu erwähnen, dass bei bis zu $10 \%$ der Patienten als unerwünschte Wirkung muskuläre Symptome auftreten. Die Beschwerden reichen von leichten Muskelschmerzen nach körperlicher Belastung und Muskelschwäche mit und ohne Erhöhung der Plasma-Kreatinkinase bis zur seltenen, aber schwerwiegenden Rhabdomyolyse, dem Zerfall von Skelettmuskelzellen mit potenziell lebensbedrohlichen Konsequenzen wie dem akuten Nierenversagen und Elektrolytverschiebungen. Dabei ist von einem Klasseneffekt auszugehen, da alle zurzeit zugelassenen Statine diese Nebenwirkungen haben können (Thompson et al. 2003). Als Faktoren, die zu einem erhöhten Risiko führen, unter der Statintherapie Muskelbeschwerden zu erleiden, sind beispielsweise eine gleichzeitige Therapie mit Medikamenten, die ebenfalls über CYP3A4 metabolisiert werden wie z. B. Ciclosporin, und der Polymorphismus des Gens SLCO1B1 bekannt (Tab. 1). Das Gen kodiert für den Organo-Anion-Transporter OATP1B1, über den unter anderem Simvastatin in die Leber aufgenommen wird (Tab. 1). Bei Polymorphismen des Gens kommt es zu einer verringerten Enzymaktivität des Transporters und damit zu erhöhten Statinkonzentrationen im Plasma (Shitara und Sugiyama 2006; SEARCH Collaborative Group 2008). Der Polymorphismus ist so über Änderungen der Pharmakokinetik der Statine mit einem erhöhten Risiko für die Statin-induzierte Myopathie vergesellschaftet (SEARCH Collaborative Group 2008).

Von den mit einer Statinbehandlung assoziierten Rhabdomyolyse-Zwischenfällen sind über 50\% auf Cerivastatin zurückzuführen; an zweiter und dritter Stelle stehen Simvastatin und Atorvastatin (Thompson et al. 2003). Aufgrund der mindestens 52 tödlichen Fälle von Rhabdomyolyse wurde Cerivastatin 2001 weltweit vom Markt genommen. Im Vergleich zu anderen Vertretern der Statine ist für Cerivastatin ein bis 
zu zehnfach erhöhtes Risiko beschrieben, eine Rhabdomyolyse hervorzurufen (Furberg und Pitt 2001). Pharmakokinetische Erklärungsansätze für diese deutlich erhöhte Muskeltoxizität liegen beispielsweise in der erhöhten Bioverfügbarkeit von Cerivastatin (Tab. 1) im Vergleich $z u$ anderen Statinen. Außerdem verfügt Cerivastatin über eine hohe intrinsische Aktivität mit einer halbmaximalen Konzentration zur Hemmung der HMG-CoA-Reduktase von nur 1-10 nmol/l (Bischoff und Heller 1998; Shitara und Sugiyama 2006) (Tab. 1).

\begin{tabular}{|c|c|c|c|c|c|c|c|}
\hline & $\begin{array}{l}\text { Simva- } \\
\text { statin }\end{array}$ & $\begin{array}{l}\text { Lova- } \\
\text { statin }\end{array}$ & $\begin{array}{l}\text { Atorva- } \\
\text { statin }\end{array}$ & $\begin{array}{l}\text { Fluva- } \\
\text { statin }\end{array}$ & $\begin{array}{l}\text { Ceriva- } \\
\text { statin }\end{array}$ & $\begin{array}{l}\text { Prava- } \\
\text { statin }\end{array}$ & $\begin{array}{r}\text { Rosuva- } \\
\text { statin }\end{array}$ \\
\hline $\begin{array}{l}\text { Metabolisierende } \\
\text { CYP-Enzyme }^{2}\end{array}$ & CYP3A4 & CYP3A4 & CYP3A4 & CYP2C9 & $\begin{array}{l}\text { CYP2C8, } \\
\text { CYP3A4 }\end{array}$ & - & - \\
\hline $\begin{array}{l}\text { OATP1B1- } \\
\text { Substrat }^{1}\end{array}$ & $\mathrm{Ja}$ & $\mathrm{Ja}$ & $\mathrm{Ja}$ & Nein & $\mathrm{Ja}$ & $\mathrm{Ja}$ & $\mathrm{Ja}$ \\
\hline Bioverfügbarkeit ${ }^{1}$ & $<5 \%$ & $<5 \%$ & $12 \%$ & $19-29 \%$ & $60 \%$ & $18 \%$ & $20 \%$ \\
\hline $\begin{array}{l}\text { LDL-Senkung } \\
\text { (in \%) }\end{array}$ & $28-41^{1}$ & $29-31^{1}$ & $41-61^{2}$ & $22-35^{2}$ & $31-45^{1}$ & $19-34^{1}$ & $22-55^{2}$ \\
\hline $\begin{array}{l}\text { Mittlere } \\
\text { inhibitorische } \\
\text { Konzentration } \\
\text { der isolierten } \\
\text { HMG-CoA- } \\
\text { Reduktase }^{1}\end{array}$ & $\begin{array}{l}11 \\
\mathrm{nmol} / \mathrm{I}\end{array}$ & $\begin{array}{l}\text { keine } \\
\text { Angabe }\end{array}$ & $\begin{array}{l}8,2 \\
\mathrm{nmol} / \mathrm{l}\end{array}$ & $\begin{array}{l}28 \\
\mathrm{nmol} / \mathrm{l}\end{array}$ & $\begin{array}{l}1-10 \\
\mathrm{nmol} / \mathrm{l}\end{array}$ & $\begin{array}{l}44 \\
\mathrm{nmol} / \mathrm{l}\end{array}$ & $\begin{array}{l}3,5-5,4 \\
\mathrm{nmol} / /\end{array}$ \\
\hline $\begin{array}{l}\text { Mittlere } \\
\text { inhibitorische } \\
\text { Konzentration } \\
\text { der hepatischen } \\
\text { HMG-CoA- } \\
\text { Reduktase }^{1}\end{array}$ & $\begin{array}{l}\text { Ratte: } \\
5,2 \\
\text { nmol/l } \\
\text { Human: } \\
8,0 \\
\text { nmol/l }\end{array}$ & $\begin{array}{l}\text { Human: } \\
8,0 \\
\mathrm{nmol} / \mathrm{l}\end{array}$ & $\begin{array}{l}\text { Ratte: } \\
0,82 \\
\mathrm{nmol} / \mathrm{l} \\
\text { Human: } \\
2,0 \\
\text { nmol/l }\end{array}$ & $\begin{array}{l}\text { Ratte: } \\
4,8 \\
\mathrm{nmol} / \mathrm{l}\end{array}$ & $\begin{array}{l}\text { Ratte: } \\
2,5 \\
\text { nmol/l }\end{array}$ & $\begin{array}{l}\text { Ratte: } \\
5,0 \\
\text { nmol/l }\end{array}$ & $\begin{array}{l}\text { Ratte: } \\
0,3 \\
\mathrm{nmol} / /\end{array}$ \\
\hline
\end{tabular}

Tabelle 1: Pharmakokinetik der Statine (Shitara und Sugiyama $2006^{1}$; Rote Liste ${ }^{\circledR}$ Service $\mathrm{GmbH}^{2}$ ).

Zurzeit werden neben Atorvastatin, Rosuvastatin, Simvastatin und Pravastatin noch Fluvastatin und Lovastatin in der Klinik verwendet. Fluvastatin hat von den genannten Statinvertretern zwar die geringste Inzidenz muskulärer Nebenwirkungen 
(ca. $5 \%$ der mit Fluvastatin behandelten Patienten klagten über muskuläre Beschwerden, im Vergleich dazu Atorvastatin 15\%), vermochte jedoch auch eine geringere Senkung von LDL zu bewirken (Bruckert et al. 2005).

Eine Reihe von potentiellen Mechanismen der Entstehung einer Myopathie unter Statinen wurde gefunden, ohne dass sich ein vollständiges Bild ergibt. Diskutiert werden unter anderem der veränderte Cholesteringehalt in den Zellmembranen, die Inhibition der Isoprenoidproduktion und die daraus möglicherweise resultierende Hemmung von zellulären Prozessen, die von isoprenylierten Rho-GTPasen abhängig sind. Hinsichtlich der Statin-Myopathie werden auch eine Störung des UbiquitinSignalweges und der RNA-Reifung durch schädliche Zwischenprodukte oder die verringerte Cholesterin- bzw. Isoprenoidsynthese diskutiert (Draeger et al. 2006; Sakamoto und Kimura 2013). Draeger et al. zeigten 2006, dass selbst in Proben von asymptomatischen Patienten unter einer Statintherapie elektronenmikroskopisch sichtbare Veränderungen in der Skelettmuskulatur nachweisbar sind wie z. B. eine gestörte Anordnung der Z-Scheiben und geschwollene T-Tubuli (Draeger et al. 2006). Sakamoto et al. zufolge ist als Ursache der Statin-Myopathie vor allem die Depletion des Geranyl-Geranyl-Pyrophosphats zu sehen (Sakamoto und Kimura 2013). Isoprenoide wie Farnesyl-Pyrophosphat und Geranyl-Geranyl-Pyrophosphat werden physiologisch zur Prenylierung als eine Form der posttranslationalen Modifikation benötigt und wie auch Cholesterin aus Mevalonat synthetisiert. Für Signalmoleküle, wie z. B. die Rho-GTPasen RhoA, Ras und Rac, ist die Isoprenylierung entscheidend für ihre korrekte intrazelluläre Lokalisation und Funktion. Unter Statinbehandlung wird die Isoprenylierung eingeschränkt, sodass Prozesse, die über RhoA, Ras und Rac1 gesteuert werden, z. B. die Proliferation von glatten Muskelzellen und die Migration von inflammatorischen Zellen, moduliert werden können (Liao und Laufs 2005; Zhou und Liao 2010). Es ist vorstellbar, dass die Statin-vermittelte Myopathie mit einer gestörten Isoprenylierung assoziiert ist. Der Theorie, dass die Muskelschädigung durch relativen Cholesterinmangel in der Zellmembran hervorgerufen sein könnte, ist entgegenzusetzen, dass Flint et al. zufolge eine Hemmung der Squalen-Synthase, ebenfalls ein essenzielles Enzym der Cholesterinbiosynthese, keine Myopathie verursacht (Flint et al. 1997). 
Neben weiteren Erklärungsversuchen, die unter anderem oxidativen Stress und einen veränderten Glukosemetabolismus (Smith et al. 2014) als mögliche Mediatoren der Statinmyopathie in Betracht ziehen, wird weiterhin eine veränderte Kalziumhomöostase im sarkoplasmatischen Retikulum der Myozyten aufgrund mitochondrialer Schädigungen (Sirvent et al. 2008) diskutiert. Dass Änderungen am Ryanodinrezeptor und somit an der Kalziumfreisetzung die Muskelfunktion beeinträchtigen können, zeigen auch Bellinger und Altamirano et.al. (Bellinger et al. 2009; Altamirano et al. 2012).

Einige Autoren weisen darauf hin, dass Muskelerkrankungen wie z. B. von Autoimmunmyopathien oder der Muskeldystrophie Typ Duchenne bekannt, mit einer gesteigerten iNOS-Expression einhergehen (Yang et al. 1998; Bellinger et al. 2009; Schmidt et al. 2012). Bellinger et al. zeigen, dass bei der Muskeldystrophie Typ Duchenne der nNOS-Dystrophin-Komplex gestört ist, was eine Steigerung der iNOSExpression zufolge hat. Sie sehen diese iNOS-Induktion als ursächlich für Kalziumlecks aus dem sarkoplasmatischen Retikulums und den für die Dystrophie typischen Kraftverlust und Muskelschaden an. Ihrer Arbeit zufolge ist die iNOSInduktion mit einem vermehrten Auftreten von reaktiven Stickstoffverbindungen assoziiert, die zur S-Nitrosylierung des Ryanodinrezeptors führen, der dadurch in seiner Funktion eingeschränkt wird (Bellinger et al. 2009). Auch Altamirano et al. konnten in Skelettmuskelzellen Dystrophin-defizienter Mäuse eine iNOS-Induktion nachweisen. Sie sehen die Muskelschädigung in Zusammenhang mit veränderten Kalziumkonzentrationen in den Skelettmuskelzellen und einer gesteigerten NF-kBAktivierung, die zu der iNOS-Induktion und dem daraus resultierenden vermehrten nitrosativen Stress führt, was letztlich die Schädigung der Myozyten erklären könnte (Altamirano et al. 2012). Ob die iNOS auch bei der Statin-induzierten Muskelschädigung eine Rolle spielt und inwiefern sie diese beeinflusst, soll Gegenstand der vorliegenden Arbeit sein. 


\subsection{NO-Synthasen im Skelettmuskel}

Die drei bekannten Stickstoffmonoxid-Synthasen, kurz NO-Synthasen, sind die neuronale NO-Synthase (nNOS), die induzierbare NO-Synthase (iNOS) und die endotheliale NO-Synthase (eNOS). Sie katalysieren die Synthese von Stickstoffmonoxid (NO) aus L-Arginin und benötigen mehrere Kofaktoren wie beispielsweise NADPH und Sauerstoff. Noch vor einigen Jahren unterteilte man die drei Isoformen in konstitutive (eNOS und nNOS) und induzierbare (iNOS) NOSynthasen. Diese Einteilung wird mittlerweile als nicht mehr zeitgemäß angesehen, da gezeigt werden konnte, dass nNOS und eNOS induziert werden können und es Gewebe (z. B. Bronchialepithel) mit einer konstitutiven iNOS-Expression gibt (Guo et al. 1995; Michel und Feron 1997).

NO-Synthasen kommen in mehr Zelltypen vor, als es ihr Name vermuten lässt: Die nNOS lässt sich nicht nur in neuronalem Gewebe, sondern auch in Skelettmuskelzellen nachweisen (Nakane et al. 1993), die eNOS nicht nur in Endothelzellen, sondern auch in Thrombozyten und Kardiomyozyten. Die iNOS hingegen ist bekannt als Enzym immunaktivierter Makrophagen (Michel und Feron 1997). Das synthetisierte NO wird von innen zur Immunabwehr benötigt. Die iNOS lässt sich aber auch in Kardiomyozyten, Gliazellen und in glatten Gefäßmuskelzellen nachweisen (Michel und Feron 1997). In der Skelettmuskulatur ist quantitativ die neuronale NO-Synthase die vorherrschende Isoform, die mit Dystrophin assoziiert ist. Auch die eNOS kommt in Skelettmuskelzellen vor. Beide Isoformen sind in ihrer Aktivität bei vermehrter Muskeltätigkeit gesteigert. Die iNOS wird im gesunden Skelettmuskel nicht konstitutiv exprimiert, es ist aber bekannt, dass sie als Antwort auf entzündliche oder andere pathologische Reize induziert werden kann. Das Wirkungsspektrum von NO auf die Skelettmuskulatur ist vielfältig. NO kann z. B. die Perfusion der Skelettmuskulatur regulieren, aber auch über die Bildung von reaktiven Sauerstoffspezies Zielmoleküle wie beispielsweise den Ryanodinrezepter und damit die elektromechanische Kopplung und Kraftentwicklung bzw. die muskuläre Ermüdbarkeit beeinflussen (Stamler und Meissner 2001). 
Reguliert werden die drei Isoformen auf unterschiedliche Art: Während eNOS und nNOS kalziumabhängig an Calmodulin gebunden und aktiviert werden, wird die iNOS in vielen Zellen vor allem über den Transkriptionsfaktor NF-kB und posttranslationale Modifikationen z. B. durch Phosphorylierung reguliert (Kleinert et al. 2004). Außerdem steigern pro-inflammatorische Moleküle wie Interleukin 1 und Tumornekrosefaktor a die iNOS-Expression (Reid 1998). Solange die eNOS an Calmodulin gebunden ist, ist sie aktiviert, gebunden an Caveolin 1, ist sie inaktiviert. HDL stabilisiert diesen Zustand, während hormonelle Faktoren die eNOS-Aktivität steigern können. Eine erhöhte Konzentration von C-reaktivem Protein hemmt hingegen die eNOS-Aktivität (Michel und Feron 1997). Die nNOS-Aktivität wird ebenfalls über Calmodulin reguliert, während die iNOS nahezu Calmodulinunabhängig aktivierbar ist: Sie ist bereits bei niedrigen intrazellulären Kalziumkonzentrationen an Calmodulin gebunden und damit aktiviert, da über die Calmodulinbindung die Elektronenabgabe von NADPH erleichtert und damit die Enzymaktivität gesteigert werden kann (Förstermann und Sessa 2012). Das synthetisierte NO ist mit einer Halbwertzeit von weniger als fünf Sekunden sehr instabil und daher in seiner Wirkung stark vom Syntheseort abhängig. Es wirkt als Second Messenger und kann beispielsweise mit Schwefelgruppen, Metallen (wie z. B. in Hämoglobin und Myoglobin vorhanden) oder mit Sauerstoff reagieren. Bei der Reaktion mit Sauerstoff entstehen als Endprodukte vor allem Nitrat und Nitrit. Je nach Zelltyp hat NO unterschiedliche physiologische Effekte (z. B. die cGMPvermittelte Vasodilatation und die unspezifische Immunabwehr), kann aber auch an der Pathogenese mehrerer Erkrankungen wie beispielsweise der Multiplen Sklerose und der Alzheimer-Erkrankung über die Beeinträchtigung der Atmungskette beteiligt sein (Calabrese et al. 2004).

Die Rolle der NO-Synthasen und des NO in der Statin-vermittelten Myopathie ist bisher nicht geklärt. In physiologischer Weise kann NO in der Skelettmuskulatur einerseits die Durchblutung, die Glukoseaufnahme und Kontraktilität regulieren und über die Bildung von reaktiven Sauerstoff- und Schwefelspezies verschiedene Signalwege vermitteln, andererseits aber auch oxidativen und nitrosativen Stress auslösen (Stamler und Meissner 2001). Außerdem scheint NO bei Reparaturmechanismen in geschädigtem Skelettmuskel eine Rolle zu spielen (Filippin et al. 2011). Inwiefern NO bei pathologischen Prozessen in der 
Skelettmuskulatur beteiligt sein kann, zeigten unter anderem D'Antona et al:: Sie beschreiben, dass NO-gekoppeltes Atorvastatin im Vergleich zu Atorvastatin in vitro weniger Muskelatrophie und im Tiermodell weniger Muskelkraftverlust verursacht (D'Antona et al. 2013). Andererseits ist bekannt, dass in verschiedenen muskulären Erkrankungen unterschiedliche Isoformen der NO-Synthasen eine - bisher nicht vollständig geklärte - Rolle spielen. So ist z. B. bei Patienten, die an der Muskeldystrophie Typ Duchenne leiden, die nNOS-Expression im Skelettmuskel erniedrigt (Brenman et al. 1995) und die iNOS-Expression erhöht (Bellinger et al. 2009; Altamirano et al. 2012). Physiologisch ist die iNOS-mRNA-Expression in Skelettmuskelzellen gering, sie lässt sich allerdings in vitro und in vivo durch LPS induzieren (Liu et al. 1993). Schmidt et al. fanden in Muskelproben von Patienten mit Einschlusskörperchenmyositis oder Autoimmunmyopathien eine erhöhte iNOSExpression, die möglicherweise durch vermehrten inflammatorischen Zellstress bedingt ist, und eine vermehrte Nitrotyrosinbildung als Korrelat der NO-bedingten Zellschädigung (Schmidt et al. 2012).

\subsection{Tissue Engineering von Skelettmuskel}

Zur Untersuchung pathologischer Zustände der Skelettmuskulatur bieten sich zum einen KO-Mäuse, wie z. B. von Bellinger et al. zur Untersuchung der Muskeldystrophie Typ Duchenne verwendet (Bellinger et al. 2009), zum anderen das so genannte Tissue Engineering an. Dabei handelt es sich um artifizielles Gewebe, das dem physiologischen Material ähnlicher sein soll als reine 2D-Zellkultur-Modelle, funktionelle Messungen erlauben und als Brücke zwischen In vivo-Tierstudien und reinen In vitro-Versuchen dienen soll (Vandenburgh 2010). Bisher publizierte Modelle stammen von Baar et al. und Vandenburgh et al., die die von innen entwickelten Gewebekonstrukte für biochemische und funktionelle Untersuchungen wie Erregbarkeit und Kontraktilität der Skelettmuskulatur zur Erforschung muskelschädigender Substanzen und Erkrankungen der Skelettmuskulatur verwenden (Baar 2005; Vandenburgh et al. 2009). Eine weitere Möglichkeit der Nutzung des Tissue Engineering ist es, eventuelle Substanzen identifizieren zu können, die einer Muskelschädigung entgegenwirken können (Vandenburgh 2010). 
Vandenburgh et al. nutzen beispielsweise aus Myozyten von $m d x$-Mäusen hergestelltes Gewebe, um Substanzen testen zu können, die die Muskeldystrophie Typ Duchenne positiv beeinflussen können (Vandenburgh et al. 2009).

Um untersuchen zu können, inwiefern die iNOS in der Statin-induzierten Myopathie eine Rolle spielt, wurde in der folgenden Arbeit ein In vitro-Skelettmuskelmodell verwendet. Das in dieser Arbeit angewendete so genannte „Engineered Skeletal Muscle“ (ESM) wird aus Myoblasten neonataler oder adulter Ratten hergestellt. Dazu werden Myoblasten aus den Hinterläufen zunächst isoliert und in Zellkulturflaschen kultiviert. Nach einigen Tagen können mithilfe von Kollagen, speziellem Wachstumsmedium und Matrigel® ESM generiert werden. ESM zeigen spontane und durch elektrische Stimulationen induzierbare Kontraktionen und ähneln mikroskopisch dem physiologischen Skelettmuskelsynzytium hinsichtlich der Morphologie und der Reife der Myozyten. Im Vergleich zu Standardkulturen von Myoblasten auf Zellkulturschalen in 2D zeigen ESM eine größere morphologische und molekulare Maturierung der Zellen und ähneln damit eher der quergestreiften Skelettmuskulatur in vivo.

Ein weiterer Vorteil ist die Möglichkeit, neben histologischen und genetischen Untersuchungen, funktionelle Muskelparameter erfassen zu können: ESM zeigen nach entsprechender Stimulation die Fähigkeit zur tetanischen Kontraktion, zur Ermüdbarkeit (fatigue) nach andauernder Kontraktion sowie zur Erholung (recovery) danach.

\subsection{Fragestellungen}

Die Erläuterungen zu Statinen und NO-Synthasen veranschaulichen, dass die Pathophysiologie der Statinmyopathie noch nicht hinreichend geklärt ist. Bezüglich der Rolle von NO bzw. NO-Synthasen in der Statinmyopathie sind sowohl Hinweise auf schützende als auch schädigende Einflüsse in der Literatur zu finden. In dieser Arbeit sollen daher folgende Fragestellungen bearbeitet werden:

1. Lässt sich Statintoxizität in ESM induzieren? 
2. Welche skelettmuskeltypischen Eigenschaften zeigen ESM?

3. Wie ist das Expressionsmuster der NO-Synthase-Isoformen in der nativen Skelettmuskulatur und in ESM?

4. Verändert sich das NO-Synthase-Expressionsmuster unter der Behandlung mit Statinen?

5. Welche Rolle spielen die NO-Synthasen in der Statin-abhängigen Myotoxizität?

6. Lässt sich die Statin-induzierte Myotoxizität durch Modifikation der NOSynthasen beeinflussen? 


\section{Material und Methoden}

\subsection{Material}

2.1.1 Geräte und Verbrauchsmaterialien

\begin{tabular}{|c|c|c|}
\hline Gerät & Typ & Firma \\
\hline Dialyseschlauch & $\# 44147$ & Serva, Heidelberg \\
\hline Dispergierer & Polytron & Kinematica, Luzern \\
\hline Feinwaage & R160P & Sartorius, Göttingen \\
\hline $\begin{array}{l}\text { Gelelektrophorese-/ } \\
\text { Blotkammer }\end{array}$ & Power-Pac & BioRad, München \\
\hline Gewebedissoziator & GentleMACS Dissoziator & $\begin{array}{l}\text { Miltenyi Biotec, Bergisch } \\
\text { Gladbach }\end{array}$ \\
\hline $\begin{array}{l}\text { Gewebedissoziator } \\
\text { Reaktionsgefäße }\end{array}$ & $\begin{array}{l}\text { Gentle MACS C- } \\
\text { Reaktionsgefäße }\end{array}$ & $\begin{array}{l}\text { Miltenyi Biotec, Bergisch } \\
\text { Gladbach }\end{array}$ \\
\hline Glaskulturschalen & $60 \mathrm{~mm}$ Durchmesser & Schott AG, Jena \\
\hline Imager & VersaDoc 400MP & BioRad, München \\
\hline Heizblock & Thermomixer Compact & Eppendorf, Hamburg \\
\hline Homogenisator & TissueLyser II & Qiagen \\
\hline Isolierte Organapparatur & 10A 5301-OW & $\begin{array}{l}\text { FMI GmbH } \\
\text { Seeheim/Ober-Beerbach }\end{array}$ \\
\hline Mikroskope & $\begin{array}{l}\text { Axiovert 200, Axiovert } \\
\text { S100TV }\end{array}$ & Zeiss, Göttingen \\
\hline Mikroskopkamera & AxioCam MRm & Zeiss, Göttingen \\
\hline Metallkugeln & $\begin{array}{l}\text { Rostfreie Edelstahlkugeln } \\
7 \mathrm{~mm} \text { Durchmesser, Cat }\end{array}$ & Qiagen, Stockach \\
\hline
\end{tabular}




\begin{tabular}{|l|l|l|}
\hline & 69990 & \\
\hline PCR-Gerät & GeneAmp® 9700 & $\begin{array}{l}\text { Applied biosystems, } \\
\text { Darmstadt }\end{array}$ \\
\hline pH-Meter & pH 523 & Schütt, Göttingen \\
\hline Photo-/Spektrometer & FlexStation 3 SoftMax Pro & $\begin{array}{l}\text { Molecular Devices, } \\
\text { Biberach }\end{array}$ \\
\hline Photo-/Spektrometer & NanoDrop 1000 & PeqLab, Erlangen \\
\hline Silikonkleber & Silikonkleber 732 & Dow-Corning, Wiesbaden \\
\hline Schüttler & & Heidolph, Schwabach \\
\hline Sterile Werkbank & Steril Card Hood Class II & Baker Company, Sanford \\
\hline Wasserbad & 1083 & $\begin{array}{l}\text { Omnilab Krannich, } \\
\text { Bremen }\end{array}$ \\
\hline Vortexer & & $\begin{array}{l}\text { Omnilab Krannich, } \\
\text { Bremen }\end{array}$ \\
\hline Zellkulturmaterialien & Flaschen etc. & Sarstedt, Nürnbrecht \\
\hline Zentrifugen & 5804 R, 5417R & Eppendorf, Hamburg \\
\hline
\end{tabular}

\section{Tabelle 2: Geräte und Verbrauchsmaterialien}

2.1.2 Tiere

\begin{tabular}{|l|l|l|}
\hline Tierart & Genetischer Hintergrund & Herkunft \\
\hline Ratten & Wistar-Kyoto & Charles River, Sulzfeld \\
\hline Mäuse & iNOS-/- & $\begin{array}{l}\text { Arbeitsgruppe Prof. Dr. } \\
\text { Jens Schmidt, Klinik für } \\
\text { Neurologie der } \\
\text { Universitätsmedizin } \\
\text { Göttingen }\end{array}$ \\
\hline Mäuse & & Jackson Laboratories \\
\hline
\end{tabular}

Tabelle 3: Versuchstiere 
Die Organentnahmen wurden unter den Aktenzeichen 10.13 und 10.14 dem Niedersächsischen Landesamt für Verbraucherschutz und Lebensmittelsicherheit angezeigt. Die in dieser Arbeit verwendeten humanen umbilikalvenösen Endothelzellen wurden freundlicherweise von der Arbeitsgruppe von Prof. Dr. med. Elke Oetjen, Institut für experimentelle und klinische Pharmakologie, Universitätsklinikum Hamburg-Eppendorf, zur Verfügung gestellt.

2.1.3 Chemikalien und Zellkultursubstanzen

\begin{tabular}{|l|l|}
\hline Acrylamidmix 30\% & Carl Roth, Karlsruhe \\
\hline Ammoniumpersulfat & Carl Roth, Karlsruhe \\
\hline Atorvastatin & NicOx, Bresso (Italien) \\
\hline Atorvastatin NCX 6560 & NicOx, Bresso (Italien) \\
\hline Aqua dest. & Braun, Melsungen \\
\hline Blockierungsreagenz „Roti - Block“ & Carl Roth, Karlsruhe \\
\hline Rinder-Serum-Albumin & Sigma-Aldrich, Taufkirchen \\
\hline Bradford - Reagenz „Roti - Nanoquant“ & Carl Roth, Karlsruhe \\
\hline $\begin{array}{l}\text { (high capacity) cDNA Reverse } \\
\text { Transcription-Kit, Cat 4374966 }\end{array}$ & $\begin{array}{l}\text { Invitrogen, Darmstadt (applied } \\
\text { biosystems) }\end{array}$ \\
\hline Cerivastatin & Sequioa Research Poducts \\
\hline Diamidinophenylindol (DAPI) & Sigma-Aldrich, Taufkirchen \\
\hline Diethylpyrocarbonat & $\begin{array}{l}\text { Sigma-Aldrich, Taufkirchen } \\
\text { Cat 95284-1L }\end{array}$ \\
\hline Dimethylsulfoxid (DMSO) & Sigma-Aldrich, Taufkirchen \\
\hline Dispase & BD Biosciences, Heidelberg \\
\hline DNase I und Inkubationspuffer (für RNA) & $\begin{array}{l}\text { Roche, Mannheim } \\
\text { Cat 04716728001 }\end{array}$ \\
\hline
\end{tabular}




\begin{tabular}{|l|l|}
\hline Diethylpyrocarbonat (DEPC) & Sigma-Aldrich, Taufkirchen \\
\hline $\begin{array}{l}\text { Dulbecco's Modified Eagle Medium (low } \\
\text { glucose, F-12 und Ham's F-12) }\end{array}$ & Gibco, Karlsruhe \\
\hline $\begin{array}{l}\text { Dulbecco's Modified Eagle Medium 10- } \\
\text { fach }\end{array}$ & Gibco, Karlsruhe \\
\hline Endothelial cell growth medium & PromoCell, Heidelberg \\
\hline Fetales Kälberserum & Gibco, Karlsruhe \\
\hline Gentle MACS Enzymlösungen A, B, C & Miltenyi Biotec, Bergisch Gladbach \\
\hline Ham's F-12 medium & Gibco, Karlsruhe \\
\hline hEGF & PeproTech, Hamburg \\
\hline hFGF & PeproTech, Hamburg \\
\hline Histofix 4\% & Carl Roth, Karlsruhe \\
\hline Insulin-Transferrin-Selen-Ethanolamin & Gibco, Karlsruhe \\
\hline Kollagenase II CLS-2 C 2-28 & Biochrom, Berlin \\
\hline L-Glutamin 200 mmol/I & Gibco, Karlsruhe \\
\hline Lipopolysaccharid & Sigma-Aldrich, Taufkirchen \\
\hline L-NAME & Sigma-Aldrich, Taufkirchen \\
\hline Lumi-LightPlus Western Blotting & Roche, Mannheim \\
\hline Substrate & BD Biosciences, Heidelberg \\
\hline Nitrate/Nitrite Colorimetric Assay Kit & Cayman Chemical, Hamburg \\
\hline NOC-12 & Merck Millipore, Darmstadt \\
\hline PBS & Gibco, Karlsruhe \\
\hline Penicillin/Streptomycin 100x & Gibco, Karlsruhe \\
\hline Pferdeserum & \\
\hline Phosphatase-Inhibitor „PhosSTOP“ & \\
\hline
\end{tabular}




\begin{tabular}{|l|l|}
\hline Proteinase-Inhibitor „Complete mini“ & Roche, Mannheim \\
\hline Proteinextraktionsreagenz „ZytoBuster” & Merck Millipore, Darmstadt \\
\hline Proteinmarker „Roti-Mark Standard“ & Carl Roth, Karlsruhe \\
\hline $\begin{array}{l}\text { Proteinmarker „Precision Plus Dual } \\
\text { color }\end{array}$ & BioRad, München \\
\hline $\begin{array}{l}\text { Protran Nitrozellulose - Membran } \\
\text { Sircol TM Collagen Assay }\end{array}$ & Schleicher \& Schuell, Dassel \\
\hline SNP & Biocolor, Carrickfergus (UK) \\
\hline SuperSignal West Dura & Carl Roth, Karlsruhe \\
\hline Taqman Universal PCR Master Mix & Thermo Fisher Scientific, Bonn \\
\hline Tetramethylendiamin & Roche, Mannheim \\
\hline Tris ultrapure & Merck Millipore, Darmstadt \\
\hline Triton & Applichem, Darmstadt \\
\hline Trizol \#15596 & Carl Roth, Karlsruhe \\
\hline Trypsin - EDTA 0,05\% & Invitrogen, Darmstadt \\
\hline $1400 W$ Dihydrochlorid & Sigma-Aldrich, Taufkirchen \\
\hline
\end{tabular}

Tabelle 4: Feinchemikalien und Zellkultursubstanzen

2.1.4 Zellkulturmedien und Puffer

2.1.4.1 Medien für zellbiologische Methoden Basalmedium:

DMEM F-12

$1 \%$ Glutamin

$5 \%$ FCS

$100 \mathrm{U} / \mathrm{ml}$ Penicillin

$100 \mu \mathrm{g} / \mathrm{ml}$ Streptomycin

Präparationsmedium:

DMEM F-12 
1\% Glutamin

100 U/ml Penicillin

$100 \mu \mathrm{g} / \mathrm{ml}$ Streptomycin

Enzymmischung Gentle MACS:

DMEM F-12

4\% Enzymlösung $A$

$1 \%$ Enzymlösung $B$

0,8\% Enzymlösung $C$

Wachstumsmedium:

Ham's F-12

1\% Glutamin

$5 \%$ FCS

100 U/ml Penicillin

$100 \mu \mathrm{g} / \mathrm{ml}$ Streptomycin

$1 \%$ ITS-X

10 ng/ml FGF

$10 \mathrm{ng} / \mathrm{ml}$ EGF

Differenzierungsmedium:

DMEM low glucose

1\% Glutamin

10\% Pferdeserum

100 U/ml Penicillin

$100 \mu \mathrm{g} / \mathrm{ml}$ Streptomycin

$1 \%$ ITS-X

2\% Hühnerembryoextrakt

Behandlungsmedium:

DMEM low glucose

1\% Glutamin

10\% Pferdeserum

100 U/ml Penicillin

$100 \mu \mathrm{g} / \mathrm{ml}$ Streptomycin 
10x-DMEM

2x-DMEM:

Blockpuffer (Färbung)

CBFHH:

2.1.4.2 Substanzen zur Behandlung und ihre Lösungsmittel

\begin{tabular}{|l|l|}
\hline Substanz & Lösungsmittel \\
\hline Atorvastatin & $100 \%$ DMSO \\
\hline Atorvastatin NCX 6560 & $100 \%$ DMSO \\
\hline Cerivastatin & $20 \%$ DMSO, $80 \% \mathrm{H}_{2} \mathrm{O}$ \\
\hline Farnesyl-Pyrophosphat & $100 \%$ Ethanol \\
\hline Geranyl-Geranyl-Pyrophosphat & $100 \%$ Ethanol \\
\hline Lipopolysaccharid & Aqua dest. \\
\hline
\end{tabular}




\begin{tabular}{|l|l|}
\hline L-NAME & DMEM F-12 \\
\hline Mevalonat & $100 \%$ Ethanol \\
\hline SNP & DMEM F-12 \\
\hline 1400W Dihydrochlorid & PBS \\
\hline
\end{tabular}

Tabelle 5: Substanzen zur Behandlung der ESM

2.1.4.3 Puffer für die Kontraktionsmessung Stamm-I-Lösung

$175 \mathrm{~g} \mathrm{NaCl}$

$10 \mathrm{~g} \mathrm{KCl}$

$20 \mathrm{ml} 2,25 \mathrm{~mol} / \mathrm{l} \mathrm{CaCl} 2$

$25 \mathrm{ml} \mathrm{1,05} \mathrm{mol} / / \mathrm{MgCl}_{2}$

ad $1000 \mathrm{ml}$ Aqua dest.

Stamm-II-Lösung

$50 \mathrm{~g} \mathrm{NaHCO}_{3}$

ad $1000 \mathrm{ml}$ Aqua dest.

Stamm-III-Lösung

$5,8 \mathrm{~g} \mathrm{NaH}_{2} \mathrm{PO}_{4}$

ad $1000 \mathrm{ml}$ Aqua dest.

$\mathrm{CaCl}_{2}-\mathrm{Stamm}$

$165,57 \mathrm{~g} \mathrm{CaCl}_{2} \times 2 \mathrm{H}_{2} \mathrm{O}$

$500 \mathrm{ml}$ Aqua dest.

$\mathrm{MgCl}_{2}$-Stamm

$106,83 \mathrm{~g} \mathrm{MgCl}_{2} \times 6 \mathrm{H}_{2} \mathrm{O}$

$500 \mathrm{ml}$ Aqua dest.

Tyrode $1,8 \mathrm{mmol} / / \mathrm{Ca}^{2+}$

$200 \mathrm{ml}$ Stamm-I-Lösung

$190 \mathrm{ml}$ Stamm-II-Lösung

$50 \mathrm{ml}$ Stamm-III-Lösung

$5 \mathrm{~g}$ Glukose

500 mg Ascorbinsäure

ad $5000 \mathrm{ml}$ Aqua dest. 
2.1.4.4. Puffer für proteinbiochemische Methoden

Elektrophorese-Puffer:

$125 \mathrm{mmol} / \mathrm{l}$ Tris

$1,25 \mathrm{~mol} / \mathrm{l}$ Glycin

$0,5 \%$ SDS (w/v)

$\mathrm{pH} 8,3$

Western-Blot-Puffer:

$25 \mathrm{mmol} / \mathrm{l}$ Tris

$190 \mathrm{mmol} / \mathrm{l} \mathrm{Glycin}$

$20 \%$ Methanol (v/v)

10x TBS-Puffer:

$100 \mathrm{mmol} / \mathrm{l}$ Tris

$1,5 \mathrm{~mol} / / \mathrm{NaCl}$

$\mathrm{pH} 7,4$

TBST-Puffer:

10\% 10x TBS-Puffer (v/v)

$0,1 \%$ Tween-20 (v/v)

Ponceau-S-Färbelösung:

0,2\% Ponceau-S (w/v)

$3 \%$ Essigsäure (v/v)

4x-SDS-Page-Probenpuffer

(Laemmli-Puffer):

$300 \mathrm{mmol} / \mathrm{l}$ Tris

$7,5 \%$ SDS (w/v)

$0,25 \%$ Bromphenolblau (w/v)

$50 \%$ Glycerin (v/v)

$10 \% \beta$-Mercaptoethanol (v/v)

$\mathrm{pH} 6,8$ 


\subsubsection{Antikörper}

2.1.5.1. Primärantikörper für Western-Blot- und Immunfluoreszenz-Analysen Die Inkubation aller Antikörper erfolgte über Nacht bei $4^{\circ} \mathrm{C}$.

\begin{tabular}{|c|c|c|c|}
\hline $\begin{array}{l}\text { Primärantikörper } \\
\text { (Klon) }\end{array}$ & Verdünnung WB/IF & Spezies & Firma \\
\hline$\beta-A k t i n\left(\lg G_{2 a}\right)$ & $1: 4000$ IF & Maus & $\begin{array}{l}\text { Sigma-Aldrich } \\
\text { A2228 }\end{array}$ \\
\hline nNOS (polyklonal) & 1:1000 WB & Kaninchen & $\begin{array}{l}\text { Cell Signaling } \\
\# 4234\end{array}$ \\
\hline iNOS $\left(\lg _{2 a}\right)$ & $1: 2000$ WB & Maus & $\begin{array}{l}\text { BD Biosciences } \\
\# 80853\end{array}$ \\
\hline eNOS $\left(\lg G_{1}\right)$ & $1: 5000$ WB & Maus & $\begin{array}{l}\text { BD Biosciences } \\
\# 91444\end{array}$ \\
\hline$\alpha$-Tubulin $\left(\lg _{1}\right)$ & 1:2000 WB & Maus & $\begin{array}{l}\text { Sigma-Aldrich } \\
\text { T5168 }\end{array}$ \\
\hline GAPDH $\left(\lg _{1}\right)$ & $1: 8000$ WB & Maus & $\begin{array}{l}\text { Biodesign } \\
\text { H86504M }\end{array}$ \\
\hline $\begin{array}{l}\text { Phospho-VASP } \\
\text { (polyklonal) }\end{array}$ & $1: 10000$ WB & Kaninchen & $\begin{array}{l}\text { Cell Signaling } \\
\# 3112\end{array}$ \\
\hline VASP (polyklonal) & $1: 10000$ WB & Kaninchen & $\begin{array}{l}\text { Cell Signaling } \\
\# 3114\end{array}$ \\
\hline eNOS $\left(\lg _{1}\right)$ & 1:1000 WB & Maus & $\begin{array}{l}\text { BD Biosciences } \\
\# 91444\end{array}$ \\
\hline Nitrotyrosin $\left(\lg _{2 b}\right)$ & $1: 1000 \mathrm{IF}$ & Maus & $\begin{array}{l}\text { Merck Millipore } \\
\text { \# } 487923\end{array}$ \\
\hline
\end{tabular}

Tabelle 6: Primärantikörper für Western-Blot- (WB) und ImmunfluoreszenzAnalysen (IF)

2.1.5.2 Sekundärantikörper für Western-Blot-Analysen

Die Inkubation aller Antikörper erfolgte für eine Stunde bei Raumtemperatur.

\begin{tabular}{|l|l|l|l|}
\hline Sekundärantiköper & Verdünnung & Spezies & Firma \\
\hline $\begin{array}{l}\text { Anti-Maus-IgG- } \\
\text { Peroxidase- }\end{array}$ & $1: 10000$ & Kaninchen & Sigma-Aldrich \\
& & & A9044 \\
\hline
\end{tabular}




\begin{tabular}{|l|l|l|l|}
\hline Konjugat & & & \\
\hline $\begin{array}{l}\text { Anti-Kaninchen- } \\
\text { IgG-Peroxidase- } \\
\text { Konjugat }\end{array}$ & $1: 20000$ & Ziege & $\begin{array}{l}\text { Jackson } \\
\text { ImmunoResearch }\end{array}$ \\
& & & $111-035-045$ \\
\hline
\end{tabular}

Tabelle 7: Sekundärantikörper für Western-Blot-Analysen

2.1.5.3 Sekundärantikörper für Immunfluoreszenz-Analysen

Die Inkubation aller Antikörper erfolgte für eine Stunde bei Raumtemperatur.

\begin{tabular}{|l|l|l|l|}
\hline Sekundärantiköper & Verdünnung & Spezies & Firma \\
\hline DyLight 549 & $1: 1000$ & Kaninchen & Rockland \\
Anti-Maus lgG & & & $610-442-002$ \\
\hline
\end{tabular}

Tabelle 8: Sekundärantikörper für Immunfluoreszenz-Analysen

\subsubsection{Primer}

Die verwendeten Primer (Tab. 9) wurden von der Firma MWG synthetisiert und sind in $5^{`} \rightarrow 3^{`}$ - Orientierung angegeben.

\begin{tabular}{|l|l|}
\hline Name & Sequenz \\
\hline nNOS forward & CCATGTCA AGTATGCCACCA \\
\hline nNOS reverse & GTGTGGAACTCGCAGCTCAT \\
\hline Probe nNOS & FAM-GAATCTCAGGTCGGCCATCACGAT-TAMRA \\
\hline iNOS forward & GAGACAGGAAAGTCGGAAGC \\
\hline iNOS reverse & AGGAACAACTACTGCTGGTGG \\
\hline Probe iNOS & FAM-GCCTTCAACACCAAGGTTGTCTGCAT-TAMRA \\
\hline eNOS forward & CAGCACAGGAAATGTTCACC \\
\hline eNOS reverse & GGAGACTTCCGGATCTGGA \\
\hline Probe eNOS & FAM-TCTTCGTTCAGCCATCACGGTGTT-TAMRA \\
\hline
\end{tabular}

Tabelle 9: Genspezifische Primer 


\subsection{Methoden}

\subsubsection{Zellbiologische Methoden}

\subsubsection{Myoblastenisolation}

\subsection{Myoblastenisolation aus der Ratte}

Zur Vorbereitung wurden $20 \mathrm{mg}$ Kollagenase in $10 \mathrm{ml}$ Präparationsmedium gelöst, steril filtriert und auf $37^{\circ} \mathrm{C}$ erwärmt. DNase wurde in Aqua dest. verdünnt $(1 \mathrm{mg} / \mathrm{ml})$, steril filtriert und auf Eis gelagert. Dispase (BD $50 \mathrm{U} / \mathrm{ml}$ ) wurde ebenfalls auf Eis gelagert. Für die Isolation der Myoblasten wurden die neonatalen Ratten (p0-2) durch Dekapitation getötet. Nach Desinfektion und Entfernung der Haut wurden die Hinterläufe abgetrennt und Ober- und Unterschenkel in $4{ }^{\circ} \mathrm{C}$ kaltes Basalmedium gegeben und bis zur weiteren Verwendung auf Eis aufbewahrt. Knochen, Sehnen, Bindegewebe und eventuelles Fett wurden vorsichtig entfernt, das übrige Muskelgewebe wurde mit einem Skalpell in ca. $0,5 \times 0,5 \mathrm{~cm}$ kleine Stücke geschnitten.

Pro Milliliter Gewebe wurde ein Milliliter Kollagenaselösung hinzugegeben und das Kollagenase-Muskel-Gemisch bei $37^{\circ} \mathrm{C}$ im Wasserbadschüttler (50 horizontale Bewegungen/Minute) für 45 Minuten verdaut. Nach einer Zentrifugation für 2 Minuten bei $250 \mathrm{xg}$ bei $4^{\circ} \mathrm{C}$ wurde der Überstand abgesaugt und die Muskelstücke mit 20-30 ml Basalmedium gewaschen. Nach einer weiteren Zentrifugation für zwei Minuten bei $250 \mathrm{xg}$ und $4^{\circ} \mathrm{C}$ wurden die Muskelstücke in $15 \mathrm{ml}$ Basalmedium und $300 \mu \mathrm{l}$ DNase resuspendiert. Mit einer Pipette mit weiter Öffnung wurden die Muskelstücke trituriert und dann durch ein 250- $\mu \mathrm{m}$-Metallsieb filtriert. Anschließend wurden sie wieder für zwei Minuten bei $250 \mathrm{xg}$ bei $4{ }^{\circ} \mathrm{C}$ zentrifugiert. Das Zellpellet wurde mit einer Pasteurpipette in $18 \mathrm{ml}$ Medium, $2 \mathrm{ml}$ Dispase und $400 \mu \mathrm{l}$ DNase trituriert und für 30 Minuten bei $37^{\circ} \mathrm{C}$ im Wasserbadschüttler (50 horizontale Bewegungen/Minute) weiterverdaut. Nach einer Zentrifugation für 5 Minuten bei $500 x$ bei $4^{\circ} \mathrm{C}$ wurde das Pellet in ca. $15 \mathrm{ml}$ Basalmedium mit einer Pasteurpipette resuspendiert und dann durch einen $100-\mu \mathrm{m}$-Filter gegeben. Das Filtrat wurde für 5 Minuten bei $500 \mathrm{xg}$ und $4{ }^{\circ} \mathrm{C}$ zentrifugiert, das Pellet wieder resuspendiert und dann durch einen 40- $\mu \mathrm{m}$-Filter gegeben. Das Filtrat wurde auf Zellkulturflaschen mit $175 \mathrm{~cm}^{2}$ Wachstumsfläche verteilt und mit Wachstumsmedium auf $25 \mathrm{ml}$ aufgefüllt. 
Nach 45 Minuten bei $37^{\circ} \mathrm{C}$ im Inkubationsschrank wurde der Überstand mit den nicht adhärenten Myoblasten von einer auf zwei neue Flaschen verteilt und wieder mit Wachstumsmedium auf $25 \mathrm{ml}$ aufgefüllt. Nach $48 \mathrm{~h}$ fand der erste Mediumwechsel mit Wachstumsmedium statt, dann jeden zweiten Tag bis zur ESM-Herstellung. Nach vier bis fünf Tagen wurden bei ausreichender Dichte und Differenzierung der Myoblasten ESM hergestellt.

\subsection{Myoblastenisolation aus der Maus}

Für die Myoblastenisolation wurden 6-8 Wochen alte Mäuse mit $\mathrm{CO}_{2}$ narkotisiert und durch Dekapitation getötet. Nach Desinfektion und Entfernung der Haut wurde die Muskulatur der Hinterläufe abpräpariert und in Präparationsmedium gesammelt. Das Gewebe wurde mit einer scharfen Schere in ca. 0,5 × 0,5 cm kleine Stücke geschnitten. Jede GentleMACS-Flasche wurde mit 2,5 ml Enzymmischung und ca. 1 Gramm Gewebe befüllt. Dann wurde das Muskel-Enzym-Gemisch für 30 Minuten bei $37^{\circ} \mathrm{C}$ im Wasserbadschüttler (80 horizontale Bewegungen/Minute) verdaut. Nach dem Verdau wurden die Muskelstücke für 35 Sekunden im GentleMACS Dissoziator im Programm h_tumor-01 zerkleinert. Dann folgte ein weiterer Verdau für 30 Minuten bei $37^{\circ} \mathrm{C}$ im Wasserbadschüttler ( 80 horizontale Bewegungen/Minute) und weitere 35 Sekunden im Programm h_tumor-01 des GentleMACS Dissoziators. Anschließend wurde die Zellsuspension trituriert und durch einen zuvor mit Präparationsmedium befeuchteten $70-\mu \mathrm{m}$-Filter gegeben. Nach einer Zentrifugation für 7 Minuten bei $300 \mathrm{xg}$ und $4{ }^{\circ} \mathrm{C}$ wurde der Überstand abgesaugt und das Pellet in Basalmedium resuspendiert. Die Zellsuspension wurde auf Zellkulturflaschen mit 175 $\mathrm{cm}^{2}$ Wachstumsfläche verteilt und 60 Minuten im Inkubationsschrank bei $37^{\circ} \mathrm{C}$ und $5 \% \mathrm{CO}_{2}$ inkubiert (preplating um schnell adhärente Fibroblasten zu reduzieren). Dann erfolgte die Passagierung des Überstandes auf neue Zellkulturflaschen, die mit Wachstumsmedium auf $25 \mathrm{ml}$ aufgefüllt wurden. Nach $48 \mathrm{~h}$ fand der erste Mediumwechsel mit Wachstumsmedium statt, dann jeden zweiten Tag. Nach sechs bis sieben Tagen wurde bei ausreichender Dichte und Differenzierung der Myoblasten ESM hergestellt. 


\subsubsection{Herstellung von Kollagen}

4-6 Rattenschwänze von adulten Ratten wurden gewaschen und mit 70\%igem Ethanol desinfiziert. Die Haut wurde abgetrennt und die Sehnen in PBS (mit $200 \mathrm{U} / \mathrm{ml}$ Penicillin und $0,2 \mathrm{mg} / \mathrm{ml}$ Streptomycin) gesammelt und gewaschen. Die Sehnen wurden dann in $4{ }^{\circ} \mathrm{C}$ kalte $0,1 \%$ ige Essigsäure überführt und 3 Tage lang bei $4{ }^{\circ} \mathrm{C}$ bis zur vollständigen Auflösung der Sehnen gerührt. Dann wurde die Lösung für 120 Minuten bei $14.000 \mathrm{xg}$ bei $4{ }^{\circ} \mathrm{C}$ zentrifugiert und der Überstand in eine $500-\mathrm{ml}$ Flasche pipettiert. 25\%iges Natriumchlorid wurde unter ständigem Rühren langsam hinzugegeben, bis der Natriumchloridgehalt je nach Volumen des Überstands bei $4 \%$ lag. Die Lösung wurde über Nacht bei $4{ }^{\circ} \mathrm{C}$ inkubiert und am Folgetag für 5 Minuten bei $10.000 \mathrm{xg}$ bei $4{ }^{\circ} \mathrm{C}$ zentrifugiert. Die Überstände wurden verworfen. Die Pellets wurden in $0,1 \%$ ige Essigsäure resuspendiert, um den Natriumchloridgehalt auf physiologische Werte zu reduzieren, und bei $4{ }^{\circ} \mathrm{C}$ bis zur vollständigen Lösung gerührt. Die Kollagenkonzentration wurde mittels eines kolorimetrischen Kollagenassays (Sircol) überprüft.

\subsubsection{Herstellung von Hühnerembryonenextrakt}

Für die Präparation wurden 120 Eier vom 7. - 9. Bruttag mit 70\%igem Ethanol desinfiziert. Die Eier wurden am abgerundeten Pol vorsichtig eingestoßen und die Eihülle geöffnet. Mit einer sterilen Pipette wurde der Embryo entnommen, dekapitiert und Kopf und Körper wurden in $150 \mathrm{ml} \mathrm{CBFHH}$ mit 4\% Penicillin und Streptomycin) auf Eis gegeben. Das Gewebe wurde mithilfe des Polytron zerkleinert, dann mit $\mathrm{CBFHH}$ auf $300 \mathrm{ml}$ aufgefüllt, in Reaktionsgefäße überführt und für 10 Minuten bei $300 x g$ bei $4{ }^{\circ} \mathrm{C}$ zentrifugiert. Die Überstände wurden gesammelt. Die Pellets wurden ebenfalls gesammelt und noch einmal mit dem Polytron homogenisiert. Nach einer weiteren Zentrigation für 10 Minuten bei $300 x g$ bei $4^{\circ} \mathrm{C}$ wurden die Überstände mit den Überständen aus der ersten Zentrifugation gemischt, portioniert und bis zur weiteren Verwendung bei $-20^{\circ} \mathrm{C}$ eingefroren.

\subsubsection{Herstellung der Engineered Skeletal Muscle-Schalen}

Vier kurze Stücke Silikonband (Durchmesser $2 \mathrm{~mm}$, Höhe ca. $10 \mathrm{~mm}$ ) wurden mit Silikonkleber in eine Glaskulturschale geklebt. Je ein Teflonplättchen mit zentralem Loch (Durchmesser insgesamt $10 \mathrm{~mm}$ ) wurde auf die angeklebten Silikonbandstücke gesteckt und vorsichtig auf den Boden der Schale gedrückt. Dann wurden die Schalen mit Silikonkleber ausgegossen und ca. 2 Wochen lang zur Aushärtung im 
Trockenschrank belassen. Danach wurden die Teflonplättchen entfernt und die Schale wurde ausgekocht. Auf jedes Stück Band wurde ein entsprechendes Stück Silikonschlauch gesteckt und dann wurde die ganze Schale autoklaviert.

\author{
2.2.1.5 Herstellung von Engineered Skeletal Muscle \\ Für $8 \mathrm{ESM}$ wurden benötigt: $\quad 800 \mu \mathrm{l} \mathrm{Kollagen}(4,7 \mathrm{mg} / \mathrm{ml})$ \\ $800 \mu \mathrm{l} 2 \mathrm{x}$-DMEM \\ $155 \mu \mathrm{l} \mathrm{NaOH} 0,1 \mathrm{~mol} / \mathrm{l}$ \\ $400 \mu \mathrm{l}$ Matrigel \\ $2045 \mu$ l Zellsuspension mit 8,8 \\ Millionen Myoblasten
}

Für die Herstellung der ESM wurde der Überstand aus den Zellkulturflaschen abgesaugt und die Myoblasten dreimal vorsichtig mit $37{ }^{\circ} \mathrm{C}$ warmem PBS gewaschen. Dann wurden die Zellen mit $4 \mathrm{ml}$ 0,05\%iger Trypsinlösung je $175 \mathrm{~cm}^{2}$ für ca. zwei Minuten bei Raumtemperatur inkubiert, bis sie sich durch leichtes Klopfen vom Plattenboden lösten. Das Trypsin wurde durch Zugabe von $8 \mathrm{ml}$ Basalmedium je Flasche inaktiviert und das Zell-Medium-Gemisch in Reaktionsgefäße pipettiert. Es folgte eine Zentrifugation für 5 Minuten bei $300 x g$ und $4{ }^{\circ} \mathrm{C}$. Nach Resuspension mit Basalmedium wurden die Zellen gezählt. Das der benötigten Zellzahl entsprechende Volumen Zellsuspension wurde erneut für 5 Minuten bei $300 \mathrm{xg}$ bei $4{ }^{\circ} \mathrm{C}$ zentrifugiert. Das Zellpellet wurde dann in dem benötigten Volumen Basalmedium resuspendiert. Auf Eis wurden zunächst Kollagen, Matrigel und 2x-DMEM vermischt. Nach Titration mit $\mathrm{NaOH}$ zur Neutralisierung des pHs wurden die Myoblasten hinzupipettiert. Pro ESM wurden $450 \mu \mathrm{l}$ Kollagen-Zell-Suspension in die vorbereiteten Schalen pipettiert (Abb. 1). Es erfolgte eine ca. 60 Minuten lange Inkubation im Brutschrank bei $37^{\circ} \mathrm{C}$ und $5 \% \mathrm{CO}_{2}$. Dann wurden $5 \mathrm{ml}$ Differenzierungsmedium pro Schale mit vier ESM hinzupipettiert. Nach $24 \mathrm{~h}$ fand der erste Mediumwechsel mit Differenzierungsmedium statt, darauffolgend jeden zweiten Tag. Am fünften Tag nach Herstellung wurden die ESM auf statische Stretcher in je $5 \mathrm{ml}$ Differenzierungsmedium pro ESM gesetzt. Nach weiteren fünf Tagen und Mediumwechsel an jedem zweiten Tag folgte die Behandlung der Muskelringe mit Behandlungsmedium und den entsprechenden Substanzen. Dabei wurde täglich das Medium gewechselt. 


\subsubsection{Herstellung von 2D-Myoblasten-Kultur}

Zur Herstellung von 2D-Myoblastenkultur wurden Myoblasten am Tag der Präparation auf beschichtete 6-well-Platten aufgetragen. Dazu wurde Matrigel im Verhältnis von $1: 50$ mit $4{ }^{\circ} \mathrm{C}$ kaltem PBS vermischt und sofort ca. $750 \mu \mathrm{l}$ dieses Gemisches je well aufgetragen. Nach zwei bis drei Stunden im Inkubationsschrank bei $37{ }^{\circ} \mathrm{C}$ und $5 \% \quad \mathrm{CO}_{2}$ wurde der Überstand abgesaugt. Die Myoblasten entstammten aus der regulären Myoblastenisolation vor der Passage in neue Zellkulturflaschen nach der einstündigen Inkubation in Basalmedium. Die Zellen wurden gezählt und je well $1 \times 10^{5}$ Zellen in $2 \mathrm{ml}$ Wachstumsmedium ausplattiert. Der erste Mediumwechsel fand am Folgetag mit Wachstumsmedium statt. Bis zur weiteren Verwendung der Zellen wurde daraufhin jeden Tag das Medium mit Differenzierungsmedium gewechselt. Wurde das Medium für Versuche benötigt, wurde es nach Abschluss der Behandlung vorsichtig abpipettiert und bis zur weiteren Verwendung bei $-20^{\circ} \mathrm{C}$ aufbewahrt.

\subsubsection{Kontraktionskraftmessung}

Die Kontraktionsmessung fand jeweils am 15. Tag nach Herstellung der ESM statt. Dazu wurden die ESM in einem Organbad mit frisch zubereiteter, oxygenierter, 1,8 $\mathrm{mmol} / / \mathrm{K}$ Kalzium enthaltener Tyrodelösung bei $37^{\circ} \mathrm{C}$ in der Organapparatur (Abb. 1) vorsichtig zwischen zwei Metallhaken aufgehängt, von denen der obere über ein Drehrädchen nach oben und unten beweglich war. Die ESM wurden bei $200 \mathrm{~mA}$ mit einer Stimulationsfrequenz von 2,5 Hertz vorgespannt, bis die isometrische Kraftentwicklung maximal war. Dann wurde durch Erhöhung der Stimulationsfrequenz auf 80 Hertz für $4 \mathrm{~ms}$ ein Tetanus zur Ermittlung der Maximalkraft ausgelöst. Zur Ermittlung der Ermüdbarkeit wurden nach 1 Minute Pause 10 weitere Tetani alle 20 Sekunden ausgelöst. Danach wurde die Tyrode einmal gewechselt. 
A

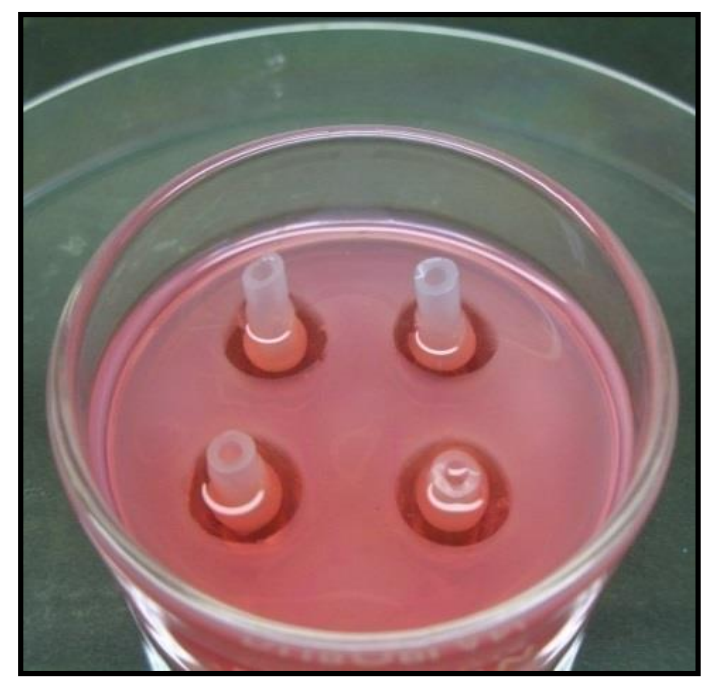

B

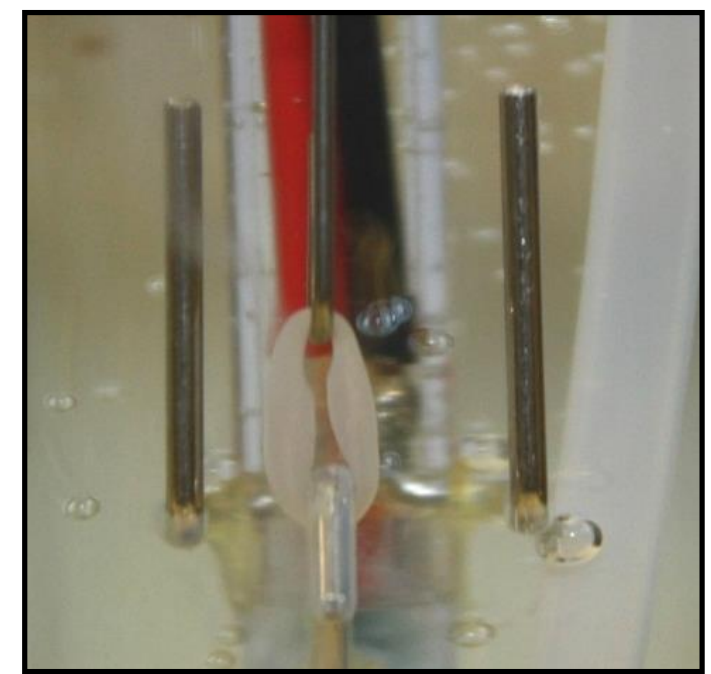

Abbildung 1: ESM-Kultur und ESM-Kontraktionsmessung.

A: ESM in ESM-Schale von Tag 0-5 nach Herstellung.

B: Kontraktionsmessung des ESM im Organbad an Tag 15 nach Herstellung.

\subsubsection{Molekulargenetische Methoden}

\subsubsection{RNA-Isolation aus Engineered Skeletal Muscle}

Je ein ESM wurde mit $1 \mathrm{ml}$ Trizol mithilfe von Metallkugeln und TissueLyser für 30 Sekunden bei 20 Hertz homogenisiert und für 5 Minuten bei Raumtemparatur (RT) inkubiert. Nach Zugabe von $250 \mu \mathrm{l}$ Chloroform pro ESM wurde die TrizolChloroform-Zell-Mischung für 15 Sekunden mit einem Vortexer geschüttelt, nochmal 3 Minuten bei RT inkubiert und dann für 15 Minuten bei $12.000 \mathrm{xg}$ bei $4{ }^{\circ} \mathrm{C}$ zentrifugiert. Die wässrige Phase, in der die RNA enthalten war, wurde in ein neues 1,5-ml- Eppendorffgefäß pipettiert. Der Lösung wurden $0,5 \mathrm{ml}$ Isopropanol hinzugefügt und nach weiteren 10 Minuten Inkubation bei Raumtemperatur wurde sie für 10 Minuten bei $12.000 \mathrm{xg}$ bei $4{ }^{\circ} \mathrm{C}$ zentrifugiert. Der Überstand wurde vorsichtig abgekippt. Das die RNA enthaltende Pellet wurde mit $1 \mathrm{ml}$ 75\%igem Ethanol gewaschen. Das Pellet sollte dabei intakt bleiben, aber sich vom Boden des Gefäßes ablösen. Nach einer weiteren Zentrifugation für 5 Minuten bei $12.000 \times$ g bei $4{ }^{\circ} \mathrm{C}$ wurde der Überstand vorsichtig abgenommen und das Pellet für 5-10 Minuten bei Raumluft getrocknet. Danach wurde es in $20 \mu \mathrm{l}$ 0,1\%igem Diethylpyrocarbonat- $\mathrm{H}_{2} \mathrm{O}$ aufgenommen, für 10 Minuten bei $58{ }^{\circ} \mathrm{C}$ inkubiert und anschließend sofort für 5 Minuten auf Eis gelagert. Die RNA-Konzentrationsbestimmung erfolgte mittels Spektrometer NanoDrop 1000. Die mittlere Ausbeute lag bei $13560 \pm 1200 \mathrm{ng} / \mathrm{ESM}$ 
( $\mathrm{n}=20)$ bzw. $23820 \pm 7820 \mathrm{ng} /$ Muskelstück. Das 260/280-Verhältnis betrug 1,86 \pm $0,04(n=12)$. Bis zur weiteren Verwendung wurde die RNA bei $-80^{\circ} \mathrm{C}$ gelagert.

\subsubsection{DNase-Behandlung der RNA}

Zur Vermeidung der Kontamination mit DNA wurde die RNA mit DNase I behandelt.

Dazu wurde $1 \mu \mathrm{g}$ RNA mit $1 \mu \mathrm{l}$ DNase-Inkubationspuffer, 0,2 $\mu \mathrm{l}$ DNase $(10 \mathrm{U} / \mu \mathrm{l})$ und

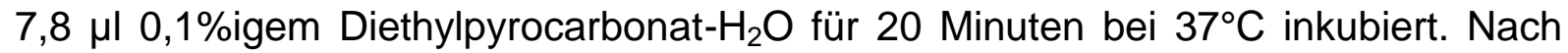
Zugabe von $0,2 \mu \mathrm{l}$ 0,2 molarer EDTA-Lösung (RNase-frei, pH 8,0) folgte für 10 Minuten eine Inkubation bei $75^{\circ} \mathrm{C}$ zur DNase-Inaktivierung.

\subsubsection{3 cDNA-Synthese}

Für die cDNA-Synthese wurde das High-Capacity cDNA reverse Transcription Kit von Invitrogen verwendet. $1 \mu \mathrm{g}$ RNA (entsprechend den $10 \mu \mathrm{l}$ aus der DNaseBehandlung) wurde mit $1 \mu \mathrm{l} 10 \times \mathrm{RT}$-Puffer, 0,8 $\mu \mathrm{l} 25 \times \mathrm{dNTP}(100 \mathrm{mM}), 0,5 \mu \mathrm{l}$ Oligo(dT), $1 \mu \mathrm{l}$ Multiscribe Reverse Transcriptase, $1 \mu \mathrm{l}$ RNase Inhibitor und 4,2 $\mu \mathrm{l}$ Diethylpyrocarbonat $-\mathrm{H}_{2} \mathrm{O}$ für 10 Minuten bei $25^{\circ} \mathrm{C}$, dann für 120 Minuten bei $37^{\circ} \mathrm{C}$ und 5 Minuten bei $85^{\circ} \mathrm{C}$ inkubiert. Die cDNA wurde bis zur weiteren Verwendung bei $-20{ }^{\circ} \mathrm{C}$ aufbewahrt.

\subsubsection{Quantitative Polymerase-Ketten-Reaktion}

Für die in dieser Arbeit durchgeführten PCR-Ansätze wurde folgendes

Pipettierschema (Tab. 10) eingehalten:

\begin{tabular}{|l|l|}
\hline Reagenz & Volumen \\
\hline Primer „forward“ $(100 \mu \mathrm{mol} / \mathrm{l})$ & $0,3 \mu \mathrm{l}$ \\
\hline Primer „reverse“ $(100 \mu \mathrm{mol} / \mathrm{l})$ & $0,3 \mu \mathrm{l}$ \\
\hline Diethylpyrocarbonat $-\mathrm{H}_{2} \mathrm{O}$ & $3,3 \mu \mathrm{l}$ \\
\hline MasterMix & $5 \mu \mathrm{l}$ \\
\hline Sonde & $0,1 \mu \mathrm{l}$ \\
\hline cDNA & $1 \mu \mathrm{l}$ \\
\hline
\end{tabular}

\section{Tabelle 10: PCR-Reaktionsansatz}

Die in dieser Arbeit durchgeführten PCR-Durchläufe wurden mit folgendem Temperaturprotokoll durchgeführt: Nach 2 Minuten bei $50{ }^{\circ} \mathrm{C}$ erfolgte eine initiale Denaturierung für 10 Minuten bei $95{ }^{\circ} \mathrm{C}$. Im dritten Schritt folgten 40 Amplifikationszyklen bestehend jeweils aus einer Phase à 15 Sekunden bei $95{ }^{\circ} \mathrm{C}$ 
und einer Phase à 60 Sekunden bei $60{ }^{\circ} \mathrm{C}$. Die verwendeten Primer- und Sondensequenzen sind in Tabelle 9 aufgeführt. Die mRNA-Menge wurde durch den Vergleich der relativen Ct-Werte (cycle threshold) bestimmt. Die GAPDH-Ct-Werte wurden von den Ct-Werten der zu bestimmenden mRNA subtrahiert ( $\Delta$ Ct-Wert). Der Mittelwert der $\Delta$ Ct-Werte der Vehikelkontrolle wurde dann von jedem einzelnen $\Delta$ Ct-Wert subtrahiert $(\Delta \Delta$ Ct-Werte), sodass dies dem relativen mRNA-Gehalt bezogen auf die Vehikelkontrolle entspricht (Livak und Schmittgen 2001). Die Transkriptmenge wurde mithilfe einer Standardkurve für jedes Gen bestimmt und auf die Transkriptmenge von GAPDH bezogen.

\subsubsection{Proteinbiochemische Methoden}

\subsection{Proteingewinnung aus Engineered Skeletal Muscle}

Zunächst wurden eine Tablette Phosphataseinhibitor und eine Tablette Proteinaseinhibitor in $10 \mathrm{ml}$ ZytoBuster gelöst. Je ein ESM $\left(-80^{\circ} \mathrm{C}\right)$ wurde in $250 \mu \mathrm{l}$ ZytoBuster (mit Phosphatase- und Proteinaseinhibitor) durch leichtes Schütteln homogenisiert und für 15 Minuten auf Eis belassen. Dann wurden die Proben für zweimal 20 Sekunden im TissueLyser (15 Hertz) homogenisiert. Das Lysat wurde für 15 Minuten bei $15.000 x$ bei $4{ }^{\circ} \mathrm{C}$ zentrifugiert und der Überstand vorsichtig abgenommen und bis zur weiteren Verwendung bei $-20^{\circ} \mathrm{C}$ eingefroren.

\subsection{Proteingewinnung aus Mäusegehirn}

Das Gehirn einer Maus wurde in $1 \mathrm{ml}$ ZytoBuster homogenisiert. Dabei wurde verfahren, wie in 2.2.4.1.1 beschrieben.

\subsubsection{Proteinkonzentrationsbestimmung}

Die Proteinkonzentrationen wurden nach der Methode nach Bradford bestimmt. Dazu wurden die Proteine und eine Proteinstandardreihe $(0 ; 0,4 ; 0,8 ; 1,2 ; 1,6 ; 2 \mu \mathrm{g}$ BSA) in eine 96-well-Mikrotiterplatte mit einem Gesamtvolumen von $50 \mu \mathrm{l}$ pipettiert. Je $200 \mu \mathrm{l}$ Bradford-Reagenz wurden zu den Proben gegeben und die sich ergebene Farbveränderung mittels eines Photometers FlexStation 3 SoftMax Pro bei $595 \mathrm{~nm}$ bestimmt. Aus der Proteinstandardreihe wurden dann die Proteinkonzentrationen der Proben errechnet. Der mittlere Proteingehalt der ESM lag bei $1050 \pm 75 \mu \mathrm{g}(\mathrm{n}=25)$. 


\subsubsection{Gelelektrophorese}

Die Proteinlysate wurden mit Laemmli-Puffer versetzt und 3 Minuten bei $95{ }^{\circ} \mathrm{C}$ denaturiert. Die Proben wurden mittels diskontinuierlicher SDS-Page bei zunächst 100 V für 15 Minuten und dann 150 V je nach Größe des gesuchten Proteins für 45 60 Minuten aufgetrennt. Um die Größen der aufgetrennten Proteine zu ermitteln, wurde jeweils immer auch ein Proteinstandard aufgetragen. Der Anteil der Acrylamidlösung im Trenngel variierte je nach Größe des gesuchten Proteins von 8 12\%. Die Acrylamidkonzentration der Sammelgele war jeweils 5\%. Die Gele wurden selbst hergestellt, indem zunächst das Trenngel zwischen zwei Glasplatten, die sich mittels Abstandhalter im Abstand von 1,5 mm befanden, pipettiert wurde und nach vollständiger Polymerisation eine Schicht Sammelgel darüber pipettiert wurde. Beispielhaft ist hier die Zusammensetzung eines Trenngels mit einer 8\%igen Acrylamidkonzentration angegeben.

Trenngel 8\%:

$6,9 \mathrm{ml}$ Aqua dest.

$4,9 \mathrm{ml} \mathrm{30 \%} \mathrm{Acrylamidmix}$

$3,8 \mathrm{ml} 1,5 \mathrm{mmol} / \mathrm{l} \mathrm{Tris} \mathrm{pH} \mathrm{8,8}$

$0,15 \mathrm{ml} 10 \%$ SDS

$0,15 \mathrm{ml}$ Ammoniumpersulfat

$0,009 \mathrm{ml}$ Tetramethylendiamin

Sammelgel 5\%

6,8 $\mathrm{ml}$ Aqua dest.

$1,7 \mathrm{ml} 30 \%$ Acrylamidmix

$1,25 \mathrm{ml} 1 \mathrm{M}$ Tris $\mathrm{pH} 6,8$

$0,1 \mathrm{ml} 10 \%$ SDS

$0,1 \mathrm{ml}$ Ammoniumpersulfat

$0,1 \mathrm{ml}$ Tetramethylendiamin

\subsubsection{Immunoblot (Western Blot)}

Über ein senkrecht angelegtes elektrisches Feld wurden die Proteine vom SDSPage-Gel auf eine Nitrozellulosemembran übertragen. Die Transferzeit belief sich auf 1,5 bis 2 Stunden bei $200 \mathrm{~mA}$ abhängig von der Größe des zu detektierenden Proteins. Dabei blieb das Muster der Proteinauftrennung unverändert. Das Proteinmuster auf der Membran wurde nach dem Transfer mit 0,2\%iger PonceauLösung angefärbt und mittels Imager VersaDoc 400MP dokumentiert. Nach 
dreimaligem Waschen für je 5 Minuten mit TBST wurde die Membran für mindestens 1 Stunde bei RT in Roti-Block inkubiert. Dann wurde die Membran erneut dreimal für je 5 Minuten mit TBST gewaschen und anschließend über Nacht bei $4^{\circ} \mathrm{C}$ mit dem Primärantikörper (Tab. 6) inkubiert. Daraufhin wurde die Membran dreimal für je 15 Minuten mit TBST gewaschen, bevor sie mit dem Sekundärantikörper für 1 Stunde bei RT inkubiert wurde. Nach erneuten drei Waschschritten mit TBST für je 15 Minuten wurde mittels der Lumineszenzreagenzien Lumi-LightPlus und SuperSignal West Dura der Primärantikörper-Sekundärantikörper-Komplex über die an den Sekundärantikörper gekoppelte Meerrettichperoxidase detektiert.

\subsubsection{NO-Messung}

Um zu untersuchen, ob $1400 \mathrm{~W}$ in der verwendeten Konzentration von $5 \mu \mathrm{mol} / \mathrm{l}$ in ausreichendem Maße zur iNOS-Hemmung führt (3.7), wurde Nitrit mithilfe des Nitrate/Nitrite Colorimetric Assay Kits als Endprodukt von NO im Medium aus 2DMyoblastenkulturen gemessen, die zuvor für $24 \mathrm{~h}$ mit LPS und unterschiedlichen Konzentrationen von 1400W bzw. L-NAME behandelt worden waren. Gemäß den Angaben des Herstellers Cayman Chemical wurde in dem zu untersuchenden Medium unter Zuhilfenahme einer Standardkurve die Nitritkonzentration photometrisch bestimmt.

\subsubsection{Immunfluoreszenzfärbungen}

Zur Färbung wurden die ESM (whole mount = Komplettpräparat) bzw. die 2DMyoblastenkulturen dreimal mit PBS für je 5 Minuten gewaschen. Dann folgte die Fixierung der 2D-Myoblastenkulturen mit vierprozentiger Formaldehydlösung (Histofix) für 15 Minuten bei Raumtemperatur. Die ESM wurden bei $4{ }^{\circ} \mathrm{C}$ über Nacht in Histofix fixiert. Nach erneutem dreimaligen Waschen für je 5 Minuten wurden die Präparate für $1 \mathrm{~h}$ bei Raumtemperatur in Blockpuffer belassen. Vor der Färbung erfolgte ein erneutes Spülen $3 \times 5$ Minuten. Die Behandlung mit dem in Blockpuffer verdünnten Primärantikörper (Tab. 6) erfolgte über Nacht bei $4{ }^{\circ} \mathrm{C}$. Die Präparate wurden nochmals $3 \times 5$ Minuten gewaschen und dann mit dem Sekundärantikörper für $1 \mathrm{~h}$ bei Raumtemperatur inkubiert. Danach wurden sie erneut für $3 \times 5$ Minuten gewaschen und bis zur weiteren Verwendung in PBS bei $4{ }^{\circ} \mathrm{C}$ und unter Lichtausschluss aufbewahrt. Zur Quantifizierung der Nitrotyrosinfärbungen wurden je 
abgebildeter Myotube drei Punkte zufällig ausgewählt und die Signaldichte auf den Hintergrundwert normalisiert.

\subsubsection{Statistische Analysen}

Die Daten in dieser Arbeit sind als arithmetische Mittelwerte mit Standardfehler (SEM) dargestellt. Die statistische Analyse erfolgte mithilfe von Microsoft Excel und GraphPad Prism mittels der einfaktoriellen ANOVA mit Bonferroni's Multiple Comparison Test, der zweifaktoriellen ANOVA mit Bonferroni's Post Test und des Student's t-Tests (unverbunden, zweiseitig). Für die statistische Analyse wurde von einer Irrtumswahrscheinlich von 5\% ausgegangen. Signifikante Unterschiede $(p<0,05)$ im Vergleich zur Kontrolle wurden durch einen Stern $\left(^{*}\right)$ gekennzeichnet. Die graphische Darstellung der Daten erfolgte mittels GraphPad Prism. 


\section{Ergebnisse}

\subsection{Morphologische und funktionelle Eigenschaften von Engineered}

Skeletal Muscle

ESM ähneln nach 15 Tagen Inkubationszeit morphologisch dem typischen quergestreiften Skelettmuskelsynzytium (Abb. 2). Die in dieser Arbeit verwendeten Kontroll-ESM entwickelten in den Messungen bei tetanischer Stimulation (80 Hertz, $200 \mathrm{~mA})$ im Durchschnitt absolute Kraftwerte von 1,7 $\pm 0,1 \mathrm{mN}(\mathrm{n}=49)$. Eine beispielhafte Messung ist in Abb. 2 B dargestellt.

A

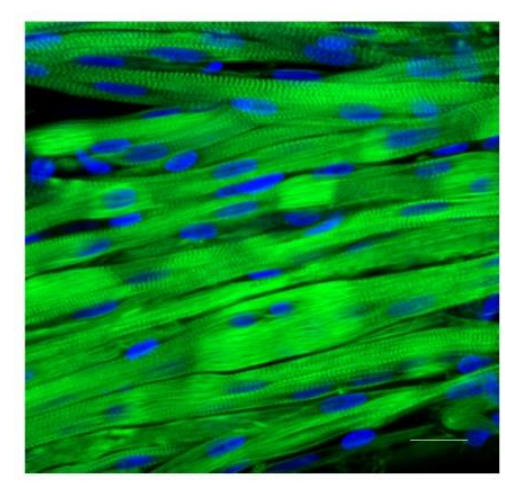

B

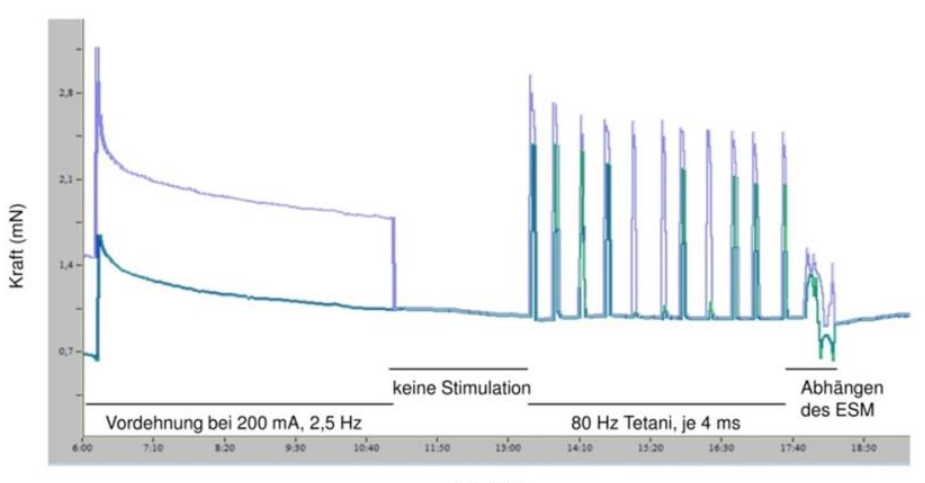

Zeit (Min)

\section{Abbildung 2: Morphologie und Funktion der ESM.}

A: Immunfluoreszenz-Analyse eines 15 Tage alten ESM. Nuclei in blau und f-Aktin in grün, Maßstab: $20 \mu \mathrm{m}$.

B: Aufzeichnung eines isometrischen Kontraktionsexperiments zur Überprüfung der Erschöpfung von ESM. Repräsentative Messung der tetanischen Kraftentwicklung eines unbehandelten Kontroll-ESM nach Vorspannung. Sichtbare leichte Abnahme der maximalen Kraft nach mehreren Tetani. 


\subsection{Effekt von Cerivastatin auf die Kontraktionskraft von Engineered Skeletal Muscle}

Die These, dass Cerivastatin in dem hier angewandten Skelettmuskelmodell zu einem Verlust der Kraftentwicklung führt, konnte durch Messungen der Kontraktionskraft in ESM bestätigt werden. ESM wurden 5 Tage mit Cerivastatin in den Konzentrationen 0,01 $\mu \mathrm{mol} / \mathrm{l}, 0,1 \mu \mathrm{mol} / \mathrm{l}$ und $1 \mu \mathrm{mol} / \mathrm{l}$ sowie Vehikel $(0,02 \%$ DMSO) behandelt. Es zeigte sich eine konzentrationsabhängige Abnahme der tetanischen Kraftentwicklung im Vergleich zur Kontrolle. Während die Kraft bei 0,01 $\mu \mathrm{mol} / \mathrm{l}$ Cerivastatin auf $76 \pm 3 \%$ und bei $0,1 \mu \mathrm{mol} / \mathrm{l}$ Cerivastatin auf $40 \pm 5 \%$ der Kontrolle abnahm, konnten in mit $1 \mu \mathrm{mol} / /$ Cerivastatin behandelten ESM nicht verlässlich tetanische Kontraktionen ausgelöst werden. Die mittlere effektive Konzentration, das heißt, die Konzentration, bei der die Kraftentwicklung halbmaximal im Vergleich zur Kontrolle war, lag bei 0,06 $\pm 0,01 \mu \mathrm{mol} / \mathrm{l}$ Cerivastatin (Abb. 3 A).

Bei der Überprüfung der ESM-Ermüdbarkeit durch Abfolgen von 10 tetanischen Kontraktionen zeigten die mit Cerivastatin behandelten ESM konzentrationsabhängig eine zunehmende Abnahme der Kontraktionskraft im Vergleich zur Kontrollgruppe (Abb. 3 B).

A

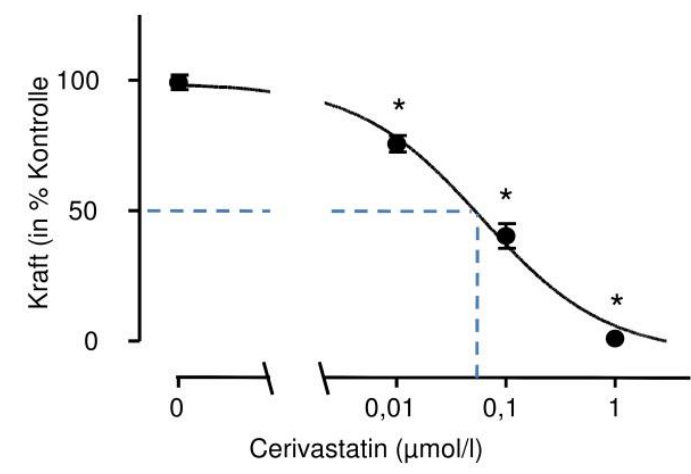

B

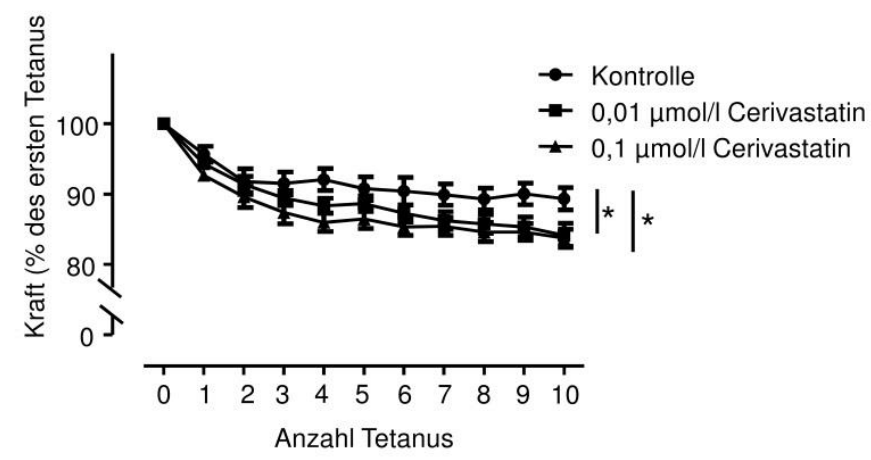

Abbildung 3: Analyse des Kraftverlusts in ESM unter chronischer Cerivastatinbehandlung.

A: Dargestellt ist die tetanische Kraft in \% zur Kontrolle ( $n=15),{ }^{*} p<0,05$ bezogen auf die Kontrolle (einfaktorielle Varianzanalyse, Bonferroni's Multiple Comparison Test).

B: Dargestellt ist die maximale Kraft unter zehn aufeinander folgenden tetanischen Stimulationen in \% des ersten Tetanus (0) $(n=14 / 13 / 9)$. Die Kraftabnahme mit 
zunehmender Anzahl der vorangegangenen Tetani ist signifikant höher bei den Cerivastatinbehandelten ESM als bei der Kontrolle, ${ }^{*} p<0,05$ für $0,01 \mu \mathrm{mol} / /$ und 0,1 $\mu \mathrm{mol} / \mathrm{l}$ Cerivastatin im Vergleich zur Kontrolle (zweifaktorielle Varianzanalyse, Bonferroni's Post Test).

\subsection{Expression der NO-Synthasen im Skelettmuskel und im Engineered Skeletal Muscle}

Um die Rolle der NOS für die Statin-induzierte Kraftabnahme im ESM zu untersuchen, wurde zunächst die Expression der NO-Synthasen auf RNA- und Proteinebene im Vergleich zur quergestreiften Skelettmuskulatur neonataler (Alter 02 Tage) Ratten untersucht. In der qRT-PCR zeigte sich, dass nNOS und eNOS ungefähr gleich stark, jedoch auf niedrigem Niveau, exprimiert sind (nNOS 0,52 \pm $0,08 \times 10^{-3} \quad[\mathrm{n}=6]$ und eNOS $0,71 \pm 0,1 \times 10^{-3} \quad[\mathrm{n}=6]$ Transkripte/GAPDHTranskriptmenge), während die RNA-Expression der iNOS insgesamt deutlich niedriger war $\left(0,08 \pm 0,008 \times 10^{-3}[n=6]\right.$ Transkript/GAPDH-Transkriptmenge, Abb. 4 A). Im Vergleich zeigte sich in der qRT-PCR aus unbehandelten ESM eine höhere Expression der iNOS $\left(0,4 \pm 0,06 \times 10^{-3}\right.$ [n=16] Transkript/GAPDH-Transkriptmenge) sowie eine deutlich niedrigere Expression der nNOS und eNOS (nNOS 0,02 \pm $0,003 \times 10^{-3}[n=12]$ und eNOS $0,04 \pm 0,006 \times 10^{-3} \quad[n=12]$ Transkript/GAPDHTranskriptmenge, Abb. 4 B).

A

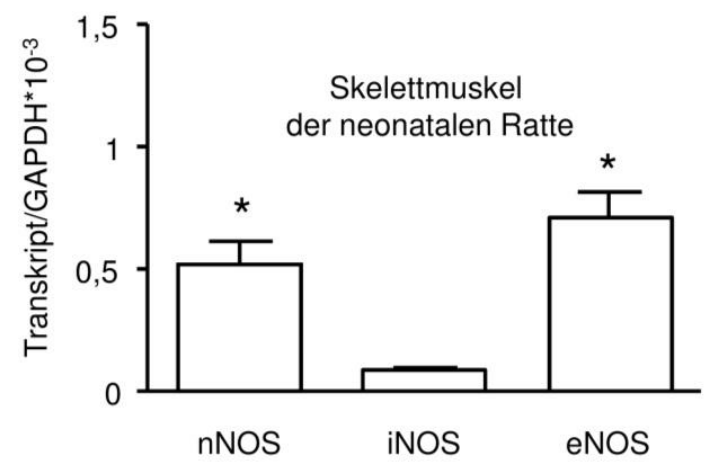

B

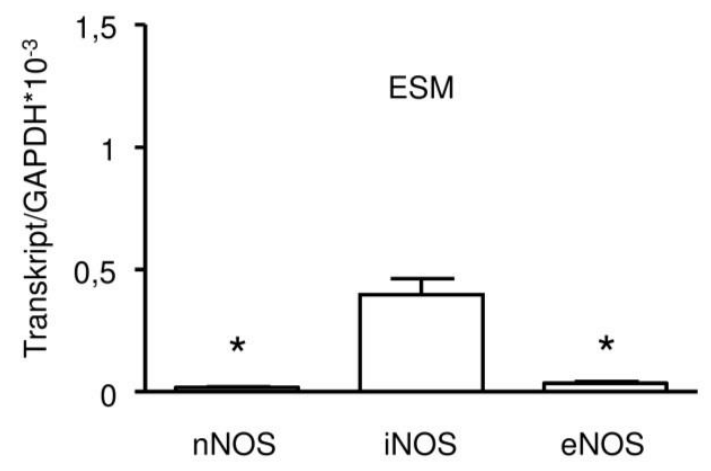

Abbildung 4: Vergleich der Genexpression von nNOS, iNOS und eNOS im Skelettmuskel der neonatalen Ratte (A) und im ESM (B). 
A: Skelettmuskel neonataler (Alter 0-2 Tage) Ratten ( $n=6 / 6 / 6)$; B: ESM-Kontrollen $(n=12 / 16 / 12)$. Auf den Ordinaten ist die auf GAPDH normalisierte Transkriptmenge der auf der Abszisse gekennzeichneten NO-Synthase-Isoform dargestellt. ${ }^{*} \mathrm{p}<0,05$ (einfaktorielle Varianzanalyse, Bonferroni's Multiple Comparison Test).

Desweiteren erfolgte die Analyse der Proteinexpression mittels Western Blot. Zur Validierung der Antikörper wurde neonataler und adulter Skelettmuskel untersucht. Als Positivkontrolle der neuronalen Isoform der NO-Synthase, nNOS, wurde das Homogenisat von Mäusegehirn eingesetzt (Abb. 5 A). Die iNOS wurde im Skelettmuskel nicht exprimiert, konnte aber durch 24-stündige Behandlung von ESM mit bakteriellem Lipopolysaccharid (LPS) induziert werden (Abb. 5 B). In unbehandelten ESM war die im Skeletmuskel voherrschende nNOS die am stärksten exprimierte NO-Synthase-Isoform (Abb. 6 A, B).

A

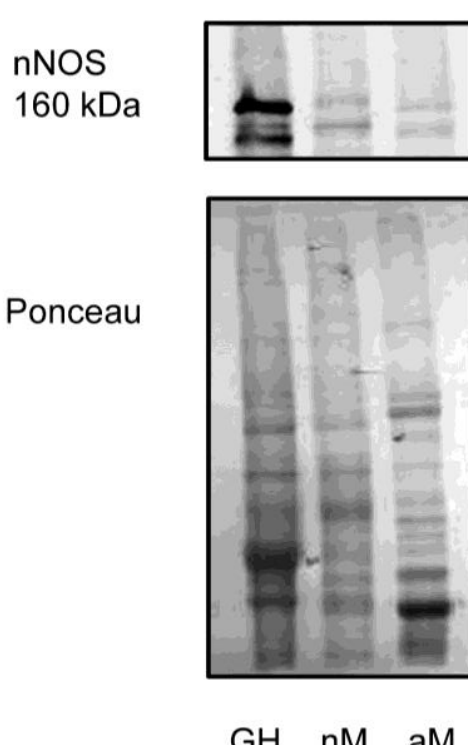

B

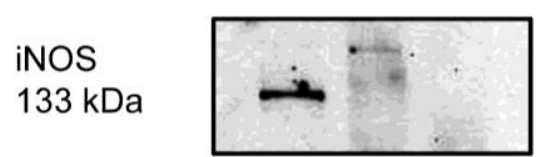

Ponceau

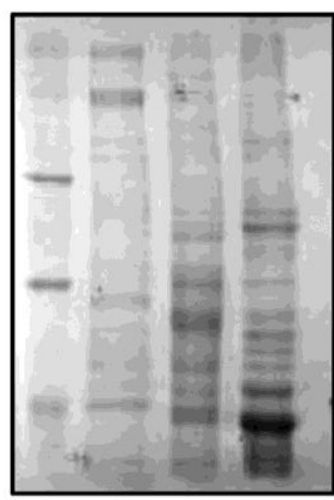

LPS nM aM

\section{Abbildung 5: Proteinexpression der nNOS und iNOS im Skelettmuskel.}

A: nNOS-Expression im Skelettmuskel neonataler (Alter 0-2 Tage, nM) und adulter (Alter 3-6 Monate, aM) Ratten (obere Bande).

B: iNOS-Expression im Skelettmuskel neonataler und adulter Ratten.

Aufgetragen wurden als nNOS-Positivkontrolle murines Gehirnhomogenat (GH), als iNOS-Positivkontrolle das Lysat von ESM nach 24-stündiger Behandlung mit Lipopolysaccharid (LPS) und Lysate aus der Skelettmuskulatur neonataler Ratten (nM) sowie adulter Ratten (aM). 
A

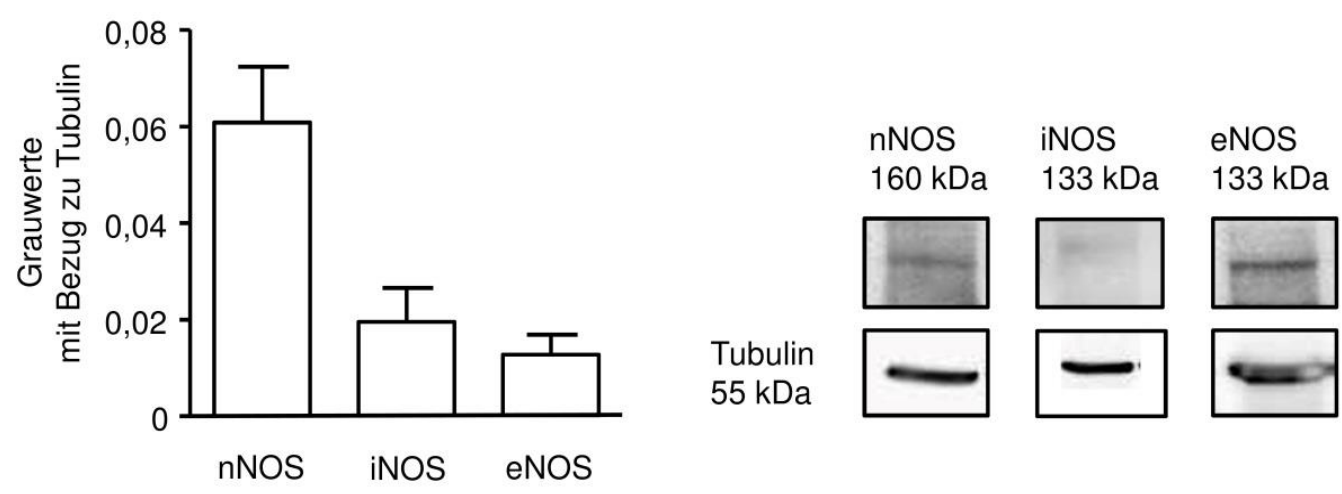

Abbildung 6: Quantifizierung der Proteinexpression der drei NO-SynthaseIsoformen in 15 Tage alten ESM.

A: Darstellung der auf Tubulin normalisierten absoluten Expression. Die Werte sind Mittelwerte + SEM $(n=3 / 8 / 4)$.

B: Repräsentative Western Blots.

3.4 Cerivastatin-Behandlung induziert die iNOS, aber nicht die nNOS und eNOS

Um untersuchen zu können, ob die Cerivastatin-abhängige Abnahme der Kontraktilität mit einer Änderung der Protein- und RNA-Expression der NOSynthasen einhergeht, wurden quantitative RT-PCR-Analysen und Western Blots durchgeführt. Darin zeigte sich eine Zunahme der iNOS-Expression in Abhängigkeit von der Cerivastatinkonzentration (Abb. $7 \mathrm{~A}$ ), während die Expression der eNOS und nNOS nicht verändert war (Abb. $7 \mathrm{~B}, \mathrm{C}$ ). Die Induktion der iNOS konnte auf Proteinebene verifiziert werden (Abb. 8). 
A
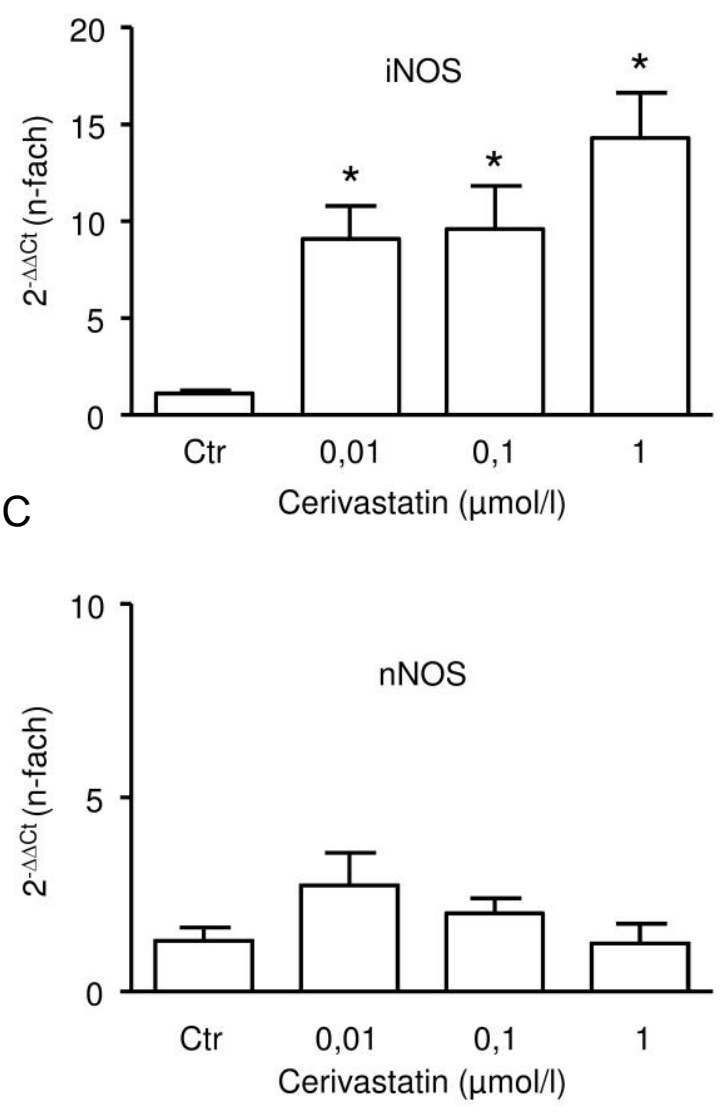

B

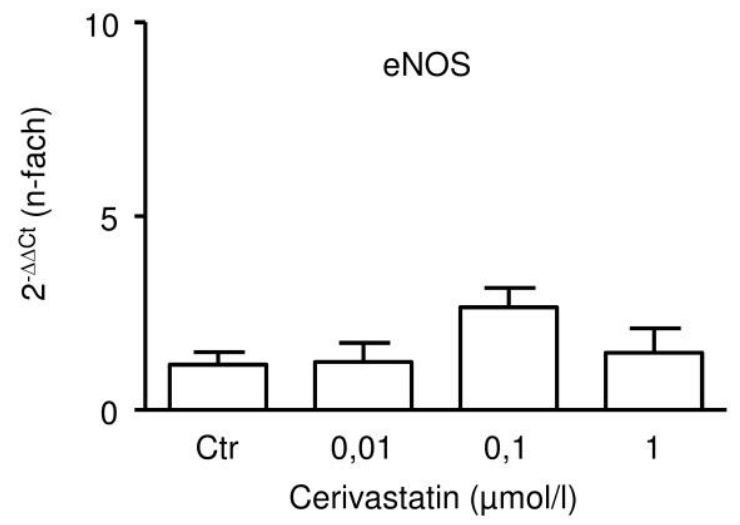

Abbildung 7: RNA-Expression der NO-Synthasen unter Cerivastatinbehandlung. Auf den Ordinaten ist der relative Unterschied der oben gekennzeichneten NO-Synthase-Isoform mit Bezug zu der unstimulierten Vehikelkontrolle (Ctr) dargestellt. Die Analyse erfolgte per qRT-PCR.

A: iNOS-RNA ( $n=10 / 10 / 10 / 10),{ }^{*} p<0,05$ bezogen auf die Kontrolle (einfaktorielle Varianzanalyse, Bonferroni's Multiple Comparison Test).

B: eNOS-RNA ( $n=10 / 10 / 9 / 10)$; C: $n N O S-R N A(n=4 / 4 / 3 / 4)$ 
A

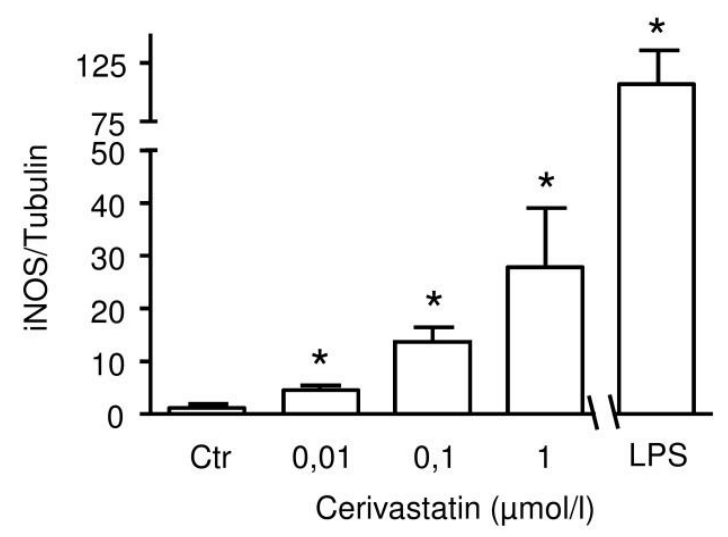

B

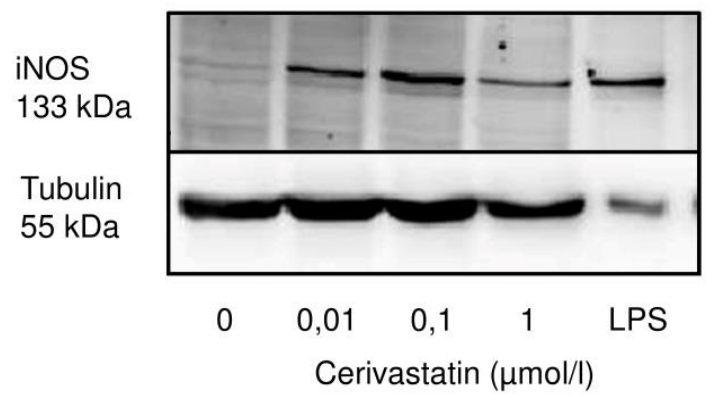

Abbildung 8: Proteinexpression von iNOS in ESM unter Cerivastatinbehandlung.

A: iNOS-Proteinexpression in mit Cerivastatin behandelten ESM. Dargestellt ist auf der Ordinate die auf Tubulin normalisierte relative iNOS-Expression unter der auf der Abszisse gekennzeichneten Cerivastatinkonzentration ( $n=7 / 7 / 7 / 7 / 5), \quad{ }^{*} p<0,05$ (Student's t-Test).

B: Repräsentativer Western Blot. Als Positivkontrolle wurde das Lysat eines ESM nach 24-stündiger Behandlung mit LPS zur iNOS-Induktion für $24 \mathrm{~h}$ aufgetragen.

\subsection{Vasodilatator-stimuliertes Phosphoprotein in Cerivastatin- geschädigtem Engineered Skeletal Muscle}

Um zu untersuchen, ob die Cerivastatin-Behandlung und iNOS-Induktion mit einer vermehrten NO-Produktion in ESM einhergehen, wurden unterschiedliche Methoden getestet. Nitrat oder Nitrit konnten im Medium aufgrund zu geringer Konzentrationen und der geringen Halbwertzeit von NO nicht detektiert werden. Da das Vasodilatatorstimulierte Phosphoprotein (VASP) NO-abhängig über cGMP und PKG phosphoryliert wird (Smolenski et al. 1998), eignet es sich als Surrogatparameter für NO. Cerivastatin behandelte ESM zeigten im Western Blot eine nicht signifikante Tendenz zu vermehrter VASP-Phosphorylierung bei 0,01 und $0,1 \mu \mathrm{mol} / \mathrm{l}$ Cerivastatin (Abb. 9), was eine vermehrte NO-Produktion unter Statingabe nahelegt. 

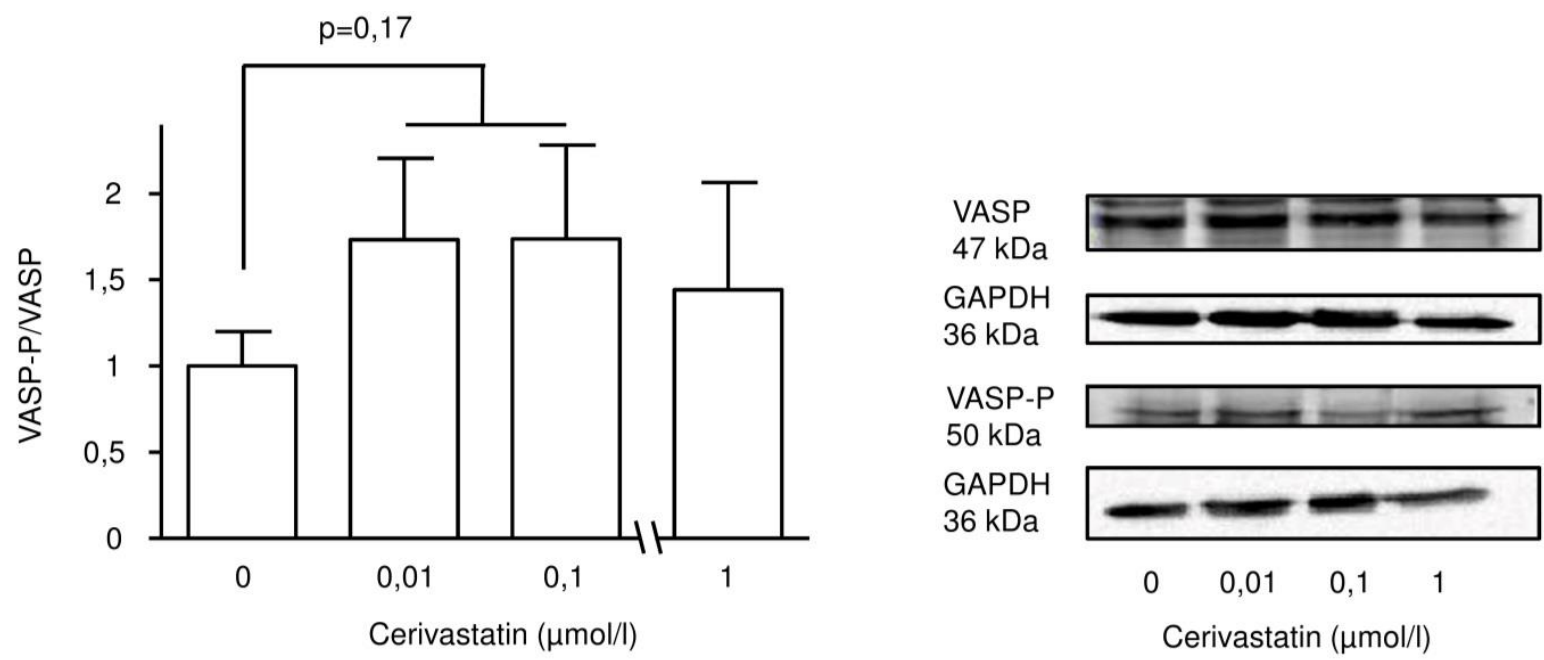

Abbildung 9: VASP-Phosphorylierung unter Cerivastatin.

A: Auf der Ordinate ist die auf GAPDH normalisierte relative Phosphorylierung ( $n=3 / 3 / 3 / 3$ unter verschiedenen Cerivastatinkonzentrationen (Abszisse) dargestellt.

B: VASP- bzw. VASP-P-Expression in ESM nach fünftägiger Cerivastatinbehandlung. Repräsentativer Western Blot.

\subsection{Kraftverlust und iNOS-Induktion sind HMG-CoA-Reduktase-abhängig}

Statine hemmen die HMG-CoA-Reduktase und damit die enzymatische Umwandlung von HMG-CoA zu Mevalonat. Mevalonat wird dann über weitere Zwischenstufen über Farnesyl-PP zu Cholsterin metabolisiert. Außerdem entstehen aus Mevalonat Zwischenprodukte wie Geranyl-Geranyl-Pyrophosphat, das eine wichtige Rolle in der Geranylierung von Proteinen spielt, aber nicht als Vorstufe für Cholesterin dient. 


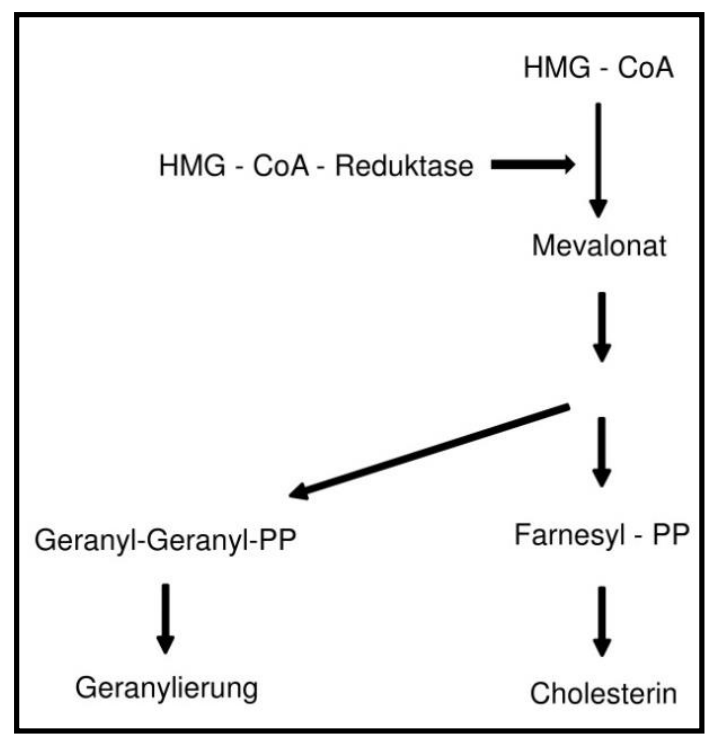

Abbildung 10: Vereinfachte Darstellung der Cholesterinbiosynthese: Mevalonat und Farnesyl-PP sind direkte Vorläufermoleküle des Cholesterins, Geranyl-GeranylPP ein wichtiges Nebenprodukt.

Um zu überprüfen, ob der nach Cerivastatinbehandlung auftretende Verlust der tetanischen Kraftentwicklung der ESM von der Hemmung der HMG-CoA-Reduktase abhängig ist und nicht von einem davon unabhängigen Nebeneffekt der Statine, wurden ESM zusätzlich zu 0,01 $\mu \mathrm{mol} / \mathrm{l}$ Cerivastatin fünf Tage mit den Zwischenprodukten der Cholesterinsynthese Mevalonat (100 $\mu \mathrm{mol} / \mathrm{l})$ und FarnesylPyrophosphat $(10 \mu \mathrm{mol} / \mathrm{l})$ behandelt. Außerdem wurden ESM mit dem Nebenprodukt Geranyl-Geranyl-Pyrophosphat, das für die post-translationale Modifikation von Proteinen notwendig ist, behandelt (10 $\mu \mathrm{mol} / \mathrm{l}$, Abb. 10). ESM, die sowohl mit Cerivastatin als auch mit Mevalonat bzw. Geranyl-Geranyl-Pyrophosphat behandelt wurden, zeigten keinen Kraftverlust im Kontraktionsexperiment, was entweder als eine vollständige Reversibilität des Kraftverlusts oder als Schutz vor der Cerivastatinwirkung verstanden werden kann. Die mit $10 \mu \mathrm{mol} / \mathrm{l}$ FarnesylPyrophosphat behandelten ESM entwickelten ebenfalls eine höhere tetanische Kraft als diejenigen ESM, die lediglich mit 0,01 $\mu \mathrm{mol} / /$ Cerivastatin behandelt wurden (Abb. 11 A). Dieser Effekt war jedoch nicht signifikant. Die Behandlung nur mit den Vorläufermolekülen selbst hatte keinen Einfluss auf die tetanische Kraftentwicklung der ESM (Abb. 11 B). 


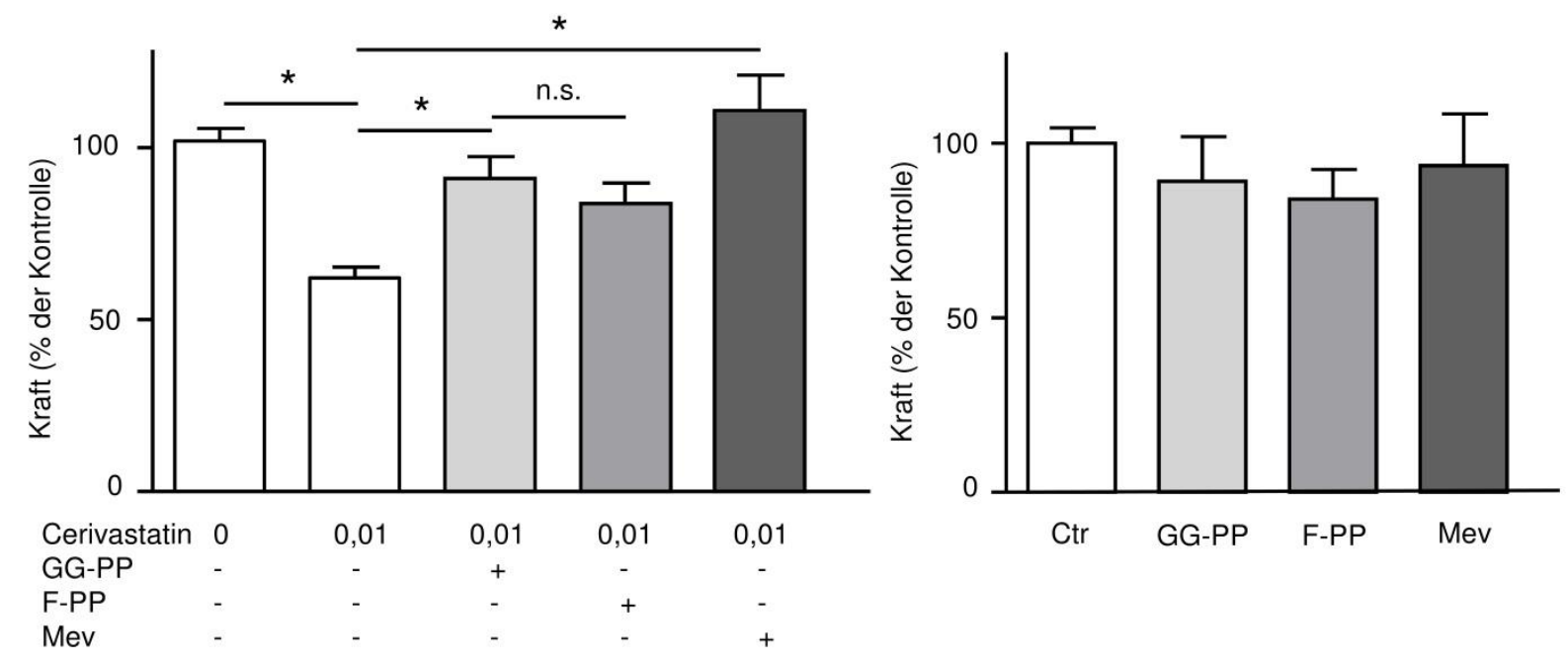

Abbildung 11: Analyse der HMG-CoA-Reduktase-Abhängigkeit des Cerivastatin-induzierten Kraftverlusts.

A: Minderung der Statinmyopathie in ESM, die mit Cerivastatin und den Cholesterinvorläufern Geranyl-Geranyl-Pyrophosphat (GG-PP), FarnesylPyrophosphat (F-PP) und Mevalonat (Mev) behandelt wurden. Auf der Ordinate dargestellt ist die maximale tetanische Kraft; auf der Abszisse die Behandlung $(n=37 / 32 / 27 / 30 / 21), \quad{ }^{*} p<0,05$ (einfaktorielle Varianzanalyse, Bonferroni's Multiple Comparison Test).

B: Einfluss der Cholesterinsynthesevorstufen auf die Kontraktionskraft der ESM. Dargestellt ist die maximale tetanische Kraft in \% der Vehikelkontrolle $(n=16 / 4 / 4 / 6)$; es zeigte sich kein signifikanter Unterschied zwischen den Gruppen.

Diese Versuchsserie verdeutlichte, dass die Statin-induzierte Kraftreduktion in ESM HMG-CoA-Reduktase-abhängig ist. Um zu überprüfen, ob auch die iNOS-Induktion anhängig von der HMG-CoA-Reduktase ist, wurde ebenfalls die iNOS-Expression gemessen. Dabei zeigte sich, dass auch der unter Cerivastatin beobachtete Anstieg der iNOS durch Farnesyl-Pyrophosphat, Geranyl-Geranyl-Pyrophosphat und Mevalonat antagonisiert werden konnte: Es zeigte sich in diesen ESM eine annähernd so geringe iNOS-Expression wie in den Kontroll-ESM ohne Cerivastatinbehandlung. Jedoch ist der Unterschied zwischen den ESM, die nur mit Cerivastatin behandelt wurden, und denen, die Cerivastatin und zusätzlich FarnesylPyrophosphat, Geranyl-Geranyl-Pyrophosphat oder Mevalonat erhielten, statistisch nicht signifikant (Abb. 12). 
A

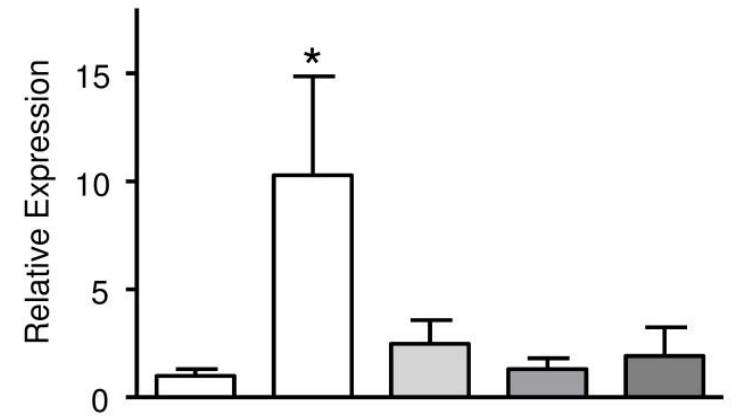

Cerivastatin $0 \quad 0,01 \quad 0,01 \quad 0,01 \quad 0,01$ GG-PP

F-PP

Mev
B

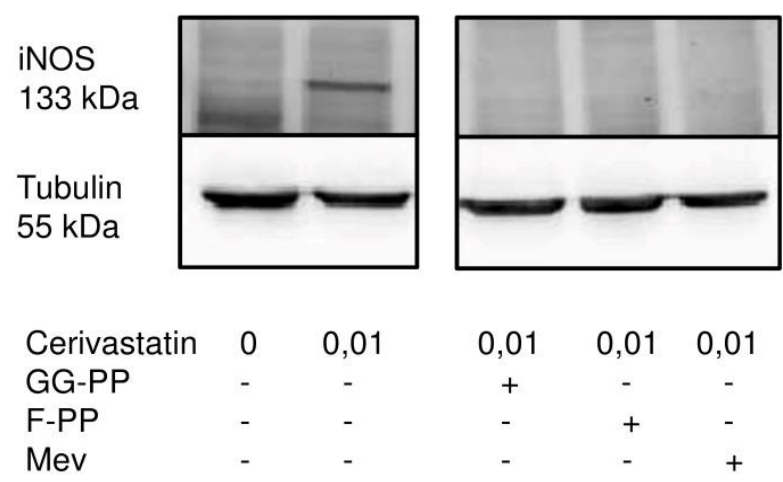

Abbildung 12: Analyse der iNOS-Proteinexpression unter Cerivastatin und Cholesterin-Vorläufermolekülen.

A: Quantifizierung der iNOS-Proteinexpression im Western Blot. Auf der Ordinate ist die auf Tubulin normalisierte relative iNOS-Proteinexpression unter der Behandlung mit den auf der Abszisse gekennzeichneten Substanzen dargestellt $(n=9 / 8 / 4 / 4 / 4)$, ${ }^{*} p<0,05$ bezogen auf die Kontrolle (Student's $\left.t-T e s t\right)$.

B: iNOS-Proteinexpression in ESM, die zusätzlich zur Cerivastatinbehandlung Cholesterinvorstufen erhielten: $10 \mu \mathrm{mol} / /$ Geranyl-Geranyl-Pyrophosphat (GG-PP), $10 \mu \mathrm{mol} / \mathrm{l}$ Farnesyl-Pyrophosphat (F-PP) oder $100 \mu \mathrm{mol} / \mathrm{l}$ Mevalonat (Mev). Repräsentativer Blot.

3.7 Die funktionelle Rolle der iNOS für die Statin-induzierte Toxizität

Um zu prüfen, ob die gesteigerte Expression der iNOS ursächlich für die Cerivastatin-abhängige Kraftreduktion (im weiteren Sinne die Statinmyopathie) sein könnte, wurden ESM zusätzlich zu Cerivastatin mit dem spezifischen iNOS-Inhibitor 1400W behandelt. Die verwendete Konzentration von $5 \mu \mathrm{mol} / \mathrm{l}$ konnte im Medium von 2D-Kultur-Myozyten eine Hemmung der NO-Synthese bewirken (Anhang 6.2), jedoch zeigte sich keine Änderung der tetanischen Kraft unter der 1400WBehandlung (Abb. $13 \mathrm{~A}$ ). Eine möglicherweise kompensatorische iNOS-Induktion konnte mittels Western Blot nicht bestätigt werden (Abb. 13 B). 
A

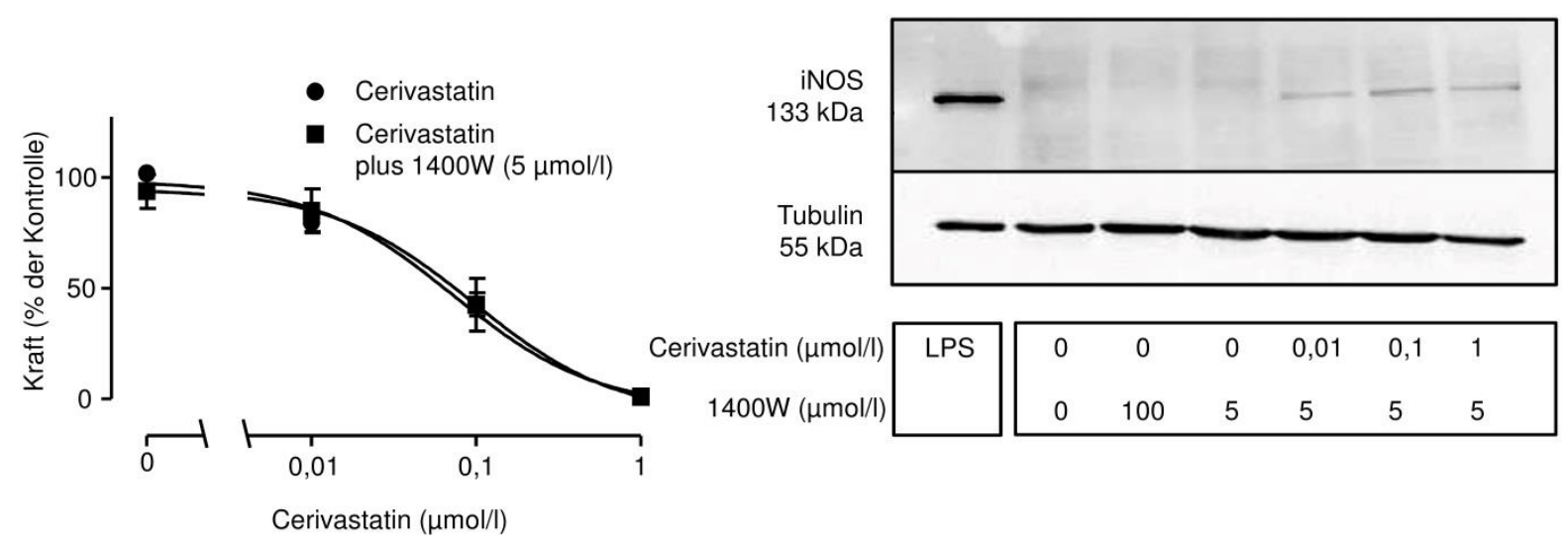

Abbildung 13: Kraftentwicklung und iNOS-Expression unter 1400W.

A: Die spezifische iNOS-Inhibition mit $5 \mu \mathrm{mol} / \mathrm{l} 1400 \mathrm{~W}$ zeigte keinen Einfluss auf die Cerivastatin-induzierte Myopathie: Dargestellt ist die maximale tetanische Kraft von ESM nach fünftägiger Behandlung mit Cerivastatin $\pm 5 \mu \mathrm{mol} / / 1400 \mathrm{~W}$ ( $\mathrm{n}=$ 21/21/14/14; 14/19/15/9/9).

B: Vergleich der iNOS-Expression in mit Cerivastatin $\pm 5 \mu \mathrm{mol} / \mathrm{l} 1400 \mathrm{~W}$ behandelten ESM. Aufgetragen wurden Proteinlysate von ESM nach fünftägiger Behandlung mit Cerivastatin \pm 1400W (bzw. 24 h mit LPS). Repräsentativer Western Blot.

\subsection{Vergleich der tetanischen Kraftentwicklung zwischen Wildtyp- und iNOS-Knockout-ESM}

Der Einfluss der iNOS auf die Kraftentwicklung der ESM wurde auch mithilfe von Knockout-Mäusen (iNOS-/-) untersucht. Insgesamt war die absolute Kraftentwicklung von ESM aus murinen Myoblasten ähnlich wie die von ESM aus Myoblasten neonataler (Alter 0-2 Tage) Ratten: Wildtyp-ESM aus Mäusemyoblasten erreichten eine maximale tetanische Kraft von 1,4 $\pm 0,2 \mathrm{mN}(\mathrm{n}=7)$, ESM aus Rattenmyoblasten von 1,7 $\pm 0,1 \mathrm{mN}(\mathrm{n}=50)$. Die iNOS-KO-ESM waren mit einer Kraft von 0,6 $\pm 0,2 \mathrm{mN}$ $(n=4)$ deutlich schwächer als die Wildtyp-ESM (Abb. 14 A).

Im Vergleich Cerivastatin-behandelter iNOS-Knockout-ESM und Cerivastatinbehandelten Wildtyp-ESM fand sich allerdings kein Unterschied in der Statintoxizität. In beiden ESM war die Kraftminderung ungefähr gleich stark ausgeprägt (Abb. 14 B). Die halbmaximale Cerivastatinkonzentration der WT-ESM lag bei 0,05 $\mu \mathrm{mol} / \mathrm{l}$, der Knockout-ESM bei $0,06 \mu \mathrm{mol} / / \mathrm{l}$ Cerivastatin. 
A

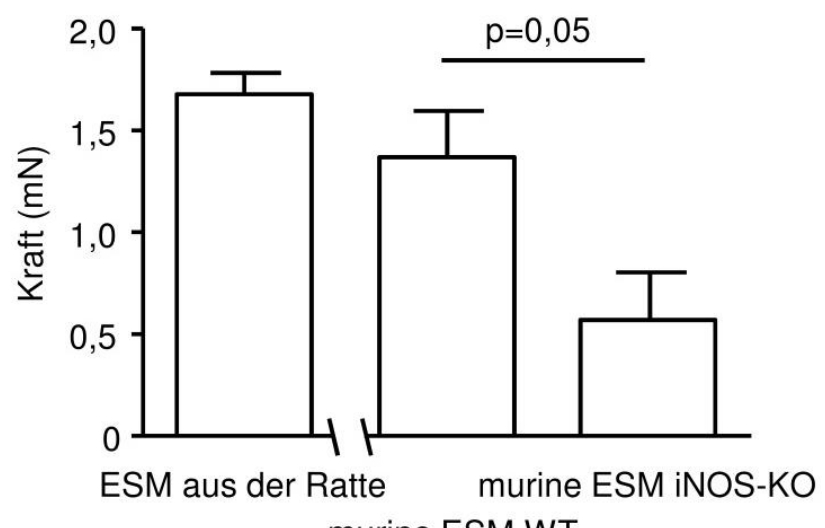

B

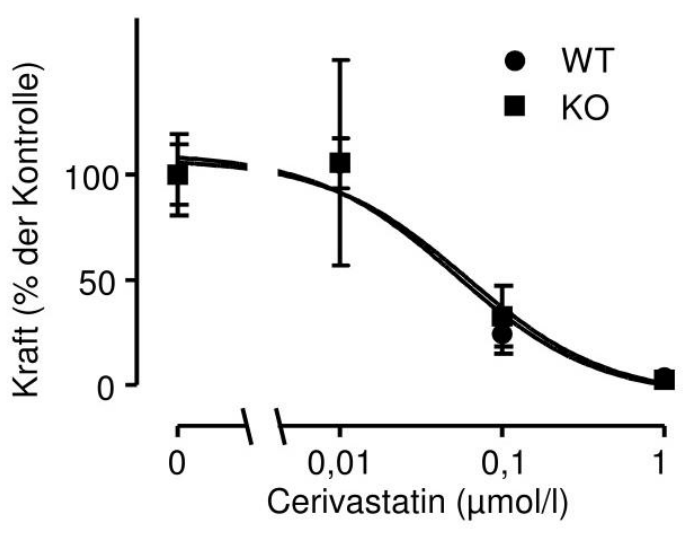

\section{Abbildung 14: Kraftentwicklung in iNOS-KO-ESM unter Cerivastatin.}

A: Vergleich der absoluten Kraft (Ordinate) der verschiedenen, auf der Abszisse gekennzeichneten ESM-Typen ( $n=49 / 7 / 4$, Student's $t-T e s t)$.

B: Analyse der Kraftentwicklung von Cerivastatin-behandelten WT-ESM und iNOSKO-ESM $(n=9 / 8 / 7 / 8 ; 5 / 3 / 5 / 5)$.

Diese Untersuchungen bestätigen einerseits, dass die iNOS-Funktion keine Rolle bei der Cerivastatin-vermittelten Toxizität spielt; zeigen auf der anderen Seite aber, dass die iNOS für die grundsätzliche Muskelfunktion von Bedeutung ist.

\subsection{Die Statintoxizität in Engineered Skeletal Muscle bei gleichzeitiger Behandlung mit L-NAME, SNP und NOC-12}

Da die spezifische iNOS-Hemmung mittels 1400W und iNOS-Knockout in dieser Arbeit keinen Effekt auf die Statinmyopathie der ESM zeigte, wurde außerdem der unspezifische NO-Synthase-Inhibitor L-NAME in einer Konzentration von $10 \mathrm{mmol} / \mathrm{l}$ verwendet, um die mögliche Rolle der anderen NO Isoformen und grundsätzlich der NO-Bildung für die Muskelfunktion unter Statingabe zu testen. Die unspezifische Blockade der NO-Synthasen und NO-Produktion durch L-NAME zeigte ebenfalls keinen protektiven Effekt, sondern im Gegenteil tendenziell eine Verschlechterung der maximalen tetanischen Kraft der mit 0,01 $\mu \mathrm{mol} / / \mathrm{bzw} .0,1 \mu \mathrm{mol} / /$ Cerivastatin behandelten ESM und der ESM, die mit Cerivastatin $(0,01 \mu \mathrm{mol} / \mathrm{I}$ und $0,1 \mu \mathrm{mol} / \mathrm{l})$ und $10 \mathrm{mmol} / \mathrm{l}$ L-NAME gleichzeitig behandelt wurden. Die mittlere Kraft bezogen auf die Kontrolle lag für $0,01 \mu \mathrm{mol} / \mathrm{l}$ Cerivastatin bei $85 \pm 5 \%$ und für $0,1 \mu \mathrm{mol} / \mathrm{l}$ Cerivastatin 
bei $54 \pm 5 \%$ der Kontrolle; bei zusätzlicher Behandlung mit L-NAME bei $65 \pm 3 \%$ für $0,01 \mu \mathrm{mol} / / \mathrm{l}$ Cerivastatin und bei $33 \pm 4 \%$ für $0,1 \mu \mathrm{mol} / \mathrm{l}$ Cerivastatin (Abb. $15 \mathrm{~A}, \mathrm{~B}$ ).

A

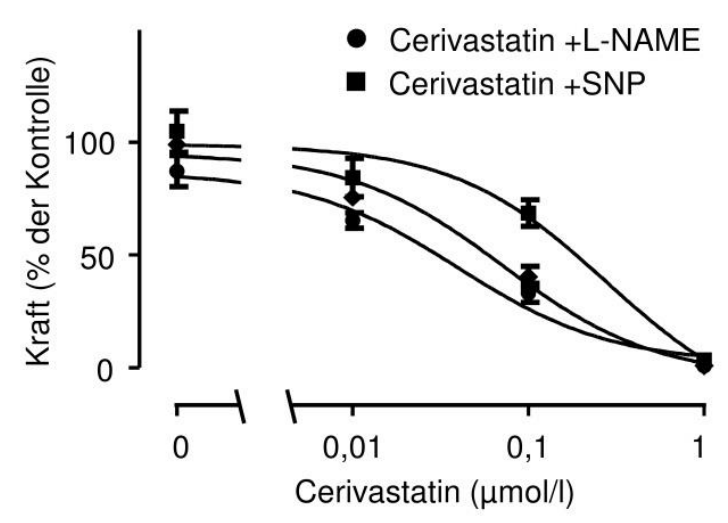

B

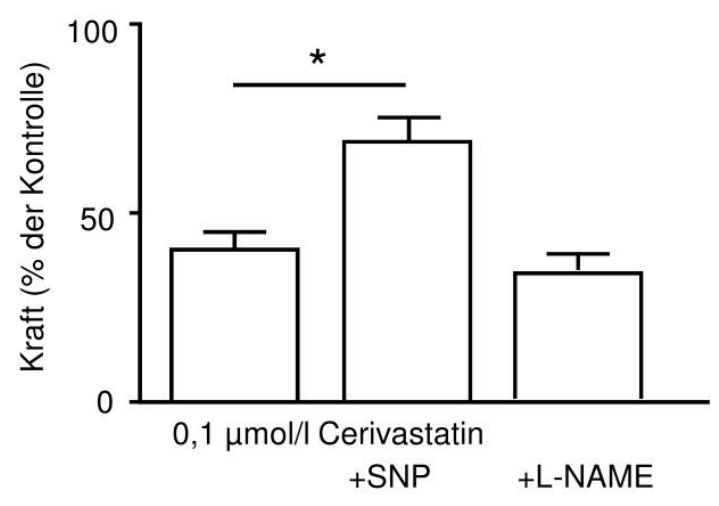

\section{Abbildung 15: Vergleich des Kraftverlusts bei gleichzeitiger B ehandlung mit SNP bzW. L-NAME.}

A: Maximale tetanische Kraftentwicklung von Cerivastatin-geschädigten ESM $\pm 0,1$ $\mu \mathrm{mol} / / \mathrm{SNP}$ beziehungsweise $\pm 10 \mathrm{mmol} / \mathrm{l}$ L-NAME. ( $\mathrm{n}:+\mathrm{SNP}=17 / 12 / 11 / 10 ;+\mathrm{L}-$ NAME=13/12/6/5; Vehikelkontrolle=26/23/14/15).

B: Maximale tetanische Kraftentwicklung von ESM, die mit $0,1 \mu \mathrm{mol} / /$ Cerivastatin und $0,1 \mu \mathrm{mol} / \mathrm{l}$ SNP bzw. $10 \mathrm{mmol} / \mathrm{l}$ L-NAME behandelt wurden $(n=15 / 11 / 6)$. Die Kraftzunahme bei zusätzlicher Behandlung mit SNP ist signifikant im Vergleich zur reinen Cerivastatinbehandlung ( ${ }^{*} p<0,05$, Student's $\left.t-T e s t\right)$.

Als eine andere Ursache für die Expressionssteigerung der iNOS wurde die Annahme überprüft, dieser Anstieg könne auch auf einen relativen NO-Mangel in den durch Cerivastatin geschädigten Myozyten zurückzuführen sein. Mit dieser Hypothese als Grundlage wurden ESM zusätzlich zum Cerivastatin mit dem NODonor Natriumnitroprussid (SNP) behandelt, der als starker Vasodilatator und Reserve-Antihypertensivum bekannt ist. SNP wirkt aufgrund von Zyanidbildung in höheren Konzentrationen zytotoxisch, sodass zunächst ein Kontraktionsexperiment zur Erstellung einer Konzentrationswirkungskurve durchgeführt wurde (Abb. 16). Konzentrationen über $1 \mu \mathrm{mol} / / \mathrm{SNP}$ zeigten eine signifikante Verschlechterung der tetanischen Kraft im Vergleich zur Kontrolle sowie vermehrt Zelldetritus in den Zellkulturschalen. Die halbmaximale toxische Konzentration lag bei 2,2 $\mu \mathrm{mol} / \mathrm{I}$ SNP. 


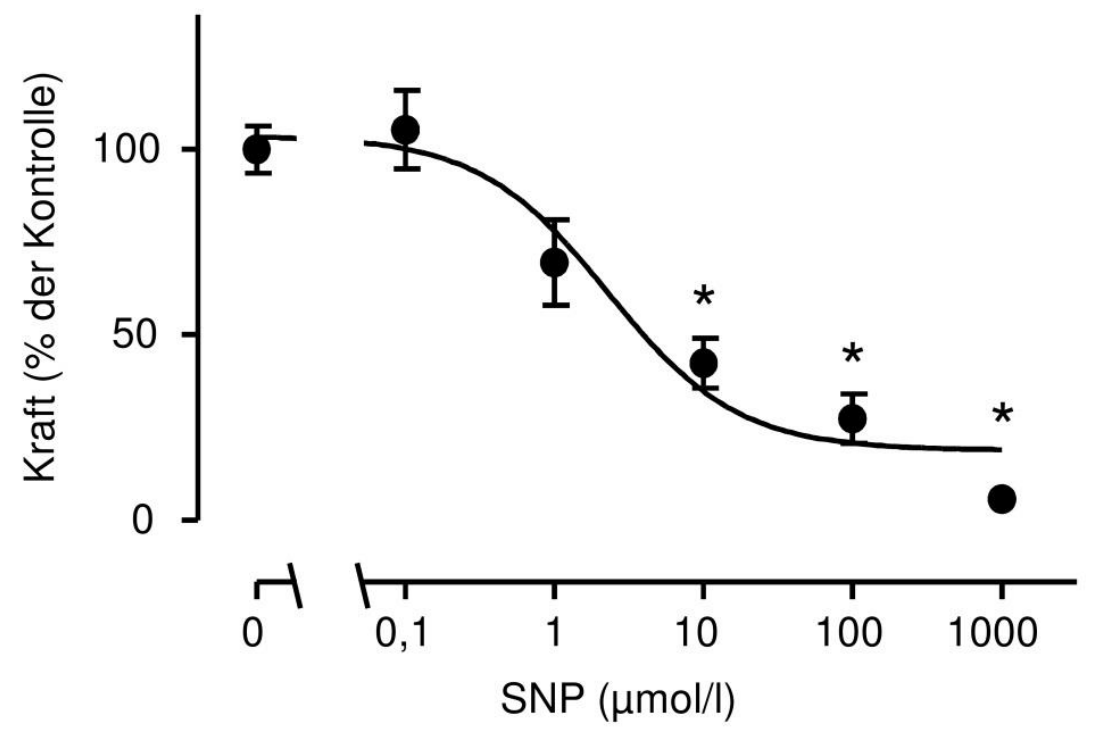

Abbildung 16: Konzentrationswirkungskurve von SNP.

Konzentrationsabhängiger Verlust der tetanischen Kraftentwicklung von ESM nach fünftägiger Behandlung mit SNP. Angegeben ist die maximale Kraft in \% der Kontrolle $(n=13 / 13 / 5 / 5 / 5 / 4), \quad{ }^{*} p<0,05$ bezogen auf die Kontrolle (einfaktorielle Varianzanalyse, Bonferroni's Multiple Comparison Test).

Die Konzentration von 0,1 $\mu \mathrm{mol} / / \mathrm{SNP}$ beeinflusste die tetanische Kraft nicht und wurde für die Behandlung der ESM, die Cerivastatin ausgesetzt waren, verwendet. Vergleicht man die beiden Gruppen, zeigt sich ein signifikanter Unterschied der Kraftentwicklung bei $0,1 \mu \mathrm{mol} / \mathrm{l}$ Cerivastatin: Die zusätzlich mit SNP behandelten ESM entwickelten eine höhere maximale tetanische Kraft als die nur mit Cerivastatin behandelten ESM (Abb. 15 B). Die halbmaximale Cerivastatinkonzentration betrug $0,12 \mu \mathrm{mol} / /$, bei Zugabe von SNP 0,28 $\mu \mathrm{mol} / \mathrm{l}$.

Da die zusätzliche Behandlung mit SNP zu einer Verbesserung der Kraftminderung führte, soll hier die iNOS-Proteinexpression untersucht werden. Es zeigte sich auf den Mittelwert bezogen eine in etwa um die Hälfte reduzierte iNOS-Expression in den zusätzlich mit $0,1 \mu \mathrm{mol} / \mathrm{I}$ SNP behandelten ESM im Vergleich zu den ESM, die lediglich $0,01 \mu \mathrm{mol} / /$ Cerivastatin erhielten. Jedoch war der Unterschied nicht signifikant (Abb. 17). 
A

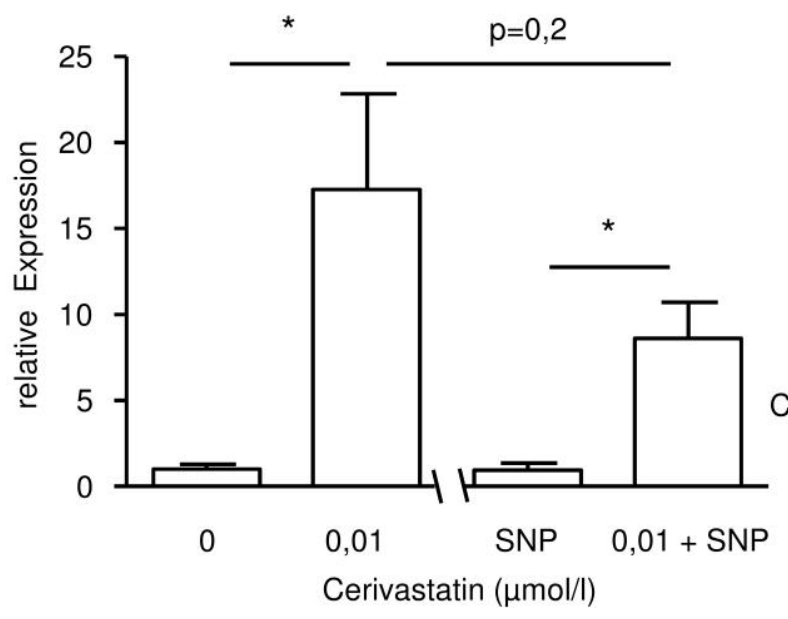

B

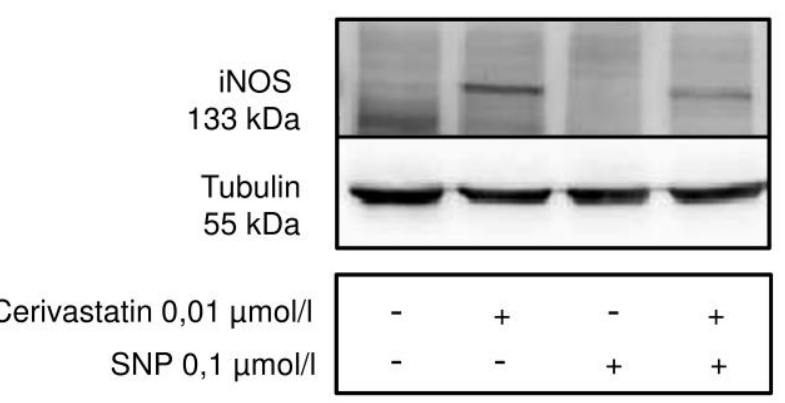

Abbildung 17: Vergleich der iNOS-Expression in ESM nach Behandlung mit Cerivastatin und SNP.

A: Quantifizierung der iNOS-Expression im Western Blot. Dargestellt ist auf der Ordinate die auf Tubulin normalisierte relative iNOS-Expression; auf der Abzsisse ist die jeweilige Behandlung der ESM gekennzeichnet $(n=4 / 4 / 4 / 4), \quad{ }^{*} p<0,05$ (einfaktorielle Varianzanalyse, Bonferroni's Multiple Comparison Test).

B: Repräsentativer Western Blot.

Als weiterer NO-Donor wurde NOC-12 verwendet. ESM, die zusätzlich zu Cerivastatin mit $100 \mu \mathrm{mol} / / \mathrm{NOC}-12$ behandelt wurden, zeigten ebenfalls eine in der Tendenz, aber statistisch nicht signifikant gesteigerte Kraft (Abb. 18). Die halbmaximale Konzentration von Cerivastatin lag bei $0,12 \pm 0,06 \mu \mathrm{mol} / \mathrm{l}$, bei zusätzlicher, gleichzeitiger Behandlung von NOC-12 bei 0,24 $\pm 0,4 \mu \mathrm{mol} / \mathrm{l}$. 


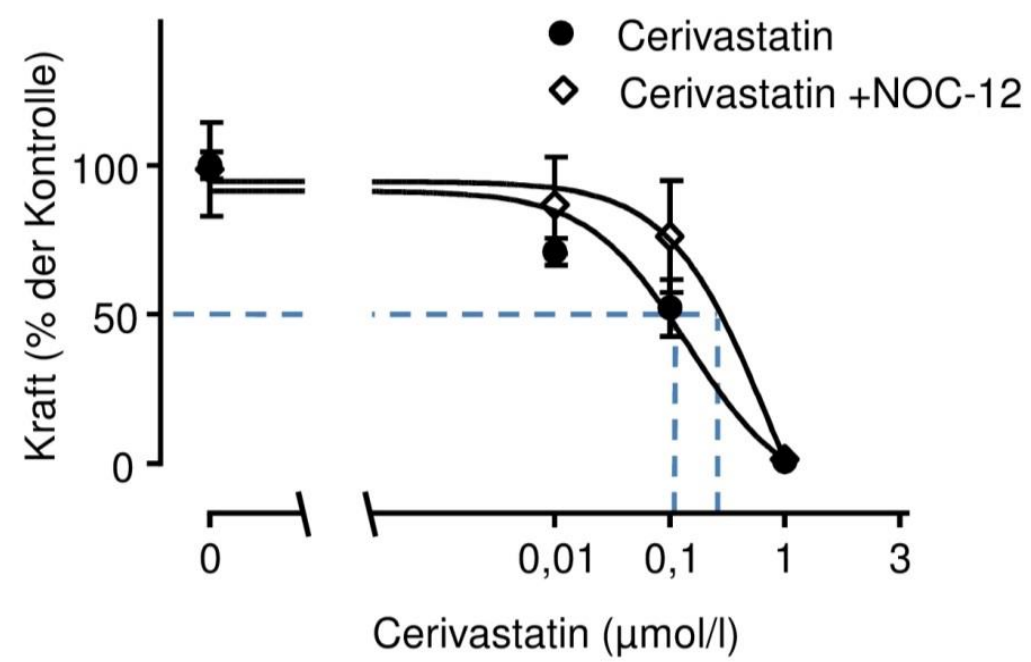

Abbildung 18: Kraftentwicklung unter Cerivastatin und NOC-12. Vergleich der maximalen Kraftentwicklung zwischen ESM, die mit zunehmenden Konzentrationen von Cerivastatin \pm NOC-12 $(100 \mu \mathrm{mol} / \mathrm{l})$ behandelt wurden ( $\mathrm{n}$ : Kontrolle $=6 / 4 / 5 / 5$; + NOC-12=6/5/4/6).

3.10 Vergleich des Einflusses von NCX 6560 und Atorvastatin auf die Kontraktionskraft von Engineered Skeletal Muscle

Neue Studien zeigten, dass NCX 6560, NO-gekoppeltes Atorvastatin, im Vergleich zu Atorvastatin die Statinmyopathie in Mäusen verringern kann (D'Antona et al. 2013). Es führte zu einem Rückgang der CK-Erhöhung und die untersuchten Mäuse zeigten weniger Ermüdung im Laufradversuch. Um zu überprüfen, ob NCX 6560 auch die Kontraktionskraft in dem hier verwendeten Skelettmuskelmodell im Vergleich zu Atorvastatin positiv beeinflussen kann, wurden ESM fünf Tage mit Atorvastatin oder NCX 6560 behandelt. Im Kontraktionsexperiment zeigte sich bei beiden Statintypen ein konzentrationsabhängiger Verlust der maximalen tetanischen Kraftentwicklung, der im Vergleich zu Cerivastatin deutlich rechtsverschoben war (Abb. 19). Zwischen Atorvastatin und NCX 6560 ließ sich kein signifikanter Unterschied feststellen. Die halbmaximale Konzentration von Atorvastatin lag bei 1,7 $\pm 0,7 \mu \mathrm{mol} / \mathrm{l}$, von NCX 6560 bei $2,5 \pm 0,8 \mu \mathrm{mol} / \mathrm{l}(\mathrm{n}=3)$. 


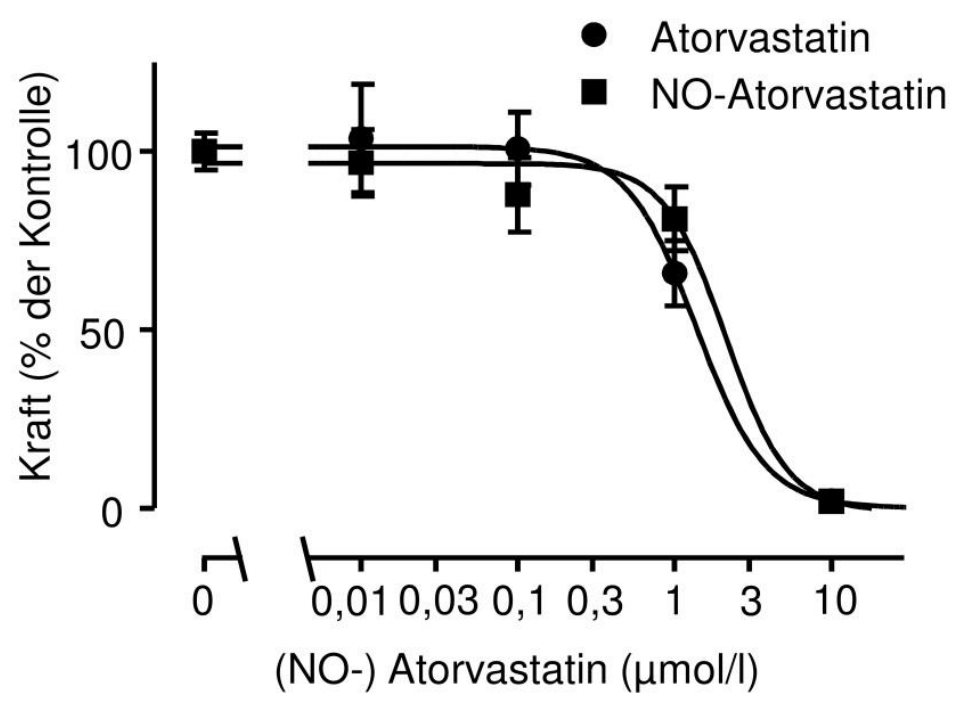

Abbildung 19: Vergleich der tetanischen Kraftentwicklung von ESM nach fünftägiger Behandlung mit Atorvastatin bzw. NO-Atorvastatin (NCX 6560). Dargestellt ist die maximale tetanische Kraft in \% der Kontrolle. ( $\mathrm{n}$ : Kontrolle=20; Atorvastatin=11/10/12/12; NO-Atorvastatin=12/8/10/12). 


\section{Diskussion}

In dieser Arbeit lag das Hauptaugenmerk auf der Rolle der NO-Synthasen, insbesondere der iNOS, in der Statin-induzierten Myotoxizität. Dafür wurde Engineered Skeletal Muscle als experimentelles In vitro-Skelettmuskelmodell genutzt. Folgende Hauptergebnisse wurden erzielt:

1) Cerivastatin erhöht konzentrationsabhängig die iNOS-Expression in ESM.

2) Die Statin-Myotoxizität und die iNOS-Induktion sind HMG-CoA-Reduktaseabhängig.

3) Die iNOS Induktion trägt funktionell nicht zu der Muskeltoxizität bei.

4) NO-Applikation verbessert die Muskelkontraktion.

\subsection{Engineered Skeletal Muscle als Modell für Statin-induzierte Myotoxizität: Rolle der NO-Synthasen}

Als Skelettmuskelmodell für die Statin-induzierte Myotoxizität wurden in der vorliegenden Arbeit ESM verwendet. Sie ähneln der reifen Skelettmuskulatur und bieten mit der Möglichkeit der direkten Kraftmessung einen wichtigen Funktionsparameter von Muskelgewebe.

Bekannt ist, dass bei Muskelerkrankungen wie Autoimmunmyopathien, aber auch bei chronischer Herzmuskelinsuffizienz die iNOS-Expression in Skelettmuskelzellen gesteigert ist (Riede et al. 1998; Tews und Goebel 1998). Riede et al. konnten mittels Elektronenmikroskopie die intrazelluläre Lokalisation der iNOS in Skelettmuskelzellen aus Biopsaten von humaner Skelettmuskulatur chronisch herzkranker Patienten nachweisen (Riede et al. 1998). Ursächlich dafür wird eine chronisch-entzündliche Reaktion angesehen. Inflammatorische Zytokine wie Interleukine und der Tumornekrosefaktor a sowie erhöhte Konzentrationen von LPS, die im Rahmen einer Sepsis infolge einer Infektion mit gramnegativen Bakterien vorkommen, können die iNOS-Expression und NO-Produktion steigern (Liu et al. 1993; Boczkowski et al. 1996; Reid 1998; Kleinert et al. 2004). Die iNOS ist diejenige Isoform der NO- 
Synthasen, die bis auf wenige Ausnahmen in den meisten ausdifferenzierten Zellen nicht konstitutiv exprimiert wird. Besonders in aktivierten Makrophagen, denen das synthetisierte NO zur unspezifischen Immunabwehr dient, kann sie detektiert werden. In Skelettmuskelzellen wird sie physiologischerweise nur in geringem Maße exprimiert (Stamler und Meissner 2001); die dort vorherrschende NO-Synthase ist das neuronale Isozym, welches in gesunden Zellen an der neuromuskulären Endplatte lokalisiert ist und den Hauptproduzenten des NO in der Skelettmuskulatur darstellt (Nakane et al. 1993; Chao et al. 1997). Die eNOS wird zwar vor allem in Endothelzellen exprimiert, kann jedoch die Funktion der Skelettmuskulatur über eine Regulation der Perfusion durch cGMP-vermittelte Vasokonstriktion und -dilatation beeinflussen. Scherkräfte, die auf die Gefäßwand und somit das Endothel wirken, gelten hier als starker Stimulus für eine Vasodilatation (Nishida et al. 1992). In Skelettmuskelzellen wird die eNOS physiologischerweise im Vergleich zur nNOS jedoch nur schwach exprimiert. Bei vermehrter Muskelarbeit sind beide Isoformen in ihrer Aktivität gesteigert (Reid 1998; Roberts et al. 1999). NO kann vorwiegend über zwei Wege verschiedene Wirkungen erzielen: Erstens über Proteinkinase Gvermittelte Signalkaskaden, zweitens über eine Nitrosylierung, d.h. die Reaktion von NO mit einer Thiolgruppe des Zielmoleküls. So können in Skelettmuskelzellen die Kontraktionskraft, die Glukoseaufnahme und die Kalziumhomöostase reguliert werden (Boczkowski et al. 1996; Mészáros et al. 1996; Maréchal und Gailly 1999). Da NO und sein Folgeprodukt Peroxynitrit Radikale sind, kann es bei erhöhten Konzentrationen zu pathophysiologischen Reaktionen wie der Bildung von Nitrotyrosin kommen (Reid 2001).

Zur Untersuchung der Rolle von iNOS und NO bei der Statinmyopathie wurde zunächst überprüft, ob das ESM-Gewebe ein geeignetes In vitro-Modell ist. ESM zeigen Eigenschaften der reifen Skelettmuskulatur: Die Myozyten bilden ein Synzytium aus, zeigen eine skelettmuskeltypische Genexpression, können sich spontan sowie nach elektrischer Stimulation kontrahieren und besitzen die Fähigkeit zur Erholung, d.h. die Reversibilität eines stressbedingten Verlusts der Kontraktionsfähigkeit (Tiburcy et al. 2012). Damit stellen sie ein Modell für die Untersuchung myotoxischer Substanzen dar, insbesondere weil durch den Aufbau und die Form der ESM eine direkte Kraftmessung möglich ist, sie dem physiologischen Skelettmuskel im Vergleich zu 2D-kultivierten Myozyten ähnlicher 
sind und Studien über einen längeren Zeitraum möglich sind. Als limitierende Faktoren des Modells sind jedoch zu nennen: die recht aufwändigen Zellkulturbedingungen mit Kontaminations- und Verletzungsrisiko und die fehlende physiologische Innervation und Perfusion der Skelettmuskulatur. Zudem ist zu erwähnen, dass die maximale tetanische Kraft der ESM nur bei ca. 10\% der Kraft präparierter nativer Skelettmuskulatur liegt (Tiburcy et al. 2012).

Auf HMG-CoA-Reduktase-Hemmer reagieren die ESM skelettmuskeltypisch im Sinne einer Beeinträchtigung der Muskelfunktion. Während einfach kultivierte Myozyten im Vergleich zur humanen Skelettmuskulatur weniger empfindlich gegenüber Statinen und auf die Statinbehandlung mit Apoptose und nicht mit Nekrose reagieren (Sakamoto und Kimura 2013), weshalb Sakamoto et al. die Verwendung von primären Myozyten zur Untersuchung der Statinmyotoxizität nicht empfehlen, liegen die halbmaximalen Konzentrationen von Cerivastatin, Simvastatin und Atorvastatin bei den ESM im Bereich derjenigen von Patienten, die eine hochdosierte Statinbehandlung erhalten (Tiburcy et al. 2012; Shitara und Sugiyama 2006). Darüber hinaus zeigten sich nekrotische und apoptotische Anteile des Statininduzierten Zelltods (beispielsweise eine Erhöhung der Kreatinkinase und der Caspase-3, eine Protease der Apoptose (Tiburcy et al. 2012))

$\mathrm{Da}$ in dieser Arbeit die Rolle der NO-Synthasen in der Statinmyopathie untersucht werden sollte, wurde die Expression der drei Isoformen in der Skelettmuskulatur der Ratte mit derjenigen im unbehandelten ESM verglichen. Die RNA-Untersuchung deutete auf eine insgesamt sehr niedrige Expression der NO-Synthasen hin. Dabei waren in der Skelettmuskulatur eNOS und nNOS stärker exprimiert; in der ESMKontrolle war die iNOS die am stärksten exprimierte Isoform (Abb. 4). Ein etwas anderes Ergebnis wies die Western-Blot-Anayse auf (Abb. 5 und 6): Die nNOS war im Skelettmuskel deutlich detektierbar, während die iNOS sowohl im ESM als auch im Skelettmuskel schwächer exprimiert war, was dem physiologischen Expressionsmuster entspricht (Reid 1998). Die Unterschiede lassen sich dadurch erklären, dass die Genexpression nicht zwangsläufig der direkten Proteinexpression entspricht.

Bei Behandlung mit Cerivastatin zeigte sich nun im ESM erstens ein konzentrationsabhängiger Verlust der tetanischen Kraftentwicklung als Parameter 
der direkten Muskelschädigung und zweitens eine signifikante Steigerung der iNOSExpression in der Proteinanalyse. Myozyten bzw. ESM nach Behandlung mit LPS wurden in dieser Arbeit als iNOS-Positivkontrolle für molekularbiologische und proteinbiochemische Methoden verwendet, da die Induktion der iNOS nach Behandlung mit LPS experimentell etabliert ist (Mao et al. 2013).

Unter Zusammenschau der oben genannten Eigenschaften der ESM ist davon auszugehen, dass sie als Modell zur Untersuchung der Statin-induzierten Muskelschädigung geeignet erscheinen.

\subsection{HMG-Co-A-Reduktase-Abhängigkeit der Myotoxizität und die Bedeutung der Isoprenylierung}

Bei der Untersuchung der Statin-induzierten Myotoxizität ist zu beachten, dass Statine über die Hemmung der HMG-CoA-Reduktase nicht nur die Synthese von Cholesterin, sondern auch die Bildung von Isoprenoiden und damit die Isoprenylierung von Zielmolekülen beeinflussen können. Als Isoprenylierung bezeichnet man die Modifikation von Proteinen durch eine Bindung an ein Terpenmolekül wie Geranyl-Geranyl-Pyrophosphat, auch Geranylgeraniol genannt. Zur Erläuterung dient die folgende Abbildung 20: Die HMG-CoA-Reduktase katalysiert die Bildung von Mevalonat und damit die Cholesterinbiosynthese, aber auch die Synthese von Isoprenoiden wie Geranyl-Geranyl-Pyrophospat (Alegret und Silvestre 2007). Daher ist bei Statinanwendung davon auszugehen, dass aufgrund einer verminderten Synthese von Geranyl-Geranyl-Pyrophosphat, FarnesylPyrophosphat und Mevalonat die Isoprenylierung von Zielmolekülen gestört wird. Dies wird zum einen als eine mögliche Ursache der Statin-induzierten Myotoxizität, aber auch der pleiotropen Statineffekte diskutiert: Sakamoto et al. und Sirvent et al. zufolge ist die Depletion der Isoprenoide möglicherweise entscheidend für die Muskelschädigung durch Statine. Sie postulieren, die Funktion der GTPasen, essenzieller Moleküle der Signaltransduktion, sowie die Abwehr gegenüber oxidativem Stress sei durch die verminderte Isoprenylierung eingeschränkt (Sirvent et al. 2008; Sakamoto und Kimura, 2013). In der Literatur werden allerdings auch die (pleiotropen) positiven Nebeneffekte der Statine, wie beispielsweise die 
Stabilisierung von atherosklerotischen Plaques oder die Inhibition des kardialen Remodellings nach einem Myokardinfarkt, von mehreren Autoren als Folge des veränderten Isoprenylierungsmusters beschrieben (Liao und Laufs 2005; Alegret und Silvestre 2007; Zhou und Liao 2010).

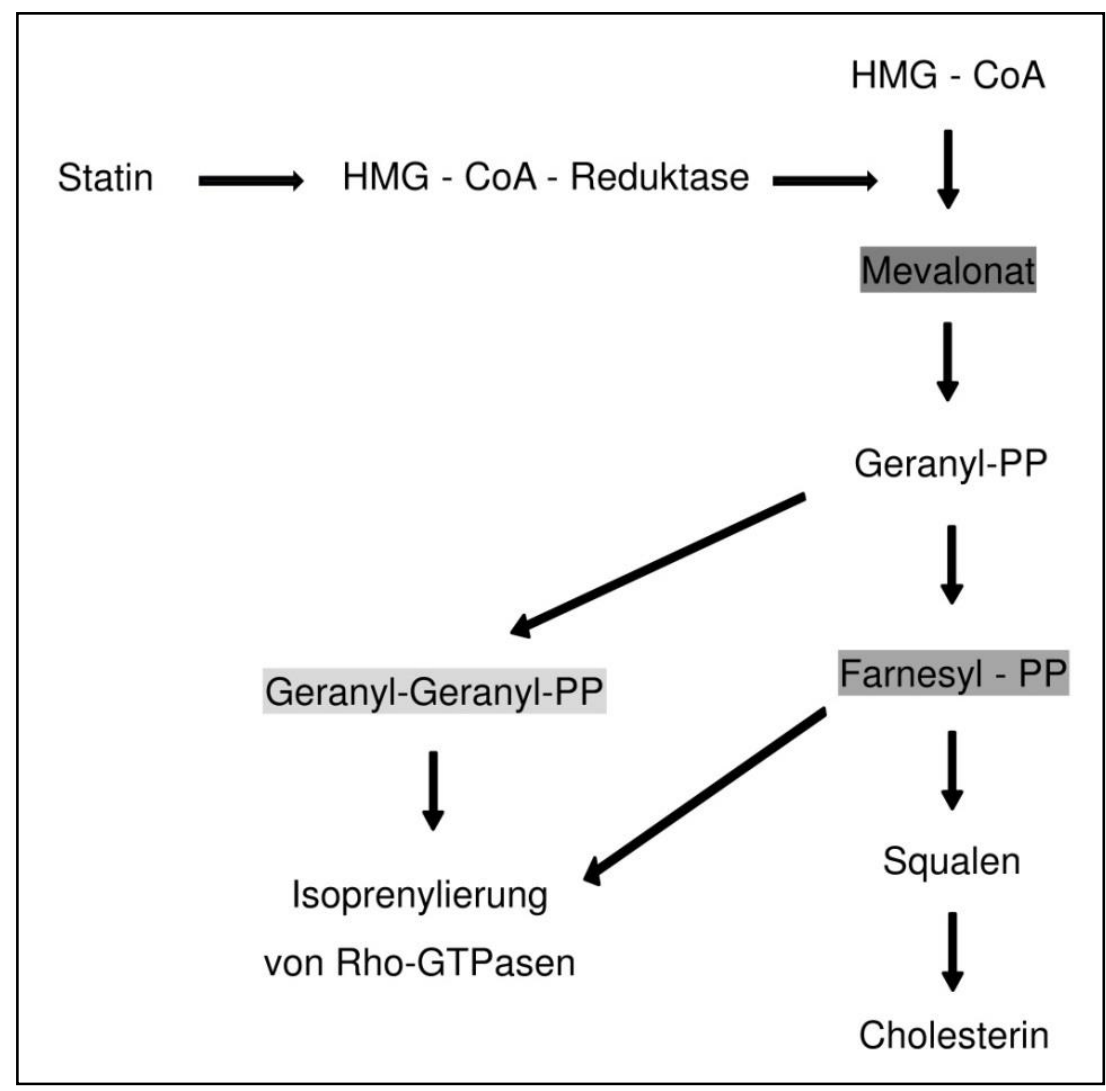

\section{Abbildung 20: Schemadarstellung der HMG-CoA-Reduktase-Hemmung auf die Cholesterinbiosynthese.}

Um überprüfen zu können, ob die Statin-induzierte Myotoxizität der ESM einerseits HMG-CoA-Reduktase-abhängig und andererseits bei Ersatz der Isoprenoide reversibel ist, wurden ESM mit Mevalonat, Geranyl-Geranyl-Pyrophosphat und Farnesyl-Pyrophosphat zusätzlich zu Cerivastatin behandelt. Interessanterweise zeigten die zusätzlich zu Cerivastatin mit Mevalonat und Geranyl-GeranylPyrophosphat behandelten ESM eine vollständige Aufhebung des tetanischen Kraftverlusts (Abb. $11 \mathrm{~A}$ ). Diese positive Wirkung von Mevalonat auf den Kraftverlust lässt vermuten, dass eine reduzierte Isoprenylierung einiger Proteine bei der eingeschränkten tetanischen Kraftentwicklung der Cerivastatin-behandelten ESM im Kontraktionsexperiment eine wichtige Rolle spielt. Diesem Ergebnis zufolge müsste es sich dabei überwiegend um Proteine handeln, deren physiologische Funktion von einer Geranylierung abhängig ist. Damit übereinstimmende Ergebnisse wurden 2009 
von Cao et al. publiziert, die untersuchten, dass sowohl Lovastatin als auch Geranylierungsinhibitoren in murinen Myozyten Muskelschäden induzieren, welche durch die Zugabe von Geranylgeraniol nicht aber Farnesol verhindert werden können (Cao et al. 2009).

Die Untersuchung der iNOS-Expression mittels Western Blot zeigte eine HMG-CoAReduktase-Abhängigkeit der iNOS-Expression: Bei zusätzlicher Inkubation mit Mevalonat, Farnesol oder Geranylgeraniol war die iNOS-Expression ohne Unterschiede zwischen den einzelnen Substanzen in den Statin-behandelten ESM verringert (Abb. 12). Somit ist zu diskutieren, ob die iNOS-Expression zum einen abhängig von der HMG-CoA-Reduktase-Hemmung, zum anderen vom Isoprenylierungsstatus sein kann oder ob verschiedene Proteine, die einer Isoprenylierung unterliegen, an der Vermittlung der Myotoxizität beteiligt sind, da in dieser Arbeit auch Farnesol zu einem zumindest teilweisen Rückgang des Cerivastatin-induzierten Kraftverlusts in den ESM führte. Die Expressionsanalyse von Zielmolekülen der Isoprenylierung wie beispielsweise die GTPasen RhoA und Rac1 (Bouitbir et al. 2011; Sakamoto und Kimura 2013) im ESM-Gewebe sowie die Verwendung von Geranylierungs- und Farnesyslierungsinhibitoren könnte weitere Informationen hinsichtlich der Statintoxizität im ESM liefern.

\section{3 iNOS und NO-Wirkung in Engineered Skeletal Muscle}

Als eines der Hauptergebnisse dieser Arbeit zeigte sich eine konzentrationsabhängige Erhöhung der iNOS-Expression in den Cerivastatin-behandelten ESM. Die iNOS ist die Isoform mit der höchsten maximalen NO-Produktion (Loibl et al. 2002). Zum Nachweis der vermehrten NO-Produktion wurde zunächst untersucht, ob sich durch Cerivastatin die NO-abhängige Phosphorylierung verändert. Der Phosphorylierungsstatus einiger Proteine ist abhängig von der Aktivität der Proteinkinase $\mathrm{G}$, welche unter anderem durch cGMP und NO regulierbar (Chao et al. 1997 ) ist. Auf der These basierend, dass NO in Cerivastatin-geschädigten Myozyten vermehrt auftritt, wurde als Surrogatmarker das phosphorylierte Vasodilatatorstimulierte Phosphoprotein (VASP-P) verwendet (Kou et al. 2012). Western Blots der Cerivastatin-behandelten ESM zeigten in der Tendenz eine Zunahme an 
phosphoryliertem VASP (am Serin 239, welches vorwiegend Proteinkinase-Gabhängig phosphoryliert wird), das eine vermehrte NO-Bildung im ESM nahelegt (Smolenski et al. 1998) (Abb. 9). Die Anzahl der untersuchten ESM ist mit $n=3$ jedoch gering, sodass weiterführende Experimente auch im Hinblick der Phosphorylierungsstelle am Serin 157 und unter zusätzlicher Behandlung mit SNP und Mevalonat bzw. Geranylgeraniol sinnvoll erscheinen. Des Weiteren gilt zu beachten, dass Statine auch über andere Signalwege eine Steigerung der VASPPhosphorylierung induzieren könnten.

Als weitere Möglichkeit der NO-Messung wurde ein Nitritassay verwendet. Hier zeigte sich im Medium der Cerivastatin-behandelten ESM kein eindeutiges Ergebnis, was am ehesten auf die niedrigmolare Konzentration von NO unter Statingabe zurückzuführen zu sein scheint. Bei Stimulation von Myozyten durch LPS in 2DKulturen ließ sich hingegen eine Steigerung der NO-Produktion mittels des Nitritassays klar nachweisen (Anhang 6.1).

Schmidt et al. beschreiben bei der Einschlusskörperchenmyositis eine iNOSInduktion, die mit einer verstärkten Nitrotyrosinbildung, d.h. der Nitrierung von Tyrosinresten von Proteinen, einhergeht und zu weiteren Zellschäden führen kann (Yang et al. 1998; Schmidt et al. 2012). Eine Untersuchung von Myozyten, die mit Cerivastatin behandelt wurden, zeigte hinsichtlich der Nitrotyrosinbildung jedoch keinen gesteigerten Befund im Vergleich zur Kontrolle (Anhang 6.2). Diejenigen Myozyten, die als Positivkontrolle mit LPS behandelt wurden, wiesen ein verstärktes Nitrotyrosinsignal auf, sodass denkbar erscheint, dass unter der Statinwirkung in ESM lediglich geringe Mengen NO produziert werden, die keine Nitrotyrosinbildung mit sich ziehen, während LPS einen deutlichen Anstieg der NO-Konzentration bewirkt.

\subsection{Stellenwert der Steigerung der iNOS-Expression für die Myotoxizität}

$\mathrm{Ob}$ und inwiefern die festgestellte Steigerung der iNOS-Expression zur Muskelschädigung beiträgt, wurde mithilfe des spezifischen iNOS-Inhibitors $1400 \mathrm{~W}$ untersucht. Basierend auf der These, dass die iNOS-Induktion ursächlich für die 
Myotoxizität sein könnte, wurden ESM zusätzlich zu Cerivastatin mit 1400W behandelt. Die Effektivität der verwendeten Konzentration $(5 \mu \mathrm{mol} / \mathrm{l})$ wurde mithilfe eines Nitritassays bestätigt: Dort zeigte sich in der verwendeten Konzentration die erwartete Reduktion der Nitritkonzentration im Medium LPS-behandelter Myozyten. Die zusätzliche Behandlung mit $1400 \mathrm{~W}$ zeigte in dem hier verwendeten Skelettmuskelmodell jedoch keine Besserung der Statin-bedingten Myotoxizität. Dass der Unwirksamkeit bezüglich der Kraftentwicklung eine kompensatorische Hochregulation der iNOS zugrunde liegt, konnte mittels Western Blot ausgeschlossen werden (Abb. 13).

Zur weiteren Untersuchung der funktionellen Rolle der iNOS wurden ESM aus iNOSdefizienten murinen Myozyten hergestellt und mit Cerivastatin behandelt. Im Kontraktionsexperiment konnte kein signifikanter Unterschied zwischen den iNOSKnockout-ESM und den Wildtyp-ESM festgestellt werden. Bei geringerer absoluter Kraft der iNOS-KO-ESM zeigten sowohl KO- als auch WT-ESM einen identischen konzentrationsabhängigen Abfall der tetanischen Kraft nach Cerivastatinbehandlung. Daraus lässt sich mutmaßen, dass die iNOS zwar durch Statine induziert wird, funktionell jedoch nicht zur Statintoxizität beiträgt. Somit galt es die Hypothese, die iNOS-Induktion könnte ursächlich für die Statin-abhängige Myotoxizität sein, zu überdenken. Möglich ist, dass die iNOS-Induktion keinen negativen Effekt auf die Kraftentwicklung im ESM hat und als eine Art „Stress-Sensor" fungiert. Ebenso könnte sein, dass durch andere Isoformen die NO-Produktion fortgeführt wird und damit mögliche schädigende Einflüsse weiter bestehen. Um dies zu untersuchen wurde der unspezifische NO-Synthase-Inhibitor L-NAME getestet, ein Molekül, das dem physiologischen Substrat der NO-Synthasen, Arginin, ähnelt und sie kompetitiv hemmt. L-NAME führte jedoch überraschenderweise zu keiner Verbesserung der Kontraktionskraft, sondern im Gegenteil zu einer Verschlechterung bei gleichzeitiger Behandlung mit Cerivastatin, was im Gegensatz zur Hypothese eher auf eine protektive Rolle von NO bei der Statin-induzierten Muskeltoxizität hindeutet.

Die Rolle von NO bezüglich der Skelettmuskelfunktion ist nicht abschließend geklärt: In der Literatur lassen sich abhängig vom Studiendesign zum Teil widersprüchliche Ergebnisse finden (Reid 1998). Meszaros et al. konnten zeigen, dass NO und Argininderivate durch Nitrosylierung des Ryanodinrezeptors im sarkoplasmatischen 
Retikulum dessen Offenwahrscheinlichkeit und damit den Kalziumfluss verringern können (Mészáros et al. 1996). Bellinger et al. fanden in der Untersuchung Dystrophin-defizienter Mäuse, die als Tiermodell für Muskeldystrophie Typ Duchenne dienen, dass die in diesen Mäusen gesteigerte iNOS-Expression mit einer Hypernitrosylierung des Ryanodinrezeptors assoziiert ist, die zur erhöhten Offenwahrscheinlichkeit des Kanals und zum unkontrollierten Kalziumverlust mit beeinträchtigter Muskelfunktion führt (Bellinger et al. 2009). Hingegen berichteten Stoyanovski et al. in den von innen durchgeführten Experimenten durch Zugabe von NO-Donoren einen höheren Kalziumfluss in der Skelettmuskelzelle erzielt zu haben (Stoyanovsky et al. 1997). In der Arbeit von Maréchal et al. wird ebenfalls auf einen eher positiven Effekt von NO auf die Kontraktionskraft von Skelettmuskelzellen verwiesen: die Zugabe von NO konnte im In vitro-Versuch die Kontraktionsgeschwindigkeit muriner Musculi extensores digitorum longi steigern (Maréchal und Beckers-Bleukx 1998). Diese scheinbar widersprüchlichen Ergebnisse scheinen unter anderem durch die unterschiedlichen Konzentrationen der NO-Spezies begründet zu sein: Pouverau et al. zufolge reduzieren niedrige Konzentrationen die Offenwahrscheinlichkeit des Ryanodinrezeptors, während hohe Konzentrationen sie zu erhöhen scheinen und damit die kontraktile Funktion der Muskulatur steigern (Pouvreau und Jacquemond 2005). Die Spannweite zwischen physiologischen und pathologisch erniedrigten und erhöhten NO-Konzentrationen scheint gering zu sein. Außerdem ist zu vermuten, dass NO weitere Zielmoleküle in der Skelettmuskulatur haben könnte, deren Aufgabe bisher nicht geklärt ist. Die Überlegungen bezüglich $\mathrm{NO}$ in der Skelettmuskulatur lassen darauf schließen, dass deren Funktion durch Inhibitoren der NO-Synthasen zu beeinflussen ist: In dieser Arbeit zeigte sich (kongruent zu Stoyanovsky et al. 1997 und Maréchal und Beckers-Bleukx 1998) nach der Behandlung mit L-NAME eine weitere Verschlechterung der Kontraktilität der Statin-geschädigten ESM. Eine mögliche Schlussfolgerung aus diesem Experiment ist, dass NO einen eher protektiven Effekt auf die Cerivastatin-geschädigten ESM haben könnte und die iNOS-Expression aufgrund relativen NO-Mangels bzw. eines Ungleichgewichts zwischen NO und anderen reaktiven Spezies (ROS) gesteigert sein könnte. Beispielsweise beschreiben Bouitbir et al. in ihren Arbeiten eine gesteigerte Konzentration reaktiver Sauerstoffspezies in Statin-geschädigten Skelettmuskelzellen. Sie sehen diese mit als Ursache für die Muskelbeschwerden unter Statintherapie an und bringen sie in Zusammenhang mit der von innen in 
Muskelproben von Patienten mit Statinmyopathie beobachteten mitochondrialen Schädigung (Bouitbir et al. 2011; Bouitbir et al. 2012). Auch Lecarpentier zufolge kann ein gestörtes Gleichgewicht zwischen verschiedenen reaktiven Spezies in der Skelettmuskulatur verschiedene pathologische Zustände hervorrufen (Lecarpentier 2007). Opie nimmt an, dass Konzentrationsänderungen der reaktiven Sauerstoffspezies sowohl an der Statin-Myotoxizität als auch an den pleiotropen Effekten der Statine beteiligt sind (Opie 2013). Unter der Hypothese, dass ein gestörtes Gleichgewicht zwischen den verschiedenen reaktiven Spezies an der Statintoxizität in ESM beteiligt ist, könnten die iNOS-Induktion und leichtgradig gesteigerte NO-Produktion als protektiv verstanden werden.

Basierend auf der Annahme, dass die gesteigerte NO-Produktion eine mögliche protektive Rolle in der Statin-Myotoxizität hat, während L-NAME-/1400WExperimente einen negativen bzw. keinen Effekt auf die Muskelfunktion zeigten, wurden ESM zusätzlich zu Cerivastatin mit dem NO-Donor SNP behandelt. SNP ist ein in der Intensivmedizin genutzter NO-Donor und ein potentes vasodilatierendes Medikament. Dosisbeschränkend ist die Freisetzung von toxischem Zyanid (Lüllmann et al. 2006). Daher wurde vor der Anwendung eine Konzentrations-Wirkungs-Kurve erstellt. In Konzentrationen unter $1 \mu \mathrm{mol} / / \mathrm{SNP}$ zeigte sich kein toxischer Effekt (= Kraftverlust) in den behandelten ESM; bei höheren Konzentrationen trat ein Verlust der tetanischen Kraft (Abb. 16) sowie vermehrt Zelldetritus in den Zellkulturschalen auf. Bei gleichzeitiger Behandlung mit 0,1 $\mu \mathrm{mol} / / \mathrm{SNP}$ und Cerivastatin zeigten die ESM interessanterweise eine signifikant gesteigerte tetanische Kraftentwicklung. Dieses Versuchsergebnis deutet daraufhin, dass der Cerivastatin-abhängige Kraftverlust NO-abhängig ist, und stützt die These, dass ein relativer NO-Mangel zum Kraftverlust führen könnte. Bei gleichzeitiger Behandlung mit einem anderen NODonor, NOC-12, zeigte sich im Kontraktionsexperiment ebenfalls eine (nicht signifikante) verbesserte maximale tetanische Kraft.

D'Antona et al. publizierten 2013, dass bei der Verwendung von Statinen, an die NO gekoppelt ist, die Muskelfunktion behandelter Mäuse weniger stark beeinträchtigt wird. Sie verwendeten für ihre Arbeit Atorvastatin und NO-Atorvastatin, NCX 6560, und beschrieben verminderte Atrophiezeichen, eine verringerte Ermüdbarkeit der Mäuse im Laufradversuch sowie einen geringeren Anstieg der Kreatinkinase für NCX 
$6560 \mathrm{im}$ Vergleich zu Atorvastatin (D'Antona et al. 2013). Die von D'Antona et al. dargestellte verbesserte Muskelfunktion konnte im Kontraktionsversuch mit ESM nicht bestätigt werden: Es zeigte sich in beiden Gruppen ein konzentrationsabhängiger tetanischer Kraftverlust ohne signifikante Unterschiede (Abb. 19). Folgende Überlegungen können dafür unter anderem als Ursache in Betracht gezogen werden: Möglicherweise liegen Unterschiede in der NOKonzentration oder NO-Bioverfügbarkeit zwischen SNP und NCX 6560 zugrunde oder die positive Wirkung von NCX 6560 wird über Zellen vermittelt, die in ESM nicht enthalten sind (z. B. Nervenzellen oder glatte Gefäßmuskelzellen).

Inwiefern sich die Behandlung mit NO-Donoren auf die quantitative iNOS-Expression auswirkt, wurde mittels Western Blot untersucht. Hier wiesen diejenigen ESM, die gleichzeitig mit SNP behandelt wurden, eine tendenziell geringere iNOS-Expression auf als diejenigen, die mit Cerivastatin allein behandelt wurden (Abb. 17). Gemäß der Theorie, dass die iNOS als Stress-Sensor fungiert und das produzierte NO zur Aufrechterhaltung des Gleichgewichts der reaktiven Sauerstoffspezies gebraucht wird, kann dies so interpretiert werden, dass die iNOS-Induktion aufgrund des behobenen relativen NO-Mangels bei SNP-Gabe nicht notwendig ist. Die Untersuchung der iNOS-Expression im Vergleich zwischen Atorvastatin und NCX 6560 wurde in dieser Arbeit nicht durchgeführt, könnte jedoch im Rahmen weiterer experimenteller Studien von Interesse sein. Dass die iNOS-Expression durch NOZufuhr beeinflussbar ist, zeigten Colasanti et al. bereits 1995 in Mikrogliazellen (Colasanti et al. 1995) sowie Lecarpentier für die Skelettmuskulatur (Lecarpentier 2007). Ihren Arbeiten zufolge besteht ein Gleichgewicht zwischen endogenem NO und der iNOS-Expression. Bei Unterschreitung eines bestimmten NOSchwellenwerts wird die iNOS-Expression induziert und umgekehrt bei erhöhten NOKonzentrationen inhibiert. Colasanti et al. sehen als Ursache dafür eine NOabhängige verminderte NF-KB-Verfügbarkeit, da NF-KB unter anderem die iNOSExpression reguliert, während Lecarpentier den Zustand einem direkten negativen Feedback zuschreibt. Huang et al. fanden in Makrophagen eine verminderte iNOSGenexpression nach Behandlung mit HMG-CoA-Reduktase-Hemmern, die sie im Zusammenhang mit einer durch das von innen verwendete Lovastatin reduzierten NF-kB-Aktivierung über ein verändertes Isoprenylierungsmuster sehen (Huang et al. 2003 und Lecarpentier 2007). Im Hinblick auf diese unterschiedlichen Daten scheint 
es nicht nur auf die untersuchten Zelltypen und Zellkulturmodelle anzukommen, sondern auch darauf, welcher Faktor den Ausgangspunkt der Signalkaskade darstellt. Für zukünftige Experimente wäre die Untersuchung der Expression von NF-kB eine mögliche Fragestellung hinsichtlich der Statin-induzierten Myopathie.

\subsection{Zusammenfassung}

In dieser Arbeit konnte gezeigt werden, dass die konzentrationsabhängige Schädigung der Myozyten durch Cerivastatin mit einem Verlust der Muskelkraft und einer Induktion der iNOS auf Protein- und mRNA-Ebene im ESM einhergeht. Diese Cerivastatintoxizität war HMG-CoA-Reduktase-abhängig. Die tendenziell zunehmende Konzentration des phosphorylierten VASP als Surrogatmarker der NOabhängigen Proteinkinase-G-Aktivierung ließ eine vermehrte NO-Produktion in Cerivastatin-behandelten ESM vermuten. Die unspezifische Hemmung der NOSynthasen durch L-NAME verschlechterte tendenziell die Ergebnisse der Kraftmessungen, während die Behandlung mit dem NO-Donor SNP die Kontraktilität signifikant zu verbessern und die iNOS-Expression zu vermindern vermochte. ESM aus murinen iNOS-Knockout-Myozyten sowie ESM nach Behandlung mit dem spezifischen iNOS-Inhibitor 1400W zeigten in Analogie zu den Versuchen mit LNAME keine verstärkte oder verminderte Cerivastatinempfindlichkeit.

Insgesamt legen die Daten der vorliegenden Arbeit nahe, dass die iNOS-Induktion in Cerivastatin-geschädigten ESM Ausdruck einer Kompensation bei funktionellem NODefizit ist, welches durch eine exogene NO-Zufuhr ausgeglichen werden kann. Die Koadministration mit einem Statin erscheint als eine mögliche neue Option in der Verringerung der Statin-induzierten Muskelschädigung. 


\section{Literaturverzeichnis}

1. Alegret M, Silvestre JS (2006): Pleiotropic effects of statins and related pharmacological experimental approaches. Methods Find Exp Clin Pharmacol. 9, 627-656.

2. Altamirano F, López J, Henríquez C, Molinski T, Allen P, Jaimovich E (2012): Increased resting intracellular calcium modulates NF-kB-dependent inducible nitric-oxide synthase gene expression in dystrophic $\mathrm{mdx}$ skeletal myotubes. $\mathrm{J}$ Biol Chem 287, 20876-20887.

3. Baar K (2005): New dimensions in tissue engineering. Exp Physiol $\underline{90}, 799$ 806.

4. Baigent C, Keech A, Kearney PM, Blackwell L, Buck G, Pollicino C, Kirby A, Sourjina T, Peto R, Collins R, Simes R (2005): Efficacy and safety of cholesterol-lowering treatment: prospective meta-analysis of data from 90,056 participants in 14 randomised trials of statins. Lancet $\underline{366}, 1267-1278$.

5. Bellinger AM, Reiken S, Carlson C, Mongillo M, Liu X, Rothman L, Matecki S, Lacampagne A, Marks AR (2009): Hypernitrosylated ryanodine receptor calcium release channels are leaky in dystrophic muscle. Nat Med 15, 325330.

6. Bischoff $\mathrm{H}$, Heller AH (1998): Preclinical and clinical pharmacology of cerivastatin. Am J Cardiol $\underline{82}$, 18J-25J.

7. Boczkowski J, Lanone S, Ungureanu-Longrois D, Danialou G, Fournier T, Aubier M (1996): Induction of diaphragmatic nitric oxide synthase after endotoxin administration in rats: role on diaphragmatic contractile dysfunction. $\mathrm{J}$ Clin Invest $\underline{98}, 1550-1559$.

8. Bouitbir J, Charles A, Rasseneur L, Dufour S, Piquard F, Geny B, Zoll J (2011): Atorvastatin treatment reduces exercise capacities in rats: involvement of mitochondrial impairments and oxidative stress. J Appl Physiol $\underline{111}$, 14771483.

9. Bouitbir J, Charles A, Echaniz-Laguna A, Kindo M, Daussin F, Auwerx J, Piquard F, Geny B, Zoll J (2012): Opposite effects of statins on mitochondria 
of cardiac and skeletal muscles: a 'mitohormesis' mechanism involving reactive oxygen species and PGC-1. Eur Heart J $\underline{33}$, 1397-1407.

10. Brenman JE, Chao DS, Xia H, Aldape K, Bredt DS (1995): Nitric oxide synthase complexed with dystrophin and absent from skeletal muscle sarcolemma in Duchenne muscular dystrophy. Cell $\underline{82}, 743-752$.

11. Bruckert E, Hayem G, Dejager S, Yau C, Bégaud B (2005): Mild to moderate muscular symptoms with high-dosage statin therapy in hyperlipidemic patients--the PRIMO study. Cardiovasc Drugs Ther 19, 403-414.

12. Bundesministerium für Bildung und Forschung: Ergebnisse der Herzkreislaufforschung: Herz in Gefahr? Ursachen, Prävention, Therapie Ergebnisse der Herzkreislaufforschung (2004). http://www.gesundheitsforschung-bmbf.de/_media/BMBF_Herz.pdf [Zugriff 14.03.2016]

13. Calabrese V, Boyd-Kimball D, Scapagnini G, Butterfield DA (2004): Nitric oxide and cellular stress response in brain aging and neurodegenerative disorders: the role of vitagenes. In Vivo $\underline{18}, 245-267$.

14. Cao P, Hanai J, Tanksale P, Imamura S, Sukhatme VP, Lecker SH (2009): Statin-induced muscle damage and atrogin-1 induction is the result of a geranylgeranylation defect. FASEB J $\underline{23}$, 2844-2854.

15. Chao DS, Silvagno F, Xia H, Cornwell TL, Lincoln TM, Bredt DS (1997): Nitric oxide synthase and cyclic GMP-dependent protein kinase concentrated at the neuromuscular endplate. Neuroscience $\underline{76}, 665-672$

16. Colasanti M, Persichini T, Menegazzi M, Mariotto S, Giordano E, Caldarera CM, Sogos V, Lauro GM, Suzuki H (1995): Induction of nitric oxide synthase mRNA expression. Suppression by exogenous nitric oxide. J Biol Chem $\underline{270}$, 26731-26733.

17. Collins R, Armitage J, Parish S, Sleight P, Peto R (2004): Effects of cholesterol-lowering with simvastatin on stroke and other major vascular events in 20536 people with cerebrovascular disease or other high-risk conditions. Lancet $\underline{363}, 757-767$.

18. D'Antona G, Mascaro A, Monopoli A, Miglietta D, Ongini E, Bottinelli R (2013): Nitric oxide prevents atorvastatin-induced skeletal muscle dysfunction and alterations in mice. Muscle Nerve $\underline{47}, 72-80$. 
19. Deutsche Gesellschaft zur Bekämpfung von Fettstoffwechselstörungen und ihren Folgeerkrankungen (Lipid-Liga) (2011): Empfehlungen zur Diagnostik und Therapie von Fettstoffwechselstörungen in der Ärztlichen Praxis. http://www.lipid-liga.de/pdf/ldiagn.pdf [Zugriff am 18.03.2016]

20. Draeger A, Monastyrskaya K, Mohaupt M, Hoppeler H, Savolainen H, Allemann C, Babiychuk EB (2006): Statin therapy induces ultrastructural damage in skeletal muscle in patients without myalgia. J Pathol 210, 94-102

21. Filippin LI, Cuevas MJ, Lima E, Marroni NP, Gonzalez-Gallego J, Xavier RM (2011): Nitric oxide regulates the repair of injured skeletal muscle. Nitric Oxide 24, 43-49.

22. Flint OP, Masters BA, Gregg RE, Durham SK (1997): Inhibition of cholesterol synthesis by squalene synthase inhibitors does not induce myotoxicity in vitro. Toxicol Appl Pharmacol. 145, 91-98.

23. Förstermann U, Sessa WC (2012): Nitric oxide synthases: regulation and function. Eur Heart J $\underline{33}$, 829-37, 837a-837d

24. Furberg CD, Pitt B (2001): Withdrawal of cerivastatin from the world market. Curr Control Trials Cardiovasc Med 2, 205-207.

25. Guo FH, Raeve HR de, Rice TW, Stuehr DJ, Thunnissen FB, Erzurum SC (1995): Continuous nitric oxide synthesis by inducible nitric oxide synthase in normal human airway epithelium in vivo. Proc Natl Acad Sci U.S.A. 92, 78097813.

26. Heart Protection Study Collaborative Group (2007): Randomized trial of the effects of cholesterol-lowering with simvastatin on peripheral vascular and other major vascular outcomes in 20,536 people with peripheral arterial disease and other high-risk conditions. J Vasc Surg $\underline{45}, 645-654$; discussion 653-4.

27. Huang K, Chen C, Chen J, Lin W (2003): HMG-CoA reductase inhibitors inhibit inducible nitric oxide synthase gene expression in macrophages. $J$ Biomed Sci $\underline{10}$, 396-405.

28. Kleinert H, Pautz A, Linker K, Schwarz PM (2004): Regulation of the expression of inducible nitric oxide synthase. Eur J Pharmacol 500, 255-266.

29. Kou R, Shiroto T, Sartoretto JL, Michel T (2012): Suppression of Gas synthesis by simvastatin treatment of vascular endothelial cells. J Biol Chem 287, 2643-2651. 
30. LaRosa JC, He J, Vupputuri S (1999): Effect of statins on risk of coronary disease: a meta-analysis of randomized controlled trials. JAMA 282, 23402346.

31. Laufs U, La Fata V, Plutzky J, Liao JK (1998): Upregulation of endothelial nitric oxide synthase by HMG CoA reductase inhibitors. Circulation $\underline{97}$, 1129-1135.

32. Lecarpentier $Y$ (2007): Physiological role of free radicals in skeletal muscles. J Appl Physiol 103, 1917-1918.

33. Liao JK, Laufs U (2005): Pleiotropic effects of statins. Annu Rev Pharmacol Toxicol $\underline{45}, 89-118$.

34. Liu S, Adcock IM, Old RW, Barnes PJ, Evans TW (1993): Lipopolysaccharide treatment in vivo induces widespread tissue expression of inducible nitric oxide synthase mRNA. Biochem Biophys Res Commun 196, 1208-1213.

35. Livak KJ, Schmittgen TD (2001): Analysis of relative gene expression data using real-time quantitative PCR and the $2-\triangle \triangle C T$ method. Methods $\underline{25}, 402-$ 408.

36. Loibl S, Minckwitz G von, Weber S, Sinn H, Schini-Kerth VB, Lobysheva I, Nepveu F, Wolf G, Strebhardt K, Kaufmann M (2002): Expression of endothelial and inducible nitric oxide synthase in benign and malignant lesions of the breast and measurement of nitric oxide using electron paramagnetic resonance spectroscopy. Cancer $\underline{95}, 1191-1198$.

37.Lüllmann H, Mohr K, Hein L: Pharmakologie und Toxikologie. 16. Auflage; Georg Thieme, Stuttgart 2006

38. Mao K, Chen S, Chen M, Ma Y, Wang Y, Huang B, He Z, Zeng Y, Hu Y, Sun S, Li J, Wu X, Wang X, Strober W, Chen C, Meng G, Sun B (2013): Nitric oxide suppresses NLRP3 inflammasome activation and protects against LPSinduced septic shock. Cell Res $\underline{23}, 201-212$.

39. Maréchal G, Beckers-Bleukx G (1998): Effect of nitric oxide on the maximal velocity of shortening of a mouse skeletal muscle. Pflugers Arch $\underline{436}, 906-$ 913.

40. Maréchal G, Gailly P (1999): Effects of nitric oxide on the contraction of skeletal muscle. Cell Mol Life Sci $\underline{55}, 1088-1102$.

41. Mészáros LG, Minarovic I, Zahradnikova A (1996): Inhibition of the skeletal muscle ryanodine receptor calcium release channel by nitric oxide. FEBS Lett $\underline{380}, 49-52$. 
42. Michel T, Feron O (1997): Nitric oxide synthases: which, where, how, and why? J Clin Invest 100, 2146-2152.

43. Nakane M, Schmidt HH, Pollock JS, Förstermann U, Murad F (1993): Cloned human brain nitric oxide synthase is highly expressed in skeletal muscle. FEBS Lett $\underline{316}$, 175-180.

44. Nishida K, Harrison DG, Navas JP, Fisher AA, Dockery SP, Uematsu M, Nerem RM, Alexander RW, Murphy TJ (1992): Molecular cloning and characterization of the constitutive bovine aortic endothelial cell nitric oxide synthase. J Clin Invest 90, 2092-2096.

45. Opie LH (2013): Exercise-induced myalgia may limit the cardiovascular benefits of statins. Cardiovasc Drugs Ther $\underline{27}, 569-572$.

46. Pouvreau S, Jacquemond V (2005): Nitric oxide synthase inhibition affects sarcoplasmic reticulum $\mathrm{Ca} 2+$ release in skeletal muscle fibres from mouse. $\mathrm{J}$ Physiol (Lond.) 567, 815-828.

47. Reid MB (1998): Role of nitric oxide in skeletal muscle: synthesis, distribution and functional importance. Acta Physiol Scand 162, 401-409.

48. Reid MB (2001): Invited Review: redox modulation of skeletal muscle contraction: what we know and what we don't. J Appl Physiol $\underline{90}$, 724-731.

49. Riede UN, Förstermann U, Drexler H (1998): Inducible nitric oxide synthase in skeletal muscle of patients with chronic heart failure. J Am Coll Cardiol $\underline{32}$, 964-969.

50. Roberts CK, Barnard RJ, Jasman A, Balon TW (1999): Acute exercise increases nitric oxide synthase activity in skeletal muscle. Am J Physiol $\underline{277}$, E390-394.

51. Rote Liste® Service GmbH: Arzneimittelinformationen für Deutschland (2015). www.fachinfo.de. [Zugriff am 05.09.2015]

52. Sakamoto K, Kimura J (2013): Mechanism of statin-induced rhabdomyolysis. J Pharmacol Sci 123, 289-294.

53. Schmidt J, Barthel K, Zschüntzsch J, Muth IE, Swindle EJ, Hombach A, Sehmisch S, Wrede A, Lühder F, Gold R, Dalakas MC (2012): Nitric oxide stress in sporadic inclusion body myositis muscle fibres: inhibition of inducible nitric oxide synthase prevents interleukin-1 $\beta$-induced accumulation of $\beta$ amyloid and cell death. Brain 135, 1102-1114. 
54.SEARCH Collaborative Group (2008): SLCO1B1 Variants and Statin-Induced Myopathy - A Genomewide Study. N Engl J Med 359, 789-799.

55. Shitara $Y$, Sugiyama $Y$ (2006): Pharmacokinetic and pharmacodynamic alterations of 3-hydroxy-3-methylglutaryl coenzyme A (HMG-CoA) reductase inhibitors: drug-drug interactions and interindividual differences in transporter and metabolic enzyme functions. Pharmacol Ther 112, 71-105.

56. Sirvent P, Mercier J, Lacampagne A (2008): New insights into mechanisms of statin-associated myotoxicity. Curr Opin Pharmacol $\underline{8}, 333-338$.

57. Smith R, Solberg R, Jacobsen LL, Voreland AL, Rustan AC, Thoresen GH, Johansen HT (2014): Simvastatin inhibits glucose metabolism and legumain activity in human myotubes. PLoS ONE $\underline{9}$, e85721.

58. Smolenski A, Bachmann C, Reinhard K, Hönig-Liedl P, Jarchau T, Hoschuetzky H, Walter U (1998): Analysis and regulation of vasodilatorstimulated phosphoprotein serine 239 phosphorylation in vitro and in intact cells using a phosphospecific monoclonal antibody. J Biol Chem $\underline{273}, 20029$ 20035.

59. Stamler JS, Meissner G (2001): Physiology of nitric oxide in skeletal muscle. Physiol Rev $\underline{81}$, 209-237.

60. Statistisches Bundesamt 2010, Krankheitskosten, Fachserie 12 Reihe 7.2 2002, 2004, 2006 und 2008 https://www.destatis.de/DE/Publikationen/Thematisch/Gesundheit/Krankheitsk osten/Krankheitskosten2120720089004.pdf?_blob=publicationFile [Zugriff am 18.03.2016]

61. Statistisches Bundesamt 2015, Todesursachen in Deutschland, Fachserie 12 Reihe 4 - 2014.

https://www.destatis.de/DE/Publikationen/Thematisch/Gesundheit/Todesursac hen/Todesursachen2120400147004.pdf?_blob=publicationFile [Zugriff am 18.03.1016]

62. Stone NJ, Robinson J, Lichtenstein AH, Merz CNB, Blum CB, Eckel RH, Goldberg AC, Gordon D, Levy D, Lloyd-Jones DM, McBride P, Schwartz JS, Shero ST, Smith SC, Watson K, Wilson PWF (2013): ACC/AHA Guideline on the Treatment of Blood Cholesterol to Reduce Atherosclerotic Cardiovascular Risk in Adults: A Report of the American College of Cardiology/American Heart Association Task Force on Practice Guidelines. Circulation 129, S1-45 
63. Stoyanovsky D, Murphy T, Anno PR, Kim YM, Salama G (1997): Nitric oxide activates skeletal and cardiac ryanodine receptors. Cell Calcium 21, 19-29.

64. Tews DS, Goebel HH (1998): Cell death and oxidative damage in inflammatory myopathies. Clin Immunol Immunopathol 87, 240-247.

65. Thompson PD, Clarkson P, Karas RH (2003): Statin-associated myopathy. JAMA $\underline{289}, 1681-1690$.

66. Tiburcy M, Engel G, Sanders S, Zimmermann WH: Antioxidant and Ryanodine Receptor Stabilizing Therapy Prevent Statin-Induced Contractile Dysfunction in a Tissue-Engineered Skeletal Muscle Model. Posterpräsentation im Rahmen des American Heart Association Congress in New Orleans, USA am 24.07.2012

67. Tousoulis D, Kampoli A, Tentolouris C, Papageorgiou N, Stefanadis C (2012): The role of nitric oxide on endothelial function. Curr Vasc Pharmacol 10, 4-18.

68. Vandenburgh $H$ (2010): High-content drug screening with engineered musculoskeletal tissues. Tissue Eng Part B Rev 16, 55-64.

69. Vandenburgh H, Shansky J, Benesch-Lee F, Skelly K, Spinazzola JM, Saponjian Y, Tseng BS (2009): Automated drug screening with contractile muscle tissue engineered from dystrophic myoblasts. FASEB J $\underline{23}, 3325$ 3334.

70. Wehling M, Diener H: Klinische Pharmakologie. 1. Auflage; Georg Thieme, Stuttgart 2005

71. Yang CC, Alvarez RB, Engel WK, Heller SL, Askanas V (1998): Nitric oxideinduced oxidative stress in autosomal recessive and dominant inclusion-body myopathies. Brain 121, 1089-1097.

72.Zhou Q, Liao JK (2010): Pleiotropic effects of statins. - Basic research and clinical perspectives -. Circ J $\underline{74}, 818-826$. 


\section{Anhang}

6.1 Nitritmessung in 2D-Myoblastenkulturen

Die Wirksamkeit von 1400W und L-NAME wurde durch Nitritmessungen im Medium von 2D-Myoblastenkulturen, bei denen es durch Behandlung mit LPS zu einer iNOSInduktion und einem Konzentrationsanstieg von NO und Nitrit gekommen war, bestätigt (Abb. 21 und 22). Auf eine Behandlung mit 1400W zeigten sich keine gesteigerten Werte für Nitrit, während im Kulturmedium der mit LPS behandelten Myoblasten eine erhöhte Nitritkonzentration messbar war. Bei gleichzeitiger Behandlung mit $1 \mu \mathrm{mol} / /, 10 \mu \mathrm{mol} / / \mathrm{l}$ und $100 \mu \mathrm{mol} / /$ 1400W lag die Nitritkonzentration ungefähr auf dem Niveau der Vehikelkontrolle (Ctr), sodass davon auszugehen ist, dass die Behandlung der ESM mit $5 \mu \mathrm{mol} / \mathrm{L}$ zu einer ausreichenden iNOS-Hemmung führt (Abb. 21). In der verwendeten Konzentration von $10 \mathrm{mmol} / \mathrm{L}$ L-NAME zeigte sich ebenfalls eine im Vergleich zur Positivkontrolle deutlich reduzierte Nitritkonzentration (Abb. 22).

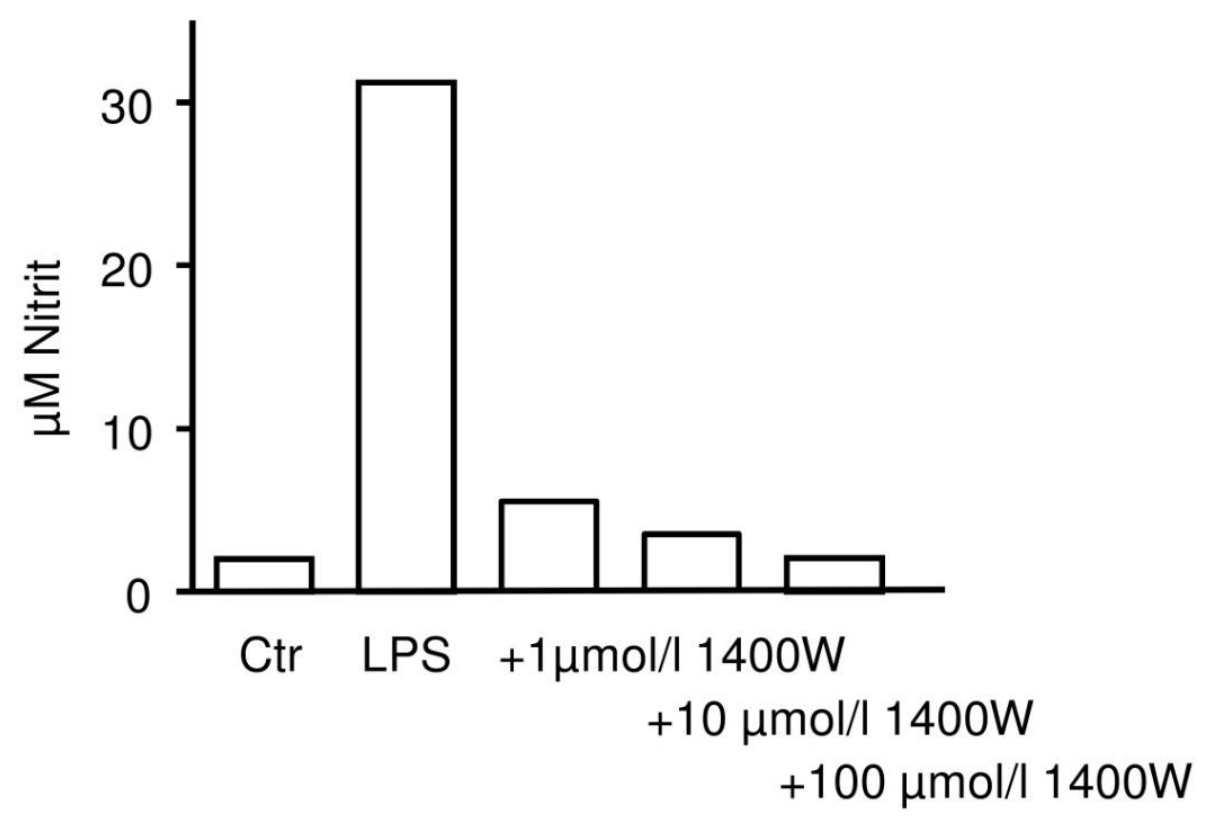

Abbildung 21: Konzentrationsabhängige Hemmung der Nitritsynthese durch 1400W in der 2D-Myoblastenkultur. Auf der Ordinate ist die Nitritkonzentration der auf der Abszisse gekennzeichneten 1400W-Konzentration von gleichzeitig mit LPS 
zur iNOS-Induktion behandelten 2D-Myoblasten dargestellt. Ctr = Vehikelkontrolle. LPS $=$ Positivkontrolle $(n=2)$.

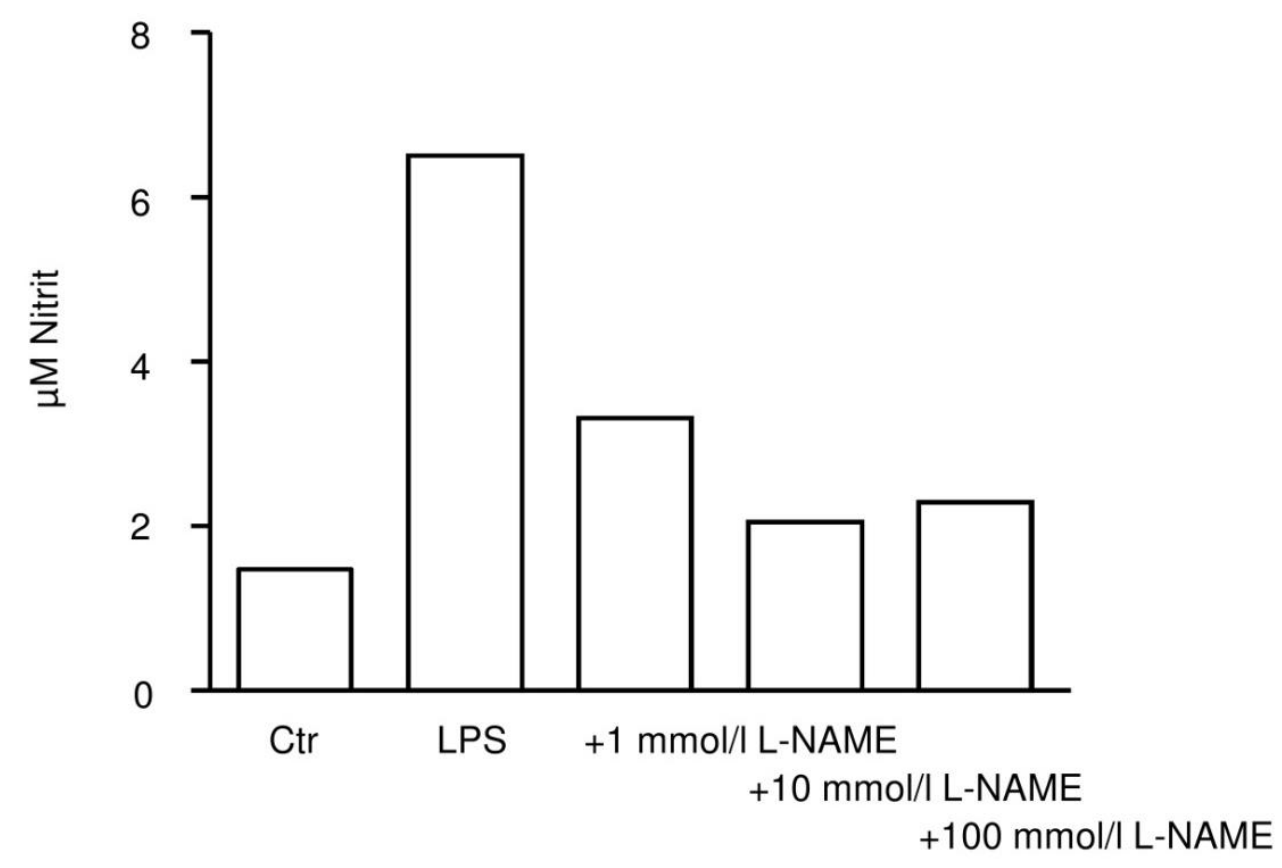

Abbildung 22: Konzentrationsabhängige Hemmung der Nitritsynthese durch L-NAME in der 2D-Myoblastenkultur. Auf der Ordinate ist die Nitritkonzentration der auf der Abszisse gekennzeichneten L-NAME-Konzentration von gleichzeitig mit LPS zur iNOS-Induktion behandelten 2D-Myoblasten dargestellt. Ctr = Vehikelkontrolle. LPS = Positivkontrolle $(n=2)$.

\subsection{Nitrotyrosinfärbung}

Nitrotyrosin wurde als Indikator für eine gesteigerte NO-Produktion und den daraus resultierenden nitrosativen Stress verwendet. Es wurden Myoblasten aus 2DMyoblastenkulturen gefärbt, die verschiedene Konzentrationen von Cerivastatin erhielten. Es zeigte sich ein signifikant gesteigertes Signal in den LPS-behandelten Myoblasten, jedoch war das Signal in den Cerivastatin-behandelten Zellen nicht erhöht. Aufgrund der Zelltoxizität von $1 \mu \mathrm{mol} / \mathrm{l}$ Cerivastatin war das Signal in diesen Proben deutlich reduziert (Abb. 23). 

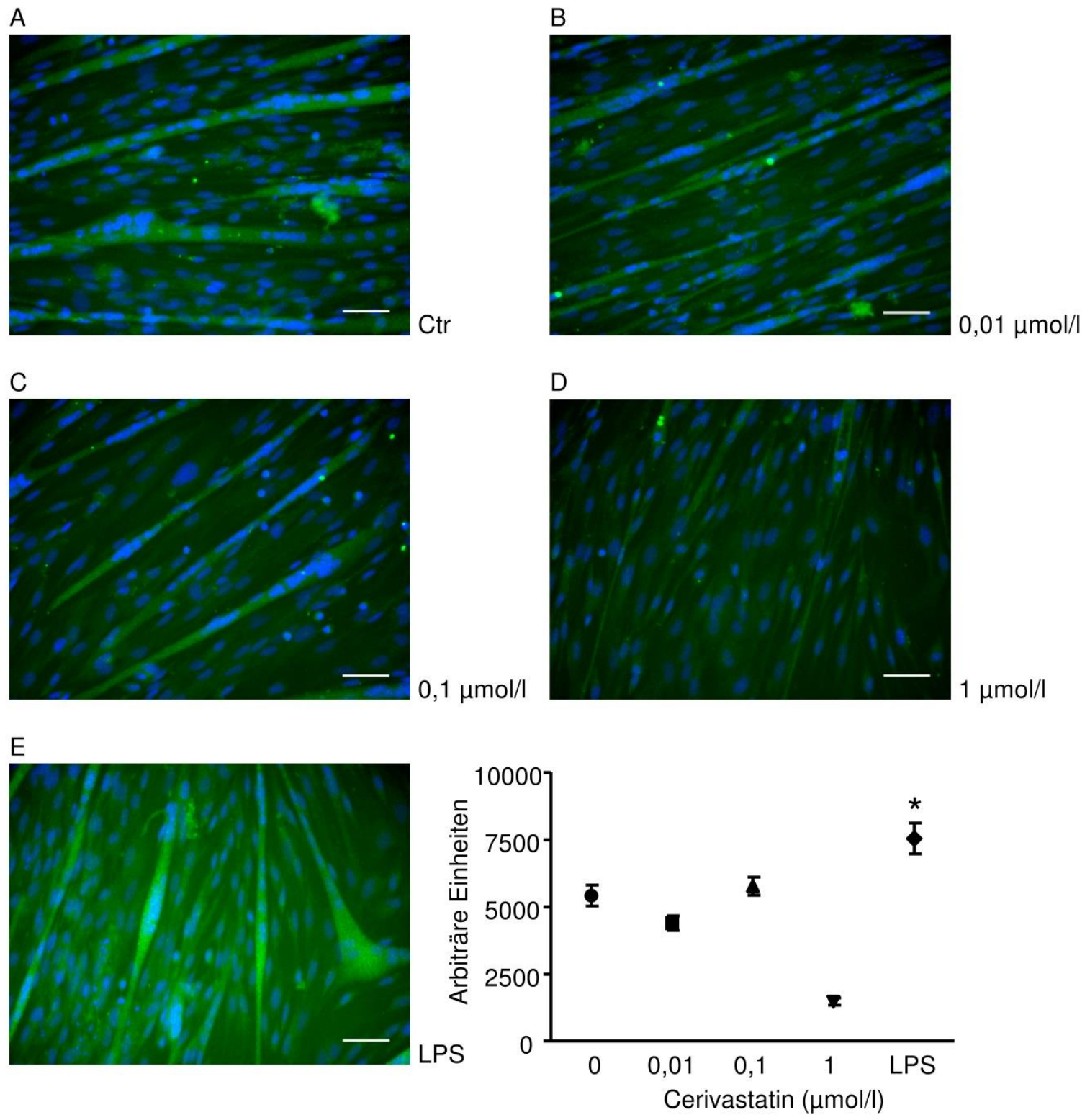

Abbildung 23: Nitrotyrosinfärbung in 2D-Myoblasten nach Behandlung mit Cerivastatin für fünf Tage.

A: Vehikelkontrolle, B: 0,01 $\mu \mathrm{mol} / /, \mathrm{C}: 0,1 \mu \mathrm{mol} / /, \mathrm{D}: 1 \mu \mathrm{mol} / \mathrm{l}$ Cerivastatin, E: LPS. Repräsentative Abbildungen. Nitrotyrosin (grün), Diamidinophenylindol (DAPI; blau). Maßstab $20 \mu \mathrm{m}$. Rechts unten: Quantifizierung des Nitrotyrosinsignals aus der Färbung von 2D-Myoblastenkulturen nach fünftägiger Cerivastatinbehandlung bzw. 24-stündiger Behandlung mit LPS ( $n=27 / 54 / 21 / 18 / 18),{ }^{*} p<0,05$ im Vergleich zur Kontrolle (einfaktorielle Varianzanalyse, Bonferroni's Multiple Comparison Test). 


\section{Danksagung}

Meinen besonderen Dank möchte ich zum einen meinem Doktorvater Prof. Dr. Wolfram-Hubertus Zimmermann und zum anderen meinem Betreuer Dr. Malte Tiburcy aussprechen. Jede Phase dieser Arbeit wurde von innen intensiv und professionell begleitet. Dr. Malte Tiburcy unterstützte mich bei der Planung, Durchführung und Auswertung der vorliegenden Arbeit außerordentlich sachkundig und geduldig.

Ich danke Prof. Dr. Jens Schmidt für die Bereitstellung der Antikörper für das Nitrotyrosin-Experiment sowie Prof. Dr. Elke Oetjen für die Bereitstellung humaner umbilikalvenöser Endothelzellen.

Prof. Dr. Susanne Lutz, Dr. Christina Würtz, Kerstin Schenk und Beate Ramba gilt mein besonderer Dank für die professionelle Unterstützung bei den Western-BlotExperimenten. Weiterer Dank gilt den technischen Assistenten Iris Quentin, Roland Blume und Andreas Schraut.

Darüber hinaus möchte ich mich bei meinen Mitdoktoranden/-innen und Kollegen aus der Arbeitsgruppe von Dr. Malte Tiburcy für ihre Unterstützung, die Vermittlung der experimentellen Fähigkeiten und die freundschaftliche Atmosphäre bedanken. Namentlich erwähnen möchte ich Dr. Amandine Godier-Furnémont und Dr. Poh Loong Soong. 